January 2001 • NREL/SR-620-29448

\title{
The Clean Air Act Amendments of 1990: Opportunities for Promoting Renewable Energy
}

\author{
Final Report \\ December 11, 2000
}

D.R. Wooley and E.M. Morss

Young, Sommer, Ward, Ritzenberg, Wooley, Baker \& Moore, LLC Albany, New York

\section{NPEI}

National Renewable Energy Laboratory

1617 Cole Boulevard

Golden, Colorado 80401-3393

NREL is a U.S. Department of Energy Laboratory

Operated by Midwest Research Institute $\bullet$ Battelle $\bullet$ Bechtel

Contract No. DE-AC36-99-G010337 
January 2001 • NREL/SR-620-29448

\section{The Clean Air Act Amendments of 1990: Opportunities for Promoting Renewable Energy}

Final Report December 11, 2000

D.R. Wooley and E.M. Morss

Young, Sommer, Ward, Ritzenberg, Wooley, Baker \& Moore, LLC Albany, New York

NREL Technical Monitor: Jeff Fang

Prepared under Subcontract No. ADC-0-30434-01

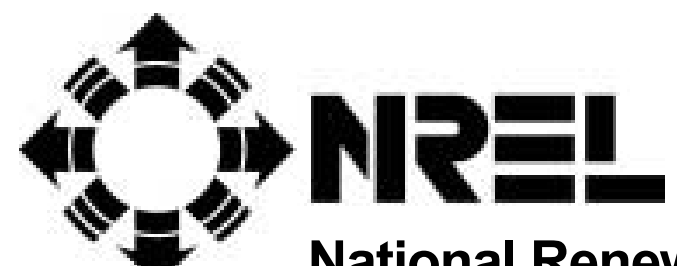

National Renewable Energy Laboratory

1617 Cole Boulevard

Golden, Colorado 80401-3393

NREL is a U.S. Department of Energy Laboratory

Operated by Midwest Research Institute • Battelle • Bechtel

Contract No. DE-AC36-99-G010337 


\section{NOTICE}

This report was prepared as an account of work sponsored by an agency of the United States government. Neither the United States government nor any agency thereof, nor any of their employees, makes any warranty, express or implied, or assumes any legal liability or responsibility for the accuracy, completeness, or usefulness of any information, apparatus, product, or process disclosed, or represents that its use would not infringe privately owned rights. Reference herein to any specific commercial product, process, or service by trade name, trademark, manufacturer, or otherwise does not necessarily constitute or imply its endorsement, recommendation, or favoring by the United States government or any agency thereof. The views and opinions of authors expressed herein do not necessarily state or reflect those of the United States government or any agency thereof.

Available electronically at http://www.doe.gov/bridge

Available for a processing fee to U.S. Department of Energy

and its contractors, in paper, from:

U.S. Department of Energy

Office of Scientific and Technical Information

P.O. Box 62

Oak Ridge, TN 37831-0062

phone: 865.576.8401

fax: 865.576.5728

email: reports@adonis.osti.gov

Available for sale to the public, in paper, from:

U.S. Department of Commerce

National Technical Information Service

5285 Port Royal Road

Springfield, VA 22161

phone: 800.553.6847

fax: 703.605.6900

email: orders@ntis.fedworld.gov

online ordering: http://www.ntis.gov/ordering.htm

Printed on paper containing at least $50 \%$ wastepaper, including $20 \%$ postconsumer waste 


\section{Acknowledgments}

The authors wish to thank Tina Kaarsberg and Joe Galdo of the U.S. Department of Energy's Office of Power Technologies, in the Office of Energy Efficiency and Renewable Energy, for funding this project. The authors also wish to thank the following reviewers for their comments and suggestions on earlier drafts: John Atcheson, David

Bassett, and Tina Kaarsberg, U.S. Department of Energy; Melanie Dean, Joe Kruger, Skip Laitner, and Rick Morgan of the U.S. Environmental Protection Agency; and Jeffrey M. Fang, Larry Goldstein, Kevin Porter, Walter Short, and Laura Vimmerstedt, National Renewable Energy Laboratory. 


\section{Table of Contents}

Page No.

Executive Summary .................................................................................................................................................

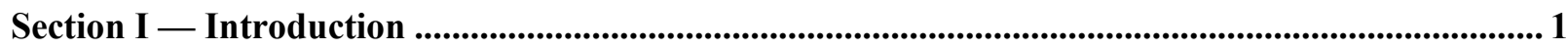

Section II — Introduction to the Federal Clean Air Act and Related Programs.................................. 3

Section III — Renewables and Sulfur Dioxide Emission Controls .............................................6

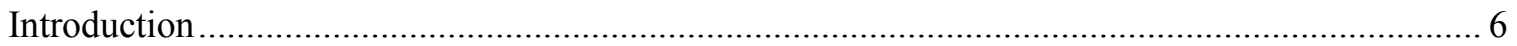

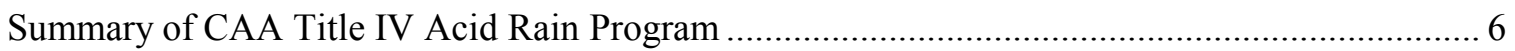

Title IV and Renewables-The Conservation and Renewable Energy Reserve Program ................ 8

Recent Legislative Proposals to Reduce $\mathrm{SO}_{2}$ Emissions .................................................... 10

Section IV — Ozone, Nitrogen Oxides Controls, and Renewables.................................................... 11

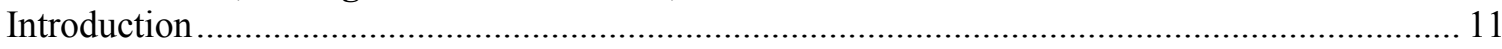

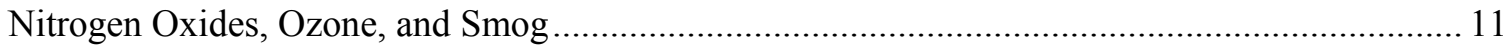

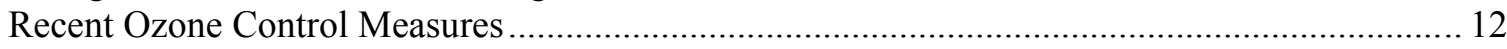

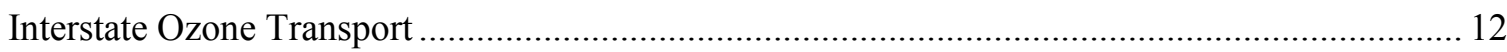

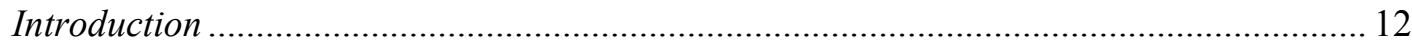

The Northeast Ozone Transport Region/NO ${ }_{x}$ Budget Model Rule .................................... 13

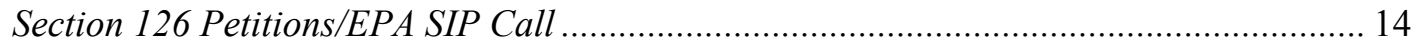

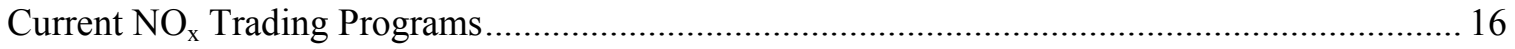

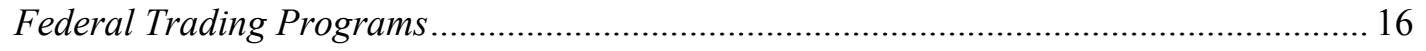

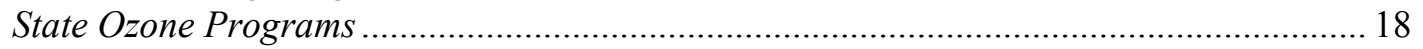

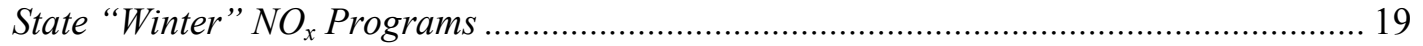

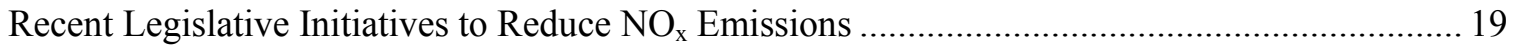

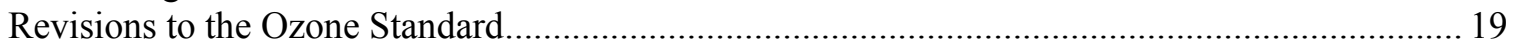

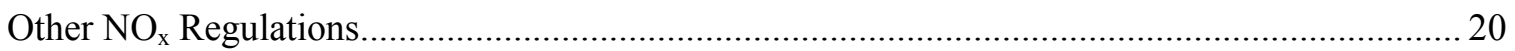

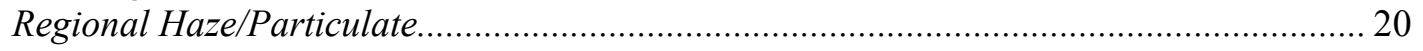

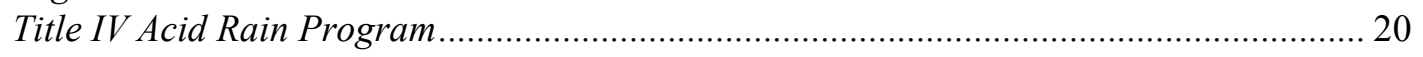

Section V - Visibility, Regional Haze, Particulate Matter, and Renewables.................................. 22

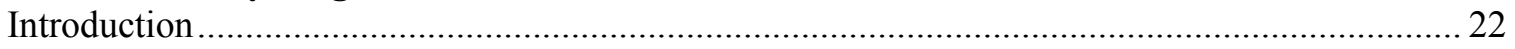

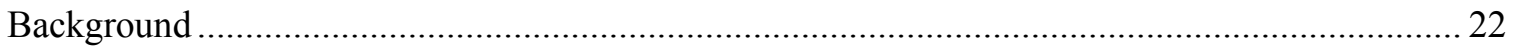

Grand Canyon Visibility Transport Commission (GCVTC) ................................................... 23

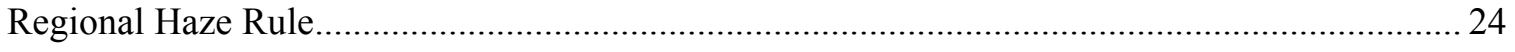

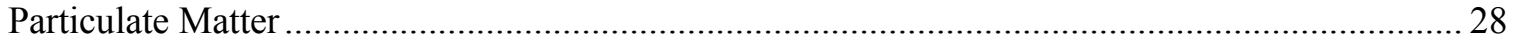




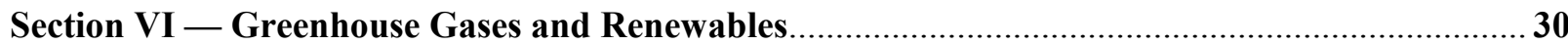

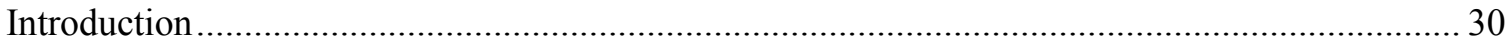

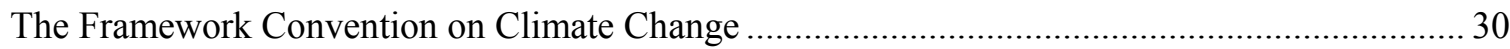

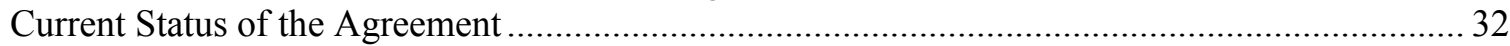

Clean Air Act Provisions Directed Toward Global Warming .................................................... 34

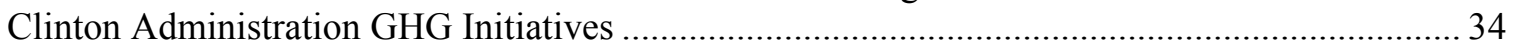

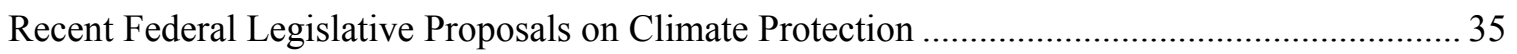

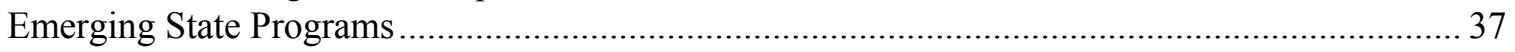

Current Status of GHG Reduction Efforts in the United States ............................................... 37

Section VII — Alternatives for Encouraging Renewable Energy ................................................... 38

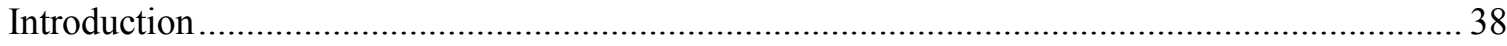

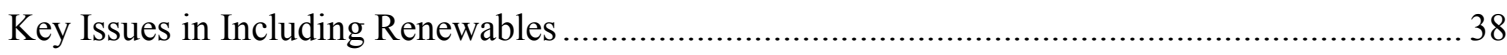

Clean Air Act Program Alternatives for Encouraging Renewable Energy .................................. 40

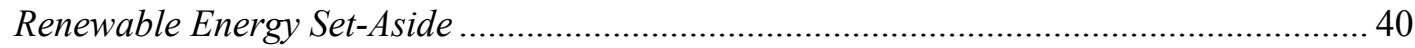

Renewable Output-Based Allowance Allocation ............................................................. 43

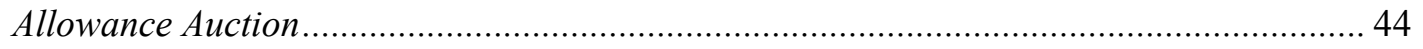

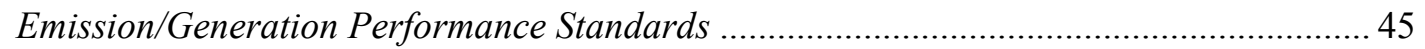

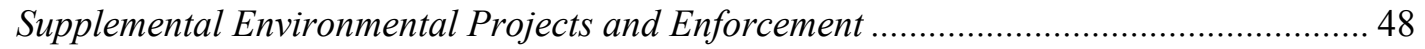

Non-Clean Air Act Program Alternatives for Encouraging Renewable Energy ............................. 49

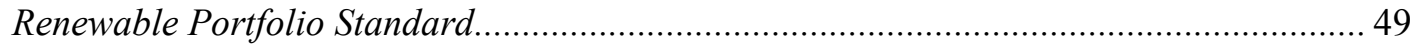

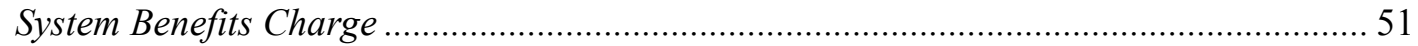

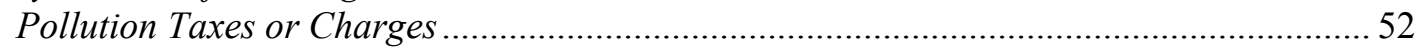

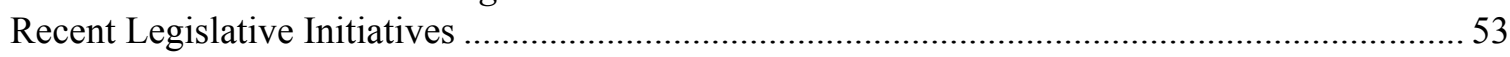

Section VIII — Specific Recommendations for Program Reform ....................................................55

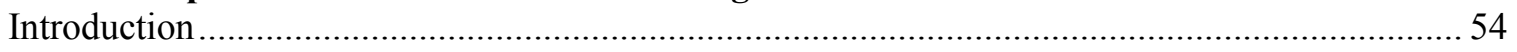

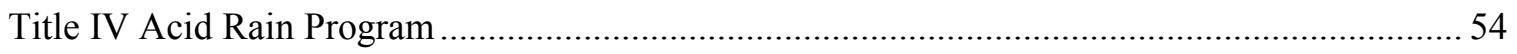

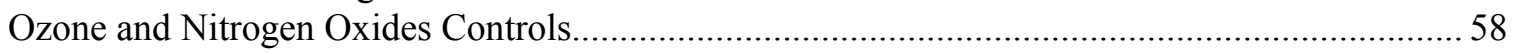

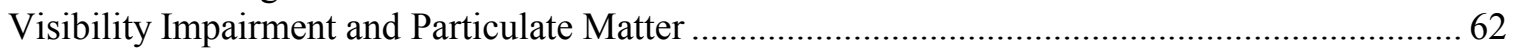

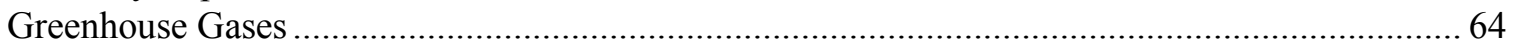

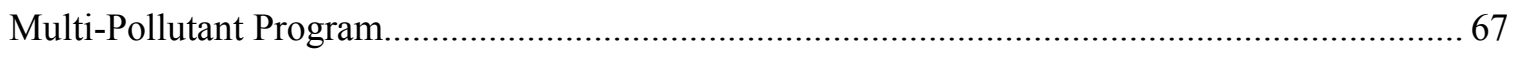

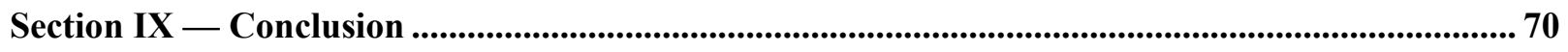

Appendix A - Summary of Key Clean Air Act Regulatory Developments

Appendix B - Status of Major Clean Air Act Litigation

Appendix C - Key Federal/State Regional Reports, Agreements and Guidance Documents

Appendix D - Summary of Recent Clean Air Act Emission Trading Legislation

Appendix E - Map of Current Ozone Nonattainment Areas

Appendix F - Timeline for States to Implement EPA's Regional Haze Rule

Appendix G - REPP Paper Tables on Financial Benefit of Trading for Renewables 


\section{Executive Summary}

This report explores key aspects of the intersection between the nation's clean air and energy goals and proposes alternatives for encouraging renewable energy in the context of the federal Clean Air Act (CAA). As with most environmental statutes enacted in the early 1970's, the 1970 CAA embraced a somewhat rigid "command-and-control" approach to achieving its clean air goals. Although effective, this approach has been criticized for discouraging creative and cost-effective solutions to reducing air emissions. In response to this concern, Congress included the first significant market-based program to address an environmental problemin this case, acid rain caused by sulfur dioxide $\left(\mathrm{SO}_{2}\right)$ emissions from power plants - in the 1990 CAA Amendments. This program prompted the federal government and various state governments to pursue other market-based programs to address air pollution problems.

The evolution of federal air-quality regulation has occurred during an era marked by significant changes in energy regulation and markets. Long lines at gasoline stations and soaring energy prices in the early 1970s awakened general interest in energy supply issues, and in the need to develop alternative renewable energy sources. Federal and state efforts to restructure the electric utility industry have provided other opportunities to promote renewable energy.

Until recently, the nation's clean air and energy policies have proceeded along largely separate tracks. However, electric generation is an essential element of the nation's air pollution problems. Currently, more than $35 \%$ of primary energy consumed in the United States is used to generate electricity. Recent government studies indicate that electric utilities in the United States are responsible for $64 \%$ of all sulfur dioxide emissions, $27 \%$ of all nitrogen oxide emissions and $36 \%$ of all carbon dioxide emissions. ${ }^{1}$ In light of the significant impact of energy generation on the nation's air quality, significant attention has focused recently on the ability of clean energy technologies to help solve both energy and air-quality problems.

This report examines how the CAA could be used at the federal and state level to encourage the development of renewable energy sources. Sections I and II provide a brief introduction to the report and to the history and key elements of the CAA. Sections III-VI of the report summarize the status of various federal and state programs that could serve as vehicles to promote renewables, including: (1) the Title IV acid rain cap-and-trade program and the Conservation and Renewable Energy Reserve program; (2) various programs to control nitrogen oxide $\left(\mathrm{NO}_{\mathrm{x}}\right)$ emissions and smog; (3) visibility and regional haze programs; and (4) programs regulating emissions of greenhouse gases, including carbon dioxide $\left(\mathrm{CO}_{2}\right)$. Section VII summarizes key considerations in developing clean-air programs to encourage renewables and provides a brief description of program options, including various cap-and-trade alternatives (set-asides, output-based allocation, auctions), emission performance standards, and other CAA programs. Section VII also describes various options not traditionally thought of as clean-air programs, such as renewable portfolio standards, system benefits charges, and pollution taxes. Section VIII proposes specific changes to the CAA and related programs to promote renewables, analyzing the benefits and barriers of each and the strategies for implementing them.

\footnotetext{
${ }^{1}$ United States Environmental Protection Agency (EPA), National Air Quality Trends Report 1997, EPA 454/R-98-016 (Dec. 1998); United States Department of Energy, Energy Information Administration, Annual Energy Outlook 1999, DOE/EIA-0383 (99) (Dec. 1998). The inclusion of non-utility electric generation sources increases the percentages for carbon dioxide $\left(\mathrm{CO}_{2}\right)$ slightly (e.g., to $40 \%$ of national $\mathrm{CO}_{2}$ emissions).
} 
As Sections III-VI of the report make clear, the CAA has not been a traditionalvehicle for encouraging development of renewable energy, despite the obvious clean-air benefits of such sources. The only program in the 1990 CAA that specifically includes a role for renewables is the Title IV acid rain cap-and-trade program, which set aside a small percentage of $\mathrm{SO}_{2}$ allowances for energy efficiency and renewable energy projects. Although the Conservation and Renewable Energy Reserve (CRER) program did not provide a significant boost to renewables directly, the broader success of the Title IV $\mathrm{SO}_{2}$ trading program has spawned significant interest in emission trading generally. For example, $\mathrm{NO}_{\mathrm{x}}$ emissions from utilities are covered by various trading programs, including those developed by states in the Northeast Ozone Transport Region and by the EPA under the so-called " $\mathrm{NO}_{\mathrm{x}}$ SIP call" and in response to petitions filed by the northeastern states under CAA $\S 126$. The EPA also has proposed emission trading as an option under its regional haze rule.

In theory, emission cap-and-trade programs favor renewables because renewable technologies are cleaner. Conventional fossil fuel-fired power plants must frequently install controls or make other costly changes or purchase emission allowance credits to comply with the requirements of a cap-and-trade program. Renewables, by comparison, emit little, if any, pollutants and thus do not incur these additional compliance costs. Unfortunately, the cost differential between conventional and renewable generation is still sufficiently large that the effect of an emission cap, by itself, is not sufficient to give renewable developers a tangible financial benefit. Hence, specific incentives are needed to overcome past and current subsidies to the fossil-fuel industry, "level the economic playing field," and ensure the development of renewable energy sources. This report focuses on one type of market-based program - clean-air incentives - which can be used to promote renewables. These clean-air incentives can be used, in combination with other policy instruments, to provide renewables with an opportunity to participate in the marketplace of solutions to air pollution. The idea is not only to promote renewables as an emerging clean-energy resource, but also to give them a fair chance to compete against emission-control technologies and fuel choices for the right to supply clean air within a regulatory structure that places distinct economic value on pollution prevention.

Clean-air incentives that would improve the ability of renewables to compete include allocating emission credits to renewable energy generators in the form of either renewable allowance "set-asides" or "output-based allocations" to renewables. As previously noted, however, the only major federal program to specifically establish a role for renewables was the CRER, which set aside a modest number of $\mathrm{SO}_{2}$ allowances for renewables. In addition, a handful of state and regional emission-trading programs has specifically addressed renewables. Recently, the states in the Grand Canyon Visibility Transport Region program proposed a backstop trading rule that allocates $\mathrm{SO}_{2}$ allowances to renewable energy producers as part of a regional haze program. In addition, several states in the Northeast Ozone Transport Region have included renewable setasides as part of their $\mathrm{NO}_{\mathrm{x}}$ emission-trading programs. Overall, however, the efforts to date to allow renewables a full opportunity to participate in air-quality programs have been ineffective, isolated, or experimental.

Ten years have elapsed since the passage of the 1990 CAA Amendments, so the time is ripe to consider expanding opportunities for renewable-energy development in the reform of clean air policies. As described in Sections VII and VIII, there are many options for encouraging renewables, either under the CAA or through programs, such as renewable portfolio standards, traditionally pursued as part of energy deregulation. Legislatively, momentum is developing in Congress to amend the CAA to either reduce the existing $\mathrm{SO}_{2}$ cap or implement new emission cap-and-trade programs for $\mathrm{NO}_{\mathrm{x}}$ and/or $\mathrm{CO}_{2}$, or both. At least one of the pending legislative proposals specifically awards air-pollution allowances based on electricity output to both conventional and renewable sources. If these reform proposals ripen, there will be a once-in-a-decade opportunity to include provisions that specifically enable and encourage renewable energy resources to compete to provide clean air benefits to the nation. Additional opportunities to encourage renewables will continue to arise at the administrative level and in the states in conjunction with the various trading programs developed to control $\mathrm{NO}_{\mathrm{x}}$ emissions and regional haze. 
After a thorough review of numerous options, we believe that the following five alternatives hold the greatest promise for promoting renewable energy resources within the context of clean air regulation:

1. Tighten the existing $\mathrm{SO}_{2}$ cap and establish an improved allowance set-aside program to replace the CRER. The success of the Title IV acid rain program and the recognized need from an environmental perspective for additional $\mathrm{SO}_{2}$ reductions to eliminate acid rain has given rise to considerable momentum in Congress to amend the CAA to further reduce the $\mathrm{SO}_{2}$ cap. A lower cap will likely mean higher $\mathrm{SO}_{2}$ allowance costs, providing more of a boost for renewables; however, targeted incentives are still needed to encourage the development of alternative energy sources. A set-aside program that provides a larger and more permanent incentive would give a significant boost to renewables. A modified set-aside should keep transaction costs for renewable developers low and avoid credit generation provisions that require, as the CRER did, renewable vendors to seek agency determinations or approvals. In the long term, a shift to an output-based allowance allocation mechanism may arguably create even better economic incentives for renewables.

2. Pursue a nationwide cap-and-trade program for $N O_{x}$. As part of legislation to reduce the $\mathrm{SO}_{2}$ cap under Title IV, proposals have been introduced in Congress to establish similar cap-and-trade programs for $\mathrm{NO}_{\mathrm{x}}$. In the short term, this option could provide an additional boost to renewables, assuming the cap also includes an allowance set-aside or other program to specifically benefit renewables. In the long term, however, it might be preferable to pursue a multi-pollutant-trading program to minimize administrative burdens, reduce total costs, and encourage comprehensive approaches to reducing pollution.

3. Encourage renewables under state programs developed under the $N O_{x}$ State Implementation Plan (SIP) call or Northeast Ozone Transport Commission trading programs. States covered under these programs have developed or are currently developing $\mathrm{NO}_{\mathrm{x}}$ trading programs. These programs, while limited geographically, could provide an opportunity for renewables. The primary obstacle is logistics - tracking and influencing legislative and/or regulatory developments in the over twenty states regulated under one or both programs.

4. Include renewables in emission-trading programs developed to implement national regional haze requirements. Both the general regional haze regulations and the alternative provisions applicable to states in the Grand Canyon Visibility Transport Region contemplate developing emission trading programs, either voluntarily as a substitute for Best Available Retrofit Technology (BART) requirements or as a backstop in the event voluntary reduction measures do not work. These programs could be designed to include a specific role for renewables. In fact, the backstop trading program proposed by the governing body for the Grand Canyon Visibility Transport Region specifically allocates allowances to renewables. Developments in this area should be monitored to ensure that all opportunities to encourage renewables are explored and implemented, as appropriate.

5. In the long term, pursue a multi-pollutant trading program. Currently, the various emission-trading schemes have developed as separate programs. As a result, many utilities, particularly in the Northeast, have been, or will be, subject to multiple trading programs, creating administrative and other difficulties. In the long term, the renewables industry should consider working with lawmakers to develop an integrated, multi-pollutant program as a substitute for multiple separate programs. This approach would make it easier for renewable producers to participate by eliminating many of the administrative burdens associated with emission trading; it would also ensure that renewables realize economically the environmental benefits they generate. The report includes a proposal for developing a multi-pollutanttrading scheme. 
Many of these programs could be combined with non-CAA alternatives, such as renewable portfolio standards or system benefits charges, to further encourage renewables.

A significant potential for renewables exists in conjunction with international efforts to reduce emissions of greenhouse gases (GHG), including $\mathrm{CO}_{2}$. Unfortunately, Congressional opposition to international GHG reduction agreements makes it difficult to develop GHG emission-reduction programs, including a cap-andtrade alternative, that would enable the renewables industry to harness this potential. The renewable industry can, however, track developments both nationally and internationally to ensure that the programs developed adequately address renewables. 


\section{Section I - Introduction}

This report examines the federal Clean Air Act (CAA) to identify opportunities for promoting renewable energy. Conventional fossil fuel-fired electric generating facilities are a significant source of environmental pollution. Power plants emit numerous air contaminants, including sulfur dioxide $\left(\mathrm{SO}_{2}\right)$, nitrogen oxides $\left(\mathrm{NO}_{\mathrm{x}}\right)$, particulate matter, heavy metals, and carbon dioxide $\left(\mathrm{CO}_{2}\right)$, which cause environmental and human health problems ranging from acid rain, regional haze, and global warming, to respiratory and other health problems. Although air pollution is the primary environmental problem associated with conventional electric generation, these facilities also cause other environmental impacts related to mining and drilling, intake and discharge of cooling water, fuel transport/spills, and the disposal of by-products of fuel combustion, among others.

Renewable energy sources, by comparison, are popular in large measure because they are environmentally benign. Wind, solar, biomass, and geothermal energy provide much-needed heat and power with relatively little damage to air, water, or land resources. Unfortunately, existing air-quality regulations and energy markets do not fully recognize and compensate the environmental benefits associated with renewable energy. As a result, renewable energy has not achieved a role in the energy marketplace commensurate with its potential value.

This report examines the current and potential interaction between renewable energy and air-quality regulation under the CAA and related state programs and discusses various strategies for revising federal and state laws and regulations to encourage development of renewables. An analysis contained in a recent report by the Renewable Energy Policy Project shows that allowing renewables to participate in emission cap-and-trade programs can provide substantial support for renewable energy development. ${ }^{2}$

Section II of the report provides a brief introduction to the CAA. Sections III-VI of the report summarize the status of various federal and state air-quality programs that have the potential for regulating pollutants through renewable energy incentives, including:

- Acid rain program, which regulates primarily $\mathrm{SO}_{2}$ and $\mathrm{NO}_{\mathrm{x}}$ emissions (Section III);

- Ground-level ozone program, which regulates $\mathrm{NO}_{\mathrm{x}}$ primarily as an ozone precursor (Section IV);

- Visibility and regional haze program, which focuses on particulate matter (PM) and its precursors (Section $\mathrm{V})$; and

- National and international efforts to prevent global warming by reducing $\mathrm{GHG}$ emissions, including $\mathrm{CO}_{2}$ (Section VI).

\footnotetext{
${ }^{2}$ A Guide to the Clean Air Act for the Renewable Energy Community, by David R. Wooley, Renewable Energy Policy Project Issue Brief \#15, February 2000, available at: www.repp.org. Several tables from the REPP report illustrating the financial impacts of a cap-and-trade program that includes renewables have been included in this report as Appendix G. The REPP paper does not suggest that participation in CAA emission trading programs is, by itself, sufficient to promote renewables, but does suggest that modified cap-and-trade programs can be used in combination with other policies to boost renewable development. In regard to the tables contained in Appendix G, note that the financial benefit calculations used average national emission rates to represent avoided emissions due to renewable development. This was a simplifying assumption, because the marginal emissions avoided by renewable energy development in any given region of the nation may differ substantially from the examples in the report. We also note that there is debate over the extent to which different forms of biomass should be eligible for award of allowances in an emission cap-and-trade program, given that some forms of biomass emit other pollutants of concern (PM and volatile organic compounds).
} 
For each program, the report summarizes key statutory and regulatory requirements both generally and in relation to potential incentives for renewables and the status of federal and state efforts to implement those requirements. Section VII identifies the key considerations in developing a program to promote renewables and provides a brief introduction to the various policy options available to achieve this goal. This section looks at programs commonly associated with the CAA as well as options, such as renewable portfolio standards, not typically thought of as clean-air programs. Section VIII proposes specific changes to the CAA and related programs to boost renewables.

Increased reliance on renewable energy sources could have environmental benefits beyond improvement of air quality. Although these benefits are potentially significant, the primary opportunities for renewables arise under the air program for several reasons. First, the primary obstacle to successfully promoting renewable energy is the failure of the marketplace to properly value the environmental benefits of these energy sources. The federal CAA and emerging international climate change agreements contain the most advanced marketbased approaches to regulating pollution. Thus, they present the greatest opportunity to promote renewable energy in the near term. Second, reducing air-contaminant emissions through renewables directly benefits other environmental media, in particular, surface and groundwater. Many water pollution problems are caused by air deposition. For example, $\mathrm{NO}_{\mathrm{x}}$ emissions from power plants are a significant cause of acid rain damage to lakes and streams and nitrogen saturation of water bodies such as Long Island Sound and Chesapeake Bay. Increased reliance on renewable energy sources will reduce these impacts. Many of the other impacts associated with fossil fuel-powered electric generating facilities, such as damage to fisheries from cooling water intakes and mining/drilling impacts, are also addressed by lessening the need for fossil fuels. Finally, many non-air-related environmental impacts are highly site specific, making developing market-based mechanisms difficult. For these reasons, this report focuses on the opportunities for promoting renewable energy under the CAA and other air programs. 


\section{Section II - Introduction to the Federal Clean Air Act and Related Programs}

Congress enacted the CAA in 1970 to "protect and enhance the quality of the Nation's air resources so as to promote the public health and welfare and the productive capacity of its population." " The 1970 CAA established specific time frames for achieving federal clean-air goals, which ultimately proved too ambitious. Accordingly, Congress amended the CAA in 1977 to adjust the deadlines and to establish several new programs aimed at further reducing emissions. In the years following the 1977 amendments, growing scientific evidence suggested that many air-pollution problems, such as acid rain and ground level ozone, were regional, rather than local, in scope. Unfortunately, the programs contained in the 1977 CAA were not well-suited to addressing regional air-pollution issues. To address this and other concerns, Congress amended the CAA again in 1990. The key components are summarized below:

- Title I. Title I establishes National Ambient Air Quality Standards (NAAQS) for so-called "criteria contaminants" and contains various programs designed to ensure that these standards are ultimately attained. ${ }^{4}$ Using ambient air monitoring data, the Environmental Protection Agency (EPA) classifies regions of the country as attainment, nonattainment, or unclassifiable based on whether the air quality in that region meets the NAAQS for a particular contaminant. The CAA then requires states to develop "state implementation plans" (SIPs) identifying the measures they will implement to achieve or maintain compliance with the NAAQS. ${ }^{5}$ Title I specifies certain measures that states must implement to satisfy their obligations under the SIP program; ${ }^{6}$ where these mandated programs will not achieve or maintain compliance with the NAAQS, states are expected to propose additional measures to reduce emissions. States are encouraged to use market-based mechanisms to achieve air-pollution control objectives.

Many states failed to comply with the NAAQS by the statutory deadlines in the 1977 CAA, prompting Congress to amend it in 1990 to classify nonattainment areas for certain contaminants based on the extent of their noncompliance. The amendment also required states to implement specific air pollution control measures based on that classification. ${ }^{7}$ Areas that fail to achieve compliance by the date specified in the

${ }^{3}$ CAA $\S 101 ; 42$ U.S.C. $\S 7401$.

${ }^{4}$ CAA $\S \S 108,109 ; 42$ U.S.C. $\S \S 7408,7409$. NAAQS have been established for six pollutants: $\mathrm{SO}_{2}$, ozone, PM, nitrogen dioxide $\left(\mathrm{NO}_{2}\right)$, carbon monoxide (CO) and lead. 40 C.F.R. Part 50.

${ }^{5}$ CAA $\S 110 ; 42$ U.S.C. $\S 7410$. The SIP is extensive, containing elements addressing emission inventories, monitoring networks, attainment demonstrations, enforcement mechanisms, memoranda of understanding between state and EPA officials and other documents. The control measures and strategies must be formally adopted by each state and then submitted to the EPA as SIP revisions, which must be approved. The SIPs for each state can be found at 40 C.F.R. Part 52.

6 Of particular interest, the CAA requires states to develop a permitting system for new or modified major sources of criteria contaminants. The prevention of significant deterioration (PSD), CAA $\S \S 160-169 ; 42$ U.S.C. $\S \S 7470-7479$, and nonattainment new source review (NSR), CAA $\S 173,42$ U.S.C. $\S 7503$, programs impose strict air-pollution control and other requirements on new or modified major stationary sources located in attainment and nonattainment areas, respectively. These programs are targeted at ensuring that new or modified sources do not adversely affect the ability of states to achieve and maintain compliance with the NAAQS. New and modified stationary sources also may be required to comply with New Source Performance Standards (NSPS). CAA $\S 111 ; 42$ U.S.C. $\S 7411$. The NSPS, which apply regardless of location, establish minimum technological standards for newly constructed or modified sources in specific source categories. To date, the EPA has established NSPS for over 75 source categories, including various types of industrial and utility boilers. 40 C.F.R. Part 60.

${ }^{7}$ In particular, the EPA established nonattainment classifications for ozone, PM, and CO. See CAA $\S \S 181-193$; 42 U.S.C. §§ 75117515. 
statute are reclassified upward and required to implement additional control measures. Title I also contains several interstate air-pollution control mechanisms that were recently relied on by the EPA to require emission reductions across a subcontinental region of the United States - utilizing a cap-and-trade form of regulation. CAA Title I is discussed in greater detail in Sections IV and V of this report, which address ground level ozone and visibility/regional haze, respectively.

- Title II. Title II regulates emissions from motor vehicles. Among other things, the statute authorizes the EPA to establish emission-control standards for vehicles and to regulate fuel composition for purposes of reducing emissions of various air contaminants. ${ }^{8}$

- Title III. This Title establishes emission standards for sources of specific "hazardous air pollutants" (HAPs). ${ }^{9}$ Under the NESHAP program, the EPA was required to develop a list of major and "area" source categories responsible for emissions of specified HAPs ${ }^{10}$ and adopt technology-based maximum achievable control technology (MACT) standards for each category in accordance with a ten-year schedule. ${ }^{11}$ Eight years after development of MACT for a particular source category, the EPA must review the standard to assess the residual risk remaining after MACT implementation. If the category continues to pose health problems, the EPA must develop stricter risk-based standards. ${ }^{12}$ Currently, utilities are not regulated under the NESHAP program. As required by the CAA, the EPA submitted to Congress the results of a study addressing HAP emissions from electric utility steam generating units. ${ }^{13}$ Based on that and other studies, the EPA is currently deciding whether to regulate utility boilers under the NESHAP program.

- Title IV. Title IV establishes the nation's most extensive market-based emission-trading system. The program attempts to prevent acid rain by imposing plant-by-plant limits on $\mathrm{SO}_{2}$ emissions from fossil fuelfired electric generating plants. The EPA assigns $\mathrm{SO}_{2}$ allowances equivalent to these limits, which facilities can then buy or sell to achieve compliance. ${ }^{14}$ Title IV also imposes emission controls on $\mathrm{NO}_{\mathrm{x}}$, another acid rain precursor. ${ }^{15}$ The acid rain program is discussed in greater detail in Section III.

\footnotetext{
8 CAA §§ 202-250; 42 U.S.C. §§ 7521-7590.

9 The CAA established a list of 189 regulated HAPs, including organic chemicals, pesticides, metals, coke-oven emissions, fine mineral fibers, and radionuclides, including radon. CAA § 112(b); 42 U.S.C. § 7412(b). The EPA may revise the list to add or remove substances in response to a petition from a third party or on its own initiative. Under this procedure, the EPA amended the list of HAPs to remove caprolactam in response to a petition from various chemical companies. 61 Fed. Reg. 30816 (June 18, 1996).

${ }^{10}$ CAA § 112(c); 42 U.S.C. § 7412(c). In 1992, the EPA issued an initial list of 174 major and area-source categories subject to regulation under Title III of the CAA. 57 Fed. Reg. 31576 (July 16, 1992). Area sources are relatively small, sources such as dry cleaning and printing operations that collectively emit significant quantities of HAPs.

11 For new sources in the source category, the MACT standard may not be less stringent than the emission control achieved in practice by the best-controlled similar source; for existing sources, MACT is based on the performance achieved by the best $12 \%$ of existing sources in that category (or the best five sources where the source category has fewer than 30 sources). CAA § 112 (d); 42 U.S.C. $§ 7412(d)$. To date, MACT standards have been set for more than 50 source categories. 40 C.F.R. Part 63.

12 CAA § 112(f); 42 U.S.C. § 7412(f).

13 CAA § 112(n)(1)(A); 42 U.S.C. § 7412(n)(1)(A). See 63 Fed. Reg. 17406 (Apr. 9, 1998). Study of Hazardous Air Pollutant Emissions from Electric Utility Steam Generation Units-Final Report to Congress, EPA-453/R-98-004 a \& b (Feb. 24, 1998).

14 CAA §§ 401-416; 42 U.S.C. §§ 7651-7651o.

15 CAA $\S 407 ; 42$ U.S.C. $\S 7651 f$.
} 
- Title $\boldsymbol{V}$. Under CAA Title V, facilities regulated under the CAA must obtain an operating permit from the appropriate regulatory agency - either the EPA or the state - depending on whether authority to issue Title $\mathrm{V}$ permits has been properly delegated. ${ }^{16}$ Title $\mathrm{V}$ does not impose new emission control requirements on sources; instead, it assembles all of the federally enforceable air pollution control requirements applicable to the facility in a single document and establishes monitoring, reporting, and record-keeping requirements essential to demonstrate compliance with those requirements.

- Title VI. Title VI establishes programs to preserve the earth's stratospheric ozone layer, which protects it from the harmful effects of ultraviolet radiation. ${ }^{17}$ The CAA calls for the phase-out of certain ozonedepleting substances such as chlorofluorocarbons. It also establishes standards for the maintenance, repair, and disposal of equipment containing ozone-depleting chemicals to ensure that such chemicals are not accidentally or intentionally released into the environment.

As discussed below, Congress, in enacting the CAA, did not include many provisions specifically targeted at promoting renewable energy. A small portion of $\mathrm{SO}_{2}$ allowances were set aside under the Title IV acid rain program to be awarded for $\mathrm{SO}_{2}$ emissions avoided through energy conservation or renewable energy projects. Restrictions on who could obtain the allowances and how they were awarded limited reliance on the program; as a result, only a small percentage of the allowances set aside for renewables have been awarded. Regulations implementing other programs, including those attempting to control regional haze and ozone transport, also include modest provisions addressing renewable energy sources. Because these programs are relatively new, their success or failure in promoting renewables is difficult to predict. These programs present both challenges and opportunities for the renewable energy industry.

To date, emissions of $\mathrm{GHG}$ such as $\mathrm{CO}_{2}$ have not been regulated under the $\mathrm{CAA}$, other than emission-reporting requirements. The primary impetus for reducing GHG emissions has been an evolving series of international agreements. As discussed below, although these agreements specifically encourage development of renewable energy sources as an alternative for reducing GHG emissions, they are not now, nor are they likely to be in the future, specifically to mandate reliance on such sources. However, these agreements do call for the development of various mechanisms, including an emission-trading program, which will provide significant opportunities for renewables if properly designed.

\footnotetext{
${ }^{16}$ CAA §§ 501-507; 42 U.S.C. $\S \S 7661-7661 f$.

${ }^{17}$ CAA $\S \S 601-617 ; 42$ U.S.C. §§ 7671-7671g.
} 


\section{Section III — Renewables and Sulfur Dioxide Emission Controls}

\section{Introduction}

A driving force behind the 1990 CAA Amendments was the desire by Congress to address the ongoing problem of "acid rain." Acid deposition occurs when $\mathrm{SO}_{2}$ and $\mathrm{NO}_{\mathrm{x}}$ emissions are transformed into acids in the atmosphere and are returned to the earth either as acid rain or in dry deposition, often many hundreds of miles from the point of emission. Acid rain damages lakes and drinking water supplies; harms forests, soils, and buildings; and contributes to reduced visibility. As previously noted, well over half of the $\mathrm{SO}_{2}$ in the United States is emitted from fossil fuel-fired power plants. In recognition of this role, Congress enacted Title IV of the CAA, which targets utilities for $\mathrm{SO}_{2}$ emission reductions.

The Title IV acid rain program was the first comprehensive attempt by Congress to harness market forces to reduce pollution. Under the program, overall emissions of $\mathrm{SO}_{2}$ from utilities are capped far below the emission levels that existed at the time of the 1990 CAA Amendments. The statute then allocates emission "allowances" to units regulated under the program, giving the owner/operator the freedom to decide whether to install controls, change fuels, or purchase emission allowances from other sources to meet the obligations. In a well meaning, but limited, attempt to encourage development of renewable energy sources, Congress set aside a small number of $\mathrm{SO}_{2}$ allowances to be allocated to renewable energy facilities, which could gain revenue by selling allowances to fossil fuel-fired electric generators. As discussed in greater detail below, lower-thanexpected prices for $\mathrm{SO}_{2}$ allowances, combined with other factors, resulted in limited participation by renewable energy industries in the set-aside program. The lessons learned from the Title IV acid rain program and the renewables set-aside provide valuable insights into the potential benefits and barriers to developing new programs and policies to encourage renewable energy under the CAA.

\section{Summary of CAA Title IV Acid Rain Program}

Title IV of the CAA requires a permanent 10-million-ton reduction in $\mathrm{SO}_{2}$ emissions from 1980 levels. To achieve this objective, Congress established a two-phase program for controlling emissions from power plants. ${ }^{18}$ The first phase, effective January 1, 1995, required 110 specific power plants listed in the statutepredominantly midwestern coal-burning units - to reduce their $\mathrm{SO}_{2}$ emissions to a rate of 2.5 pounds per million British thermal units $\left(\mathrm{SO}_{2} \mathrm{lbs} . / \mathrm{mmBtu}\right)$ multiplied by the unit's average 1985-1987 baseline heat input to the combustion units. ${ }^{19}$ This creates a cap on aggregate emissions from the affected sources. In Phase II, discussed below, the cap is expanded to apply to a wider range of sources and is based on a lower rate (a "declining cap"). An owner or operator of a Phase I unit has the option to reassign or substitute all or part of the affected power plant's $\mathrm{SO}_{2}$ reduction requirements to any other power plant under the control of that owner or operator provided certain conditions are met. ${ }^{20}$ Upon approval of the reassignment or substitution proposal by the EPA, each substituted power plant becomes subject to the Phase $\mathrm{I} \mathrm{SO}_{2}$ reduction program. ${ }^{21}$

\footnotetext{
18 Title IV of the CAA also contains restrictions on $\mathrm{NO}_{\mathrm{x}}$ emissions from coal-fired boilers. CAA § 407; 42 U.S.C. § 7651f. These provisions are discussed in greater detail in Section IV of this report.

19 CAA § 404(a); 42 U.S.C. § 7651c(a).

${ }^{20}$ CAA $\S 404(b),(c) ; 42$ U.S.C. $\S 7651 c(b),(c)$.

${ }^{21}$ In addition, the owner or operator of an affected power plant regulated under Phase I may petition the EPA for an extension of up to two years from the deadline to meet the Phase I requirements, provided the affected power plant employs a "qualifying Phase I technology" or transfers its Phase I emission reduction obligation to a unit using a qualifying Phase I technology, CAA § 404(d); 42 U.S.C. $\S 7651 \mathrm{c}(\mathrm{d})$. If the request is approved, the EPA will allocate allowances from a reserve set aside for that purpose. A qualifying
} 
Phase II, effective January 1, 2000, applies to virtually all fossil fuel-fired utility units with a 25-megawatt (MW) or greater electrical output. ${ }^{22}$ Units regulated under Phase II generally must reduce their emissions to a level equivalent to the product of an emission rate of $1.2 \mathrm{SO}_{2} \mathrm{lbs} . / \mathrm{mm}$ Btu multiplied by their 1985-1987 baseline heat input, although the statute establishes special emission rates for certain units based on various factors, including their location, size, and/or fuel burned. In addition to the basic Phase II allowance allocations, in each year from 2000-2009, the EPA will allocate up to 530,000 Phase II bonus allowances for certain categories of sources, including power plants in "high growth" states, certain municipally owned power plants, and others. With some exceptions, beginning in January 1, 2000, total emissions of $\mathrm{SO}_{2}$ from affected units are capped at 8.9 million tons. ${ }^{23}$

To encourage utilities to develop the most efficient strategy for achieving the required emission reductions, the Title IV program establishes a market-based system for controlling $\mathrm{SO}_{2}$. Under that system, the EPA assigns $\mathrm{SO}_{2}$ allowances to affected units in accordance with the emission-rate parameters previously discussed, with each allowance representing one ton of $\mathrm{SO}_{2}$ emissions. Affected units must not emit $\mathrm{SO}_{2}$ in excess of the allowances they hold. To meet their emission obligations, electric power generators can pursue various options, including switching to lower-sulfur coal or natural gas, installing scrubbers or other controls to remove $\mathrm{SO}_{2}$ from flue gases, or retiring facilities. As an alternative, they can purchase allowances from another source that has controlled its $\mathrm{SO}_{2}$ emissions more than Title IV requires. At the end of each year, each source must hold allowances at least equal to the amount of $\mathrm{SO}_{2}$ it emitted during that year, or face significant penalties.

To ensure that allowances are available for new sources, including independent power producers, the EPA conducts yearly auctions and direct sales for a small portion of the total allowances allocated each year. These allowances are made available by withholding $2.8 \%$ of the allocation from affected power plants and placing them in a "Special Allowance Reserve." A specified number of allowances from the Special Allowance Reserve are then made available for auction each year. ${ }^{24}$ These auctions are conducted for the EPA by the Chicago Board of Trade. Allowances are sold based on a bid price, starting with the highest price bid and continuing until all allowances for sale have been allocated. Any allowances offered for sale but not sold at auction are returned without charge, on a pro rata basis, to the owner or operator of the affected power plants from whom they were withheld. In addition, any person holding allowances may submit them to the EPA to be offered for sale at auction.

Responsibility for implementing the allowance program rests with the EPA, which has established an electronic tracking system for trading acid rain emission allowances. Under that system, entities holding allowances must establish an "Allowance Tracking System Account" with the EPA. ${ }^{25}$ Each allowance is assigned a serial

Phase I technology is defined as a continuous emission-reduction system that achieves a $90 \%$ reduction in $\mathrm{SO}_{2}$ emissions from the emissions that would have resulted from using emission controls. CAA § 402(19); 42 U.S.C. § 7651a(19).

${ }^{22}$ CAA $\S 405 ; 42$ U.S.C. $\S 7651 d$.

23 The owners/operators of Phase II units could extend their Phase II compliance deadline by four years, to December 31, 2003, by demonstrating that they intended to repower with a qualifying clean coal technology. To obtain the extension, the owner/operator was required to commit to repower by January 1, 1997, and to provide documentation of the preliminary design and an executed contract for the majority of the equipment needed to repower the unit by January 1, 2000. Repowered units receive allowances according to a formula specified in the statute, which they can then transfer to other units or sell. CAA $\S 409 ; 42$ U.S.C. § 7651h.

${ }^{24}$ CAA § 416; 42 U.S.C. § 7651o. Regulations establishing the Special Allowance reserve are set forth at 40 C.F.R. § 73.27 ; see 58 Fed. Reg. 3590 (Jan. 11, 1993). A table summarizing key regulations is attached as Appendix A.

${ }^{25}$ Requirements and procedures for allocating $\mathrm{SO}_{2}$ allowances, tracking, holding, and transferring allowances, deducting allowances for compliance purposes, and selling allowances were published by the EPA on January 11, 1993. 58 Fed. Reg. 3590, 3687 ; 40 C.F.R. Part 73. 
number, which is recorded in that account. Facilities regulated under the program must install continuous emission monitoring systems (CEMS) to measure their actual emissions of $\mathrm{SO}_{2}$, opacity, and other parameters, ${ }^{26}$ at the end of the year, the EPA compares the emissions information measured by the CEMS with the allowances held in the facility's account. If the facility is not holding allowances equal to or greater than the emissions measured by the CEMS, it must pay a penalty for each ton of excess emissions. The penalty was initially set at $\$ 2,000$ per ton and is adjusted annually for inflation. The facility also must submit a plan to offset any excess emissions in the upcoming year. ${ }^{27}$

The provisions of the Title IV acid rain program are implemented through permits issued to power plants under the CAA Title V permitting provisions. Each initial permit application from a power plant must be accompanied by a compliance plan detailing how the plant will meet the requirements of Title IV. The plant ultimately receives a facility permit from the EPA or the state in which the power plant is located, depending on whether the state has an approved CAA operating permit program. ${ }^{28}$

\section{Title IV and Renewables-The Conservation and Renewable Energy Reserve Program}

Beginning in 2000, the $\mathrm{SO}_{2}$ cap-and-trade program would theoretically be expected to provide a boost to renewables because renewables, unlike conventional fossil fuel-fired plants, need not possess allowances to operate, and because fossil generators facing load growth will be unable to gain a larger emission allowance allocation. Unfortunately, the differential in production costs between conventional and renewable resources is still too great to cause the cap, by itself, to create an effective incentive for electricity producers to invest in renewables as a means of clean-air compliance. In apparent recognition of the need for an additional short-term incentive to encourage energy conservation and renewable energy sources, Congress established a Conservation and Renewable Energy Reserve (CRER) containing a total of 300,000 $\mathrm{SO}_{2}$ allowances, a minimum of 60,000 of which were allotted for renewable energy sources. ${ }^{29}$ The allowances, which represent less than $0.3 \%$ of the allowance pool, were set aside to be awarded to qualified utilities for $\mathrm{SO}_{2}$ emissions avoided through energy conservation, biomass (including landfill gas), solar, geothermal, and wind energy projects implemented between 1992 and 1999. An allowance can be earned for every 500 megawatt-hours (MWh) of energy produced by a qualified utility ${ }^{30}$ through renewable energy generation measures.

\footnotetext{
${ }^{26}$ CAA $\S 412 ; 42$ U.S.C. $\S 7651 \mathrm{k}$. Regulations establishing the monitoring requirements under Title IV are set forth at 40 C.F.R. Part 73, Subpart E; see 58 Fed Reg. 3717 (Jan. 11, 1993).

${ }^{27}$ CAA $\S 411 ; 42$ U.S.C. $\$ 7651$ j. Regulations governing excess emissions penalties are set forth at 40 C.F.R. Part 77; see 58 Fed. Reg. 3757 (Jan. 11, 1993).

${ }^{28}$ CAA $\S 408 ; 42$ U.S.C. $\S 7651 \mathrm{~g}$. The regulations implementing the permit program for sources regulated under the Title IV acid rain program are set forth at 40 C.F.R. Part 72; see 58 Fed. Reg. 3590 (Jan. 11, 1993).

${ }^{29}$ CAA $\S 404(\mathrm{f})$, (g); 42 U.S.C. $\S 7651 \mathrm{c}(\mathrm{f})$, (g). The regulations implementing the CRER are set forth at 40 C.F.R. Part 73, Subpart F; see 58 Fed. Reg. 3695 (Jan. 11, 1993).

30 The CAA limits eligibility for CRER allowances to entities that own an "affected unit," a power plant covered by Title IV $\mathrm{SO}_{2}$ controls. 42 U.S.C. $\S 7651 \mathrm{c}(\mathrm{f})(2)(\mathrm{B})(\mathrm{v})$. Further, it requires the utility to engage in a "least-cost planning" procedure, resulting in a plan approved by the applicable state designed to evaluate a range of clean energy resources for meeting future demand at the lowest system cost. 42 U.S.C. $§ 7651 \mathrm{c}(\mathrm{f})(2)(\mathrm{B})(\mathrm{iii})$.
} 
Although well intentioned, the CRER did not provide a significant boost to renewable energy sources. As of June 1999 , less than $12 \%$ of the 300,000 allowances had been allocated, although utilities can continue to submit applications for previously realized savings until 2010 . Of this $12 \%$, only about 6,700 allowances went to renewable energy projects. ${ }^{31}$ There are several reasons for the CRER's disappointing performance:

- The program was designed primarily to encourage early reductions (occurring before the statutory deadlines) and not as a long-term incentive for renewables. Perhaps the program would have worked better had the set-aside of allowances from the overall cap and eligibility for awards been extended to new renewable generation coming on-line after 2000;

- Facilities could easily meet their emission limits under Title IV by switching to low-sulfur coal, installing controls, or pursuing other, relatively inexpensive compliance strategies. Because the cost of compliance was low, so was the price of allowances. As a result, facilities had little economic incentive to avail themselves of the CRER;

- The statute awarded $\mathrm{SO}_{2}$ allowances at a rate of one allowance per $500 \mathrm{MWh}$ of generation from renewable energy facilities. This rate was arguably too low in that it did not fully reflect the emissions actually avoided by displacing fossil-fuel generation by adding renewables to the generation mix. As described in a recent paper by the Renewable Energy Policy Project, this conversion rate could be increased by threefold to reflect the average emission-reduction effect of renewable energy production, although the number would vary by region; ${ }^{32}$

- The CRER allowed only utilities to acquire $\mathrm{SO}_{2}$ allowances from the set-aside. The interest of utilities in renewables, low to begin with, was further limited by the uncertainties associated with an increasingly deregulated energy market. Renewable energy developers, those with the greatest motivation, were unable to participate independent of utility involvement;

- The CRER program failed to anticipate the impact of electricity industry restructuring and deregulation. To participate in the program, utilities were required to engage in least-cost planning in acquiring new generation sources. Least-cost planning is a mechanism developed during the period of retail electric sales monopolies to influence the way utilities acquired new generation to meet changing load patterns. In theory, it would have required a utility to have a program to compare the cost of new fossil fuel-fired plants with alternatives such as energy efficiency and renewables. This concept no longer applies in today's largely deregulated environment, where the markets largely decide what generation will be used and constructed;

- With respect to energy efficiency, the CRER also did not anticipate other changes in electric utility structure. To receive allowance awards for energy efficiency, utilities were also required to adopt an income neutrality element in rate structures to prevent revenue erosion resulting from utility investments in energy efficiency. This mechanism, which was always highly unpopular with utilities, is no longer appropriate in today's newly deregulated energy markets.

\footnotetext{
31 See EPA's CRER Web site: www.epa.gov/ardpublc/acidrain/crer/crerpg.html.

32 See Table 4, Renewable Energy Policy Project, A Guide to the Clean Air Act for the Renewable Energy Community, by David R. Wooley, 2000, available at: www.repp.org. Several of the REPP Report tables have been included in this report as Appendix G. The CRER allowance of one ton per $500 \mathrm{MWh}$ arguably undervalues the renewables contribution by a factor of three when compared with the Phase II standards and by a factor of six when compared to the Phase I standards.
} 


\section{Recent Legislative Proposals to Reduce $\mathrm{SO}_{2}$ Emissions}

The consensus in both the public and private sectors is that the Title IV acid rain cap-and-trade program has achieved its intended goal of reducing $\mathrm{SO}_{2}$ emissions in an efficient and cost-effective manner. However, many scientists and environmental groups believe that the environmental objective of eliminating acid rain cannot be achieved without additional emission reductions. The success of the market-based approach, and the recognition of the need for additional reductions, has prompted several members of Congress to propose amendments to the CAA that would impose stricter limits on $\mathrm{SO}_{2}$ emissions, typically as part of a larger CAA reform program. For example, the Clean Smokestacks Act of 1999, sponsored by Congressman Henry Waxman and 116 cosponsors (H.R. $2900 \mathrm{IH}$ ), would require power plants to reduce their $\mathrm{SO}_{2}$ emissions $75 \%$ from 1997 levels by January 2005. This bill would result in a new national $\mathrm{SO}_{2}$ cap of approximately 2.5 million tons per year compared with the 8.9-millionton cap that the current statute will achieve by 2010. Other legislation, such as the Acid Deposition Control Act (H.R. 657, H.R. 25, S.172) would reduce $\mathrm{SO}_{2}$ emissions by making each existing allowance worth one-half ton of $\mathrm{SO}_{2}$ beginning in 2005. A table summarizing recent federal legislation to establish emission-trading programs under the CAA is attached as Appendix D.

These bills arise in part from citizen group campaigns focused on the "grandfathered" status of older power plants under the CAA. While all sulfur-emitting power plants are subject to the acid rain controls of Title IV, the plants have the opportunity to meet control obligations by purchasing allowances, and can, in many cases, avoid emission reductions. On average, the controls required by Title IV are less stringent than those required for new and modified sources under the "best available control technology" requirements of the Prevention of Significant Deterioration (PSD) provisions of the CAA. ${ }^{33}$ This fact, coupled with recent scientific research showing that acid rain will continue to harm freshwater bodies after full implementation of Title IV, has given rise to proposals by legislators and environmental advocates for additional $\mathrm{SO}_{2}$ reductions.

This campaign to adopt stricter $\mathrm{SO}_{2}$ limits is gaining momentum. Currently, more than 126 members of the House of Representatives have endorsed one or more of the bills discussed above. In the Senate, the various competing bills have received similar support.

33 CAA §§ 160-169; 42 U.S.C. §§ 7470-7479. 


\section{Section IV—Ozone, Nitrogen Oxide Controls, and Renewables}

\section{Introduction}

This section describes the various programs for controlling $\mathrm{NO}_{\mathrm{x}}$ emissions under the federal CAA and parallel state control regimes. As this section will show, regulation of $\mathrm{NO}_{\mathrm{x}}$ is extremely complex. Because the pollutant has a variety of adverse health and environmental impacts, it is the subject of multiple and somewhat overlapping control programs designed to address various regional air pollution problems, including acid rain, ground level ozone, fine particles, and visibility impairment.

Although $\mathrm{NO}_{\mathrm{x}}$ is emitted from a variety of sources, a significant portion of the pollution burden is associated with large fossil fuel-fired electric generators. Consequently, $\mathrm{NO}_{\mathrm{x}}$ control programs present a significant opportunity both for emission trading generally and for renewables, in particular. To date, although both the federal government and a dozen states in the Northeast have developed $\mathrm{NO}_{\mathrm{x}}$ emission trading programs, renewable energy set-asides are limited to only a few states. Moreover, the value of the credits for renewable energy industries remains limited by the seasonal nature of the controls. These $\mathrm{NO}_{\mathrm{x}}$ emission-trading programs nevertheless represent an important first step in establishing a broader role for renewables.

\section{Nitrogen Oxides, Ozone and Smog}

Ground-level ozone pollution has been one of the nation's most persistent air pollution problems. Ground-level ozone is formed when volatile organic compounds (VOCs) and $\mathrm{NO}_{\mathrm{x}}$ react in sunlight to form ozone. Although ozone in the upper atmosphere is essential to protect the earth from harmful ultraviolet radiation, at ground level it can cause various health problems, including decreased lung function and respiratory symptoms, particularly in sensitive populations such as children and the elderly. Combined with airborne particulate matter, groundlevel ozone creates the air pollution problem more commonly known as "smog."

Eliminating ozone pollution has been an important goal of the CAA since it was first enacted in 1970. For the first 20 years, the CAA focused primarily on limiting local emissions of VOCs, which were thought to be the primary precursor to ozone pollution. ${ }^{34}$ Despite the imposition of significant limitations on VOC emissions, as of 1990, approximately one-half of the population of the United States continued to live in areas that were designated nonattainment for ozone. To address this problem, Congress overhauled the CAA's ozone requirements, imposing significantly stricter requirements for compliance and expanding the scope and breadth of the program. Two changes, in particular, have had and will continue to have a significant effect on the regulation of utilities and, by extension, the potential opportunities for renewables. First, with the 1990 CAA Amendments, Congress made its first serious effort to regulate $\mathrm{NO}_{\mathrm{x}}$ as an ozone precursor. As a result of this change, combustion sources such as utility boilers and industrial furnaces for the first time face significant emission reduction obligations under the ozone nonattainment program. Second, Congress acknowledged that ozone pollution is a regional problem, expressly designating the nation's first "ozone transport region" in the northeastern United States. ${ }^{35}$ This change has prompted both the EPA and certain states to implement comprehensive $\mathrm{NO}_{\mathrm{x}}$ control programs that include an emission-trading component.

\footnotetext{
34 VOCs are organic compounds that participate in atmospheric photochemical reactions. VOCs are commonly found in paints, solvents, gasoline and petroleum products, and other similar substances.

${ }^{35}$ CAA $\S 184 ; 42$ U.S.C. $§ 7511$ c.
} 


\section{Recent Ozone Control Measures}

Ozone is one of six criteria contaminants for which NAAQS have been set. ${ }^{36}$ Each state must therefore include in its SIP the measures it will implement to attain and maintain the NAAQS for ozone in the state. ${ }^{37}$ Originally, the CAA established deadlines for areas to attain compliance with the NAAQS without regard to the seriousness of the nonattainment problem. As previously noted, however, despite implementing measures to reduce VOC emissions, serious ozone pollution remained in 1990. To address this ongoing problem, Congress adopted a graduated control program, imposing stricter standards on areas with more serious ozone nonattainment problems but allowing them more time to achieve attainment. ${ }^{38}$ Under this scheme, ozone nonattainment areas are classified as marginal, moderate, serious, severe, or extreme based on their ambient ozone levels. States must then enact specific measures depending on their nonattainment classification; ${ }^{39}$ if these measures will not be sufficient to achieve attainment by the specified deadline, the state must propose additional control measures that will be included in the SIP. Areas that fail to achieve attainment by the deadline are bumped into the next highest nonattainment classification and subjected to stricter control requirements. A map showing the location of ozone nonattainment areas is attached as Appendix E.

With the 1990 CAA Amendments, Congress profoundly affected ozone regulation by specifically including $\mathrm{NO}_{\mathrm{x}}$ as an ozone precursor. As a result of this change, combustion sources such as utilities are now subject to the various regulatory programs intended to help states achieve the NAAQS for ozone. This change means that many existing major sources of $\mathrm{NO}_{\mathrm{x}}$ are required to install reasonably available control technology (RACT); new or significantly modified major sources of $\mathrm{NO}_{\mathrm{x}}$, meanwhile, are now subject to strict nonattainment new source review requirements, including the requirement to offset increased emissions.

\section{Interstate Ozone Transport}

\section{Introduction}

The pre-1990 CAA contained several provisions addressing interstate air pollution. Among other things, the Act required SIPs to contain provisions to prevent air pollution sources from contributing significantly to nonattainment or interfering with efforts to maintain the NAAQS in another state. The Act also created interstate notice requirements for new sources, and a petition process by which a state may ask the EPA to shut down or impose emissions limitations on sources in other states. ${ }^{40}$ The 1990 Amendments strengthened considerably the interstate regulation of ozone pollution. This development, if properly managed, holds considerable potential for encouraging the growth of renewable energy sources.

\footnotetext{
3640 C.F.R. Part 50.

37 CAA $\S 110 ; 42$ U.S.C. $\S 7410$.

38 CAA $\S ~ 181-186 ; 42$ U.S.C. $\S \S 7511-7511 f$.
}

39 Among other things, under the 1990 CAA Amendments, the more serious the ozone nonattainment problem, the lower the major source threshold (ranging from 100 tons per year of $\mathrm{VOCs}$ or $\mathrm{NO}_{\mathrm{x}}$ in marginal areas to 10 tons per year in extreme areas). This change means that relatively small sources in areas classified as moderate and higher must comply with various control requirements, such as the requirement to install reasonably available control technology on existing sources. In addition, under the 1990 Amendments, the emission offset ratio for sources subject to nonattainment new source review increases the higher the nonattainment classification (from 1.1 to 1 in marginal ozone nonattainment areas to 1.5 to 1 in extreme ozone nonattainment areas). States also must implement different vehicle inspection requirements and comply with other requirements, depending on their attainment status.

${ }^{40}$ CAA $\S \S 110(a)(2)(D), 126 ; 42$ U.S.C. $\S \S 7410(a)(2)(D), 7426$. 


\section{The Northeast Ozone Transport Region/NO $x$ Budget Model Rule}

The most direct recognition by Congress of the ozone transport problem was its creation of a permanent Northeast Ozone Transport Region (OTR), extending north from northern Virginia to Maine and encompassing 13 states and the District of Columbia. ${ }^{41}$ States in the OTR are regulated, at minimum, as "moderate" ozone nonattainment areas regardless of their actual attainment status. As a result of this classification, stationary sources with the potential to emit 50 tons of VOCs or more per year are considered "major" and must comply with all RACT and other applicable control requirements. ${ }^{42}$ In addition, states in the OTR must implement enhanced vehicle inspection and maintenance programs for automobiles.

The activities of the OTR are governed by the Ozone Transport Commission (OTC), which is composed of the governor of each state (or designee), an air pollution control official from each state, and representatives of the EPA. ${ }^{43}$ The OTC is responsible for assessing the degree of ozone transport in the region and recommending additional measures to be applied in the region to reach attainment. These recommendations must be approved by the EPA, which will issue a notice requiring member states to revise their SIPs to include these new measures.

In 1994, the Northeast OTR states, with one exception, entered into a Memorandum of Understanding (MOU), under which the states agreed to promulgate regulations to reduce $\mathrm{NO}_{\mathrm{x}}$ emissions during the summer when ozone problems typically occur. ${ }^{44}$ The EPA has approved the program, which caps $\mathrm{NO}_{\mathrm{x}}$ emissions from regulated sources at about half the level of the baseline years. The MOU emission reduction program is being implemented in three phases. Phase I requires all major sources in the Northeast that have not already done so to install RACT. The second and third phases, implemented in 1999 and 2003, respectively, divide the participating states into three regions - inner, outer, and northern. ${ }^{45}$ During Phase II, the MOU requires emission reductions by 1999 equivalent to $.20 \mathrm{lbs} . / \mathrm{mm}$ Btu, or a $65 \%$ reduction from 1990 baseline levels in the inner zone, whichever is less stringent, with slightly smaller reductions required in the outer zone (which has a less serious ozone nonattainment problem). During Phase III, which takes effect in 2003, sources in the inner and outer zones must reduce emissions by $75 \%$ from baseline or emit $\mathrm{NO}_{\mathrm{x}}$ at a rate no greater than .15 $\mathrm{lbs} . / \mathrm{mm}$ Btu, whichever is less stringent. ${ }^{46}$

To allow for the greatest flexibility in achieving the required $\mathrm{NO}_{\mathrm{x}}$ emission reductions, the $\mathrm{MOU}$ utilizes a region-wide $\mathrm{NO}_{\mathrm{x}}$ allowance trading system to reduce emissions from electric utility power plants and large industrial boilers. The criteria for the trading program are set forth in the $\mathrm{NO}_{\mathrm{x}}$ Budget Model Rule, which was developed by the Northeast States for Coordinated Air Use Management (NESCAUM) for the OTC. The $\mathrm{NO}_{\mathrm{x}}$

${ }^{41}$ CAA $\S 184 ; 42$ U.S.C. $\$ 7511 \mathrm{c}$.

42 The threshold for NOx remains 100 tons per year in sections of the OTR that are not specifically designated nonattainment for ozone.

43 CAA § 176A; 42 U.S.C. § 7506a.

44 Memorandum of Understanding Among the States of the Ozone Transport Commission on Development of a Regional Strategy Concerning the Control of Stationary Sources of Nitrogen Oxide Emissions, signed September 27, 1994 . Virginia declined to participate in the 1994 MOU. A summary of key EPA/State guidance documents and memoranda is attached as Appendix C.

45 The "inner zone" consists of the various contiguous ozone nonattainment areas extending from New Hampshire south to northern Virginia. The "northern zone" includes the states of Vermont and Maine, and the areas of northern New York and New Hampshire that have been designated attainment. The remainder of the OTR is part of the "outer zone."

46 During Phase III, smaller reductions are also required from affected sources in the northern zone. 
Budget Model Rule establishes a framework for states to follow in designing their own trading programs under the MOU. As set forth in detail below, although the $\mathrm{NO}_{\mathrm{x}}$ Budget Model Rule does not expressly require participating states to establish a role for renewables, several states have created set-asides and other programs to encourage development of renewable energy sources. In addition, the OTC has issued guidance recommending using system benefits charges to encourage development of renewable energy sources to reduce $\mathrm{NO}_{\mathrm{x}}$ emissions. $^{47}$

In the long term, the states in the OTR are exploring an expanded role for renewables as a way of further reducing $\mathrm{NO}_{\mathrm{x}}$ emissions. ${ }^{48}$ In June 2000 , members of the OTC executed a MOU under which they agreed to evaluate specific ozone control measures. Under the MOU, the member states agreed to assess control measures to limit emissions from architectural and industrial maintenance coatings, consumer products, mobile equipment refinishing, solvent cleaning, fuels for on-road vehicles and off-road equipment (diesel or gasoline) and fuel combustion sources by the end of 2001. By the end of 2002, the states agreed to assess other, longer-term control approaches, most of which are targeted at creating incentives for energy efficiency, conservation, and renewable energy. Among the specific alternatives to be considered are system benefits charges, environmental performance standards, and renewable energy and energy efficiency programs.

This MOU is the first step in a long process of implementing reasonably uniform state regulations in the OTR. In accordance with the schedule above, the OTC will study the various ozone reduction measures and, perhaps, develop a model program for implementing those reductions. States that commit to achieving these reductions will be required to develop their own regulations consistent with the OTC program.

\section{Section 126 Petitions/EPA SIP Call}

The 1994 MOU targets emissions of $\mathrm{NO}_{\mathrm{x}}$ from combustion sources in the Northeast. For many years, however, states in the Northeast have complained that their difficulties in achieving the ozone NAAQS can be attributed, in large part, to emissions from facilities outside the region, particularly coal-burning midwestern power plants. In the mid-1990s, the midwestern, southern, and northeastern states formed the Ozone Transport Assessment Group (OTAG) to study the transport of ozone and smog precursors. After two years, OTAG presented its conclusions and recommendations to the EPA. The final report and recommendations confirmed that ozone is transported, sparking further debate between the northeastern, midwestern, and southern states concerning the cause and possible solutions to the Northeast's ongoing ozone problems.

Buoyed by the results of the OTAG study, eight New England and Mid-Atlantic states petitioned the EPA, under Section 126 of the CAA, for relief from transport of smog pollutants that interfere with attainment of the NAAQS for ozone. CAA § 126 authorizes one state to petition the EPA for a finding that a major source or group of sources in another state is emitting pollutants at levels that contribute significantly to nonattainment in, or interfere with maintenance by, that state. ${ }^{49}$

\footnotetext{
47 OTC, "Emission Reduction Measures" (Undated) found at http://www.sso.org/otc/er measure.htm.

${ }^{48}$ Memorandum of Understanding Among the States of the Ozone Transport Commission Regarding the Development of Specific Control Measures to Support Attainment and Maintenance of the Ozone National Ambient Air Quality Standards (June 1, 2000) available at www.sso.org/otc/mou003.htm.

4942 U.S.C. $\$ 7426$.
} 
Shortly after the northeastern states filed their 126 petitions, the EPA proposed a draft " $\mathrm{NO}_{\mathrm{x}}$ SIP call" rule under CAA $\S 110$, requiring additional $\mathrm{NO}_{\mathrm{x}}$ emission reductions from sources in the Northeast, Midwest, and South. CAA $\S 110$ requires the SIP in each state covered by the SIP call to contain adequate provisions prohibiting a source or sources within a state from contributing significantly to nonattainment, or interfering with maintenance of attainment in, other states. ${ }^{50}$ Under the $\mathrm{NO}_{\mathrm{x}}$ SIP call, which was finalized in October 1998, the EPA concluded that $\mathrm{NO}_{x}$ emissions from 22 states and the District of Columbia were contributing significantly to ozone nonattainment conditions in the northeastern states. ${ }^{51}$ To address the problem, the EPA proposed caps on $\mathrm{NO}_{\mathrm{x}}$ emissions that would reduce total summertime emissions of $\mathrm{NO}_{\mathrm{x}}$ by approximately $28 \%$ (1.2 million tons) from 1990 levels beginning in 2003. The SIP call rulemaking allocated these emission reductions among the affected states. Although the states were responsible for deciding how to achieve these reductions, the SIP call assumed that the principal burden of the program would fall on electric utility generating plants and, to a lesser extent, on large industrial boilers. ${ }^{52}$ In establishing these emission reductions, the SIP call was expected to "level the playing field" between northeastern, southern, and midwestern utilities by requiring the imposition of similar $\mathrm{NO}_{\mathrm{x}}$ controls throughout the OTAG region.

The EPA did not specifically require states to adopt a cap-and-trade program to implement the SIP call. Instead, it issued a model rule, known as the $\mathrm{NO}_{\mathrm{x}}$ Budget Trading Program. States interested in achieving compliance by using a trading program have the option of either incorporating the federal regulations, set forth at 40 CFR Part 96, by reference or adopting state regulations that mirror Part 96 with certain minor variations. ${ }^{53}$ The EPA's model regulation includes an optional allowance-allocation methodology, but allows states to allocate as they see fit within certain broad parameters. As discussed below, although the federal model regulations do not specifically address renewable sources, subsequent EPA guidance establishes a framework for developing a renewable set-aside program. ${ }^{54}$

As might be expected, the final SIP call regulations were promptly challenged in court by various midwestern and southern states. The Court of Appeals for the District of Columbia Circuit initially stayed implementation of the SIP call rule, which required states to submit their plans for implementing the SIP call by September 1999. In March 2000, the court largely upheld the SIP call against various challenges, both to the EPA's general authority to issue the SIP call, and to the underlying basis for the rulemaking. ${ }^{55}$ Shortly thereafter, the

5042 U.S.C. $\$ 7410(\mathrm{a})(2)$.

51 See Finding of Significant Contribution and Rulemaking for Certain States in the Ozone Transport Assessment Group Region for Purposes of Reducing Regional Transport of Ozone, 63 Fed. Reg. 57356 (Oct. 27, 1998).

52 For utilities, the EPA chose a control level of .15 lb./mm Btu, which is achievable using available, cost-effective technology, and which corresponded to the most protective level recommended by OTAG. For non-utility sources, the EPA chose a control level that represents a $60 \%$ reduction from uncontrolled levels for large industrial boilers and turbines and a $90 \%$ reduction from stationary combustion engines.

5363 Fed. Reg. 57456, 57458 (Oct. 27, 1998).

54 EPA, Office of Atmospheric Programs, "Guidance on Establishing an Energy Efficiency and Renewable Energy (EE/RE) Set-Aside in the $\mathrm{NO}_{\mathrm{x}}$ Budget Trading Program” (Mar. 1999).

55 Michigan v. U.S. Environmental Protection Agency, 213 F.3d 663 (D.C.Cir. 2000). The plaintiffs in Michigan v EPA argued, among other things, that the EPA was required to establish an ozone transport commission prior to issuing the SIP call. The court rejected this suggestion based on the plain language of the CAA. Petitioners also argued that the EPA did not sufficiently analyze emissions from each state to assess their contribution to downwind ozone problems. In response, the court concluded that petitioners were doing nothing more than "quibbl[ing] with state-specific modeling" and that it would not question the EPA's judgment on this matter. The court also considered other general arguments as well as arguments from specific states that all or part of the state should not be included in the SIP call. 
court lifted the stay and set a deadline of October 30,2000, for submitting SIPs required by the SIP call; the SIP call must be implemented by May 2004. A petition for review has been filed with the U.S. Supreme Court. (A table summarizing the status of recent key CAA litigation is attached as Appendix B.)

During the pendency of the litigation involving the SIP call, the EPA began processing the CAA $\S 126$ petitions submitted by the northeastern states. In January 2000, the EPA granted the petitions filed by four northeastern states (Connecticut, Massachusetts, New York, and Pennsylvania) seeking to reduce ozone pollution through reductions in $\mathrm{NO}_{\mathrm{x}}$ emissions from other states. ${ }^{56}$ The Section 126 final action requires 392 facilities in 12 states and the District of Columbia to reduce annual emissions of $\mathrm{NO}_{\mathrm{x}}$ by a total of 510,000 tons from 2007 levels. Each affected facility must participate in a federal $\mathrm{NO}_{\mathrm{x}}$ emissions cap-and-trade program similar to the OTC $\mathrm{NO}_{\mathrm{x}}$ Budget Model Rule. Midwestern states covered by the 126 finding have filed a lawsuit in federal court challenging the EPA's final 126 rulemaking.

\section{Current $\mathrm{NO}_{\mathrm{x}}$ Trading Programs}

\section{Federal Trading Programs}

Currently, there are several $\mathrm{NO}_{\mathrm{x}}$ trading regimes in place, each of which takes a different approach toward renewable energy resources. At the federal level, each facility regulated under the EPA's 126 rulemaking must participate in a federal $\mathrm{NO}_{\mathrm{x}}$ emissions cap-and-trade program, known as the Federal $\mathrm{NO}_{\mathrm{x}}$ Budget Trading Program, to be set forth at 40 CFR Part 97. ${ }^{57}$ The Federal $\mathrm{NO}_{\mathrm{x}}$ Budget Trading Program caps overall emissions of $\mathrm{NO}_{\mathrm{x}}$ from the 392 sources specifically identified as significantly contributing to ozone transport problems in the petitioning states, a group that consists of certain utility boilers and turbines and very large industrial boilers. ${ }^{58}$ The EPA will then allocate emission "allowances" - each of which is equal to one ton per year of $\mathrm{NO}_{\mathrm{x}}$ - to these emission sources in accordance with a specified formula. ${ }^{59}$ Sources regulated under the program cannot emit $\mathrm{NO}_{\mathrm{x}}$ in excess of the number of allowances they hold. As with the Title $\mathrm{IV} \mathrm{SO}_{2}$ cap-and-trade program, sources have the option of either controlling their own emissions to achieve the emission reductions required under the cap or purchasing allowances from other sources regulated under the Federal $\mathrm{NO}_{\mathrm{x}}$ Budget Trading Program. The goal is to enable sources to achieve the reductions required under the program at the least possible cost. Affected sources under the program are required to monitor emissions beginning May 1, 2002; full compliance with the Federal $\mathrm{NO}_{\mathrm{x}}$ Budget Trading Program is required starting May 1, 2003. The program does not include a specific role for renewables.

\footnotetext{
${ }^{56}$ Findings of Significant Contribution and Rulemaking on Section 126 Petitions for Purposes of Reducing Interstate Ozone Transport, 65 Fed. Reg. 2554 (Jan. 18, 2000).

5765 Fed. Reg. 2674 (Jan. 18, 2000).

58 The program regulates fossil fuel-fired boilers or combustion turbines that serve an electric generating unit with a rated output of greater than $25 \mathrm{MW}$ or a maximum rated heat input capacity of greater than $250 \mathrm{~mm} \mathrm{Btu} /$ hour.

59 The EPA established a control level of $0.15 \mathrm{lbs} . / \mathrm{mm}$ Btu for electric generating units and a $60 \%$ reduction in $\mathrm{NO}_{\mathrm{x}}$ emissions for industrial boilers. To set emission limits for individual sources, the EPA apportioned the state trading budgets among the named sources based on each unit's heat input.
} 
The Federal $\mathrm{NO}_{\mathrm{x}}$ Budget Trading Program is very similar to the $\mathrm{NO}_{\mathrm{x}}$ Budget Trading Program developed to help implement the $\mathrm{NO}_{\mathrm{x}}$ SIP call. ${ }^{60}$ Both programs assume the same level of control for large electric generating units and industrial boilers, and both adopt similar monitoring, record-keeping, and reporting requirements. Consequently, sources may trade emissions between programs. The chief difference between the two programs is that the SIP call version of trading is voluntary; states have the option of reducing emissions through means other than the trading program. Therefore, only those states that choose to control their emissions through the SIP call $\mathrm{NO}_{\mathrm{x}}$ Budget Trading Program (which has some additional flexibility) can trade with sources in the Federal $\mathrm{NO}_{\mathrm{x}}$ Budget Trading Program implemented under CAA § 126. In addition, as set forth below, the two programs adopt different strategies for allocating allowances.

Neither of the two federal programs include any mandatory provisions specifically establishing a role for renewables. The SIP call includes a recommended strategy for allocating allowances based on heat input. In addition, the EPA has issued guidance to encourage states to establish energy efficiency and renewable energy set-aside programs. The EPA's Guidance on Establishing an Energy Efficiency and Renewable Energy (EE/RE) Set-Aside in the NO $O_{x}$ Budget Trading Program, dated March 1999, outlines the benefits of an allowance set-aside program, the key elements of the program, eligibility criteria, and other key components of an allowance set-aside program. The EE/RE Guidance, which was intended to be the first of three documents on developing allowance set-aside programs, provides recommendations on several key elements of designing a set-aside program, including: (1) the size of the set-aside; (2) who is eligible to participate (entities and types of projects); (3) encouraging "new" as opposed to "business as usual" projects; (4) providing credit for early actions (i.e., those occurring prior to the 2003 deadline for implementing regulations required under the SIP call); (5) the length of award; and (6) adjusting pool size (if program is under- or over-subscribed). In addition, the EE/RE Guidance outlines the procedures states must follow to obtain approval of a set-aside program. As discussed below, EPA's EE/RE Guidance provides a valuable framework for developing allowance set-asides under the various emission-trading programs that have been or are being developed at the state, national, and international level.

The preamble to the $\mathrm{NO}_{\mathrm{x}}$ SIP call also notes that states have the option of allocating allowances based on electric output rather than heat input. Under this approach, allowances would be awarded based on the quantity of electricity generated rather than the amount of fuel burned. The EPA declined to propose an output-based allocation mechanism as part of the $\mathrm{NO}_{\mathrm{x}}$ SIP call because it would require changes to existing monitoring regulations to obtain necessary data concerning electric output. ${ }^{61}$ In May 2000, the EPA issued a detailed guidance, Developing and Updating Output-Based $\mathrm{NO}_{x}$ Allocations, to assist states implementing output-based allowance programs under the $\mathrm{NO}_{\mathrm{x}}$ SIP call. Although targeted at the SIP call, the document provides useful guidance on the criteria for developing output-based allowance programs, addressing such factors as whether allowances should be allocated to units, plants, or generators; the technical and policy considerations in selecting the location for measuring output data to be used in allocations, monitoring, recording, and reporting output data; and potential sources of output data. It also includes sample regulatory provisions for inclusion in state rules.

Like the SIP call regulations, the EPA's Federal $\mathrm{NO}_{\mathrm{x}}$ Budget Trading Program under CAA § 126 also allocates allowances on an input basis. Effective in 2008, however, the EPA will allocate allowances on an updating output basis. Under this approach, the EPA will award allowances based on the quantity of energy generated, updating the allocation every five years. According to the EPA, this approach will reward and encourage energy efficiency and reduce "leakage" - the purchase of additional electricity from sources not regulated by the CAA

\footnotetext{
6040 C.F.R. Part 96.

6163 Fed. Reg. 57470.
} 
$\S 126$ rulemaking. In adopting this approach, the EPA concluded that it lacked the data necessary to allocate allowances on an output basis in the short term. By 2005, however, sufficient data should be available to enable the EPA to allocate output-based allowances beginning in 2008. The EPA declined to decide whether the output-based allowances would be awarded to all electric generating sources, including renewables, or only to fossil fuel-fired sources. ${ }^{62}$

To date, no states have implemented trading under either the Section 126 or SIP call programs, primarily because of delays caused by the court challenge to the SIP call. As discussed below, several states in the Northeast have designed their OTC trading programs to conform to the federal requirements.

\section{State Ozone Programs}

In addition to the federal trading programs, states in the OTC recently have adopted trading programs to implement the $1994 \mathrm{NO}_{\mathrm{x}}$ reduction program that are patterned after the OTC's $\mathrm{NO}_{\mathrm{x}}$ Budget Model Rule. Under the $\mathrm{NO}_{\mathrm{x}}$ Budget Model Rule, affected sources must hold allowances for all $\mathrm{NO}_{\mathrm{x}}$ emitted during the summer ozone season. Once the summer ozone season ends, each source must evaluate emissions and obtain additional $\mathrm{NO}_{\mathrm{x}}$ allowances, as necessary. At year's end, each source must submit a certificate of compliance; if the source does not hold sufficient allowances, it must offset excess emissions and pay penalties.

States committed to the MOU were required to implement their own $\mathrm{NO}_{\mathrm{x}}$ budget programs based on the $\mathrm{NO}_{\mathrm{x}}$ Budget Model Rule and to allocate allowances among sources in the state. The second phase of the emission reduction program has been implemented by all states that signed the MOU; several states specifically adopted provisions addressing renewable energy sources, most setting aside a portion of allowances for allocation to renewables and energy efficiency. Several of these programs are described briefly below:

- Massachusetts. Massachusetts has proposed a program to reduce utilities' $\mathrm{NO}_{\mathrm{x}}$ emissions by $75 \%$ from 1990 levels. ${ }^{63}$ This program is a cap-and-trade program similar to the Title IV $\mathrm{SO}_{2}$ allocation system. The program provides for a set-aside account for renewables and efficiency. In Phase II (beginning in 2003), $1 \%$ of the total $\mathrm{NO}_{\mathrm{x}}$ budget ( 135 tons) is to be set aside and awarded to energy efficiency and renewable energy developers. The system will allocate emissions to renewables at a rate of $1.5 \mathrm{lbs}$. of $\mathrm{NO}_{\mathrm{x}} / \mathrm{MWh}$.

- New Jersey. New Jersey has also adopted a $\mathrm{NO}_{\mathrm{x}}$ cap-and-trade budget system, including an energy efficiency and renewable energy incentive. ${ }^{64}$ Like Massachusetts, New Jersey's allowances are allocated at a rate of $1.5 \mathrm{lbs}$. of $\mathrm{NO}_{\mathrm{x}} / \mathrm{MWh}$.

- New York. In September 1999, New York finalized a seasonal $\mathrm{NO}_{\mathrm{x}}$ cap-and-trade budget of 40,000 tons. ${ }^{65}$ For the control periods between 2003 and $2007,3 \%$ of the budget allowances will be made available for energy efficiency and renewable energy projects in New York. These projects are eligible for allowances for five years.

\footnotetext{
6265 Fed. Reg. 2674, 2698 (Jan. 18, 2000).

${ }^{63}$ See 310 CMR § 7.27 and supporting guidance documents.

${ }^{64}$ See N.J.A.C. 7:27.

65 See 6 NYCRR Part 204.
} 
Both the state and federal $\mathrm{NO}_{\mathrm{x}}$ budget programs are premised on achieving emission reductions that would achieve an overall $\mathrm{NO}_{\mathrm{x}}$ emission rate of $.15 \mathrm{lbs} . / \mathrm{mm}$ Btu beginning in 2003. As a result, although implementation of the two federal $\mathrm{NO}_{\mathrm{x}}$ Budget Trading Programs has been delayed by litigation over the validity of the EPA's SIP call rulemaking (which indirectly delayed approval of the various state 126 petitions), several states, including New York, have implemented trading programs that attempt to satisfy the requirements of both the federal and Northeast regional $\mathrm{NO}_{\mathrm{x}}$ budget programs.

\section{State "Winter" $\mathrm{NO}_{x}$ Programs}

Section 116 of the federal CAA gives states the authority to adopt emission controls for new sources that are more stringent than federal requirements. ${ }^{66}$ New York, Massachusetts and Connecticut are considering implementing programs that would convert the summer season $.15 \mathrm{lb} . / \mathrm{mm}$ Btu control targets established under the Northeast MOU and the SIP call into an annual emission-control requirement. For example, in an initiative announced by Governor George Pataki, New York currently is revising its existing regulations to apply its summer $\mathrm{NO}_{\mathrm{x}}$ control program year-round. Massachusetts recently announced an agreement between the state and its utilities to implement a similar program. In Connecticut, the legislature failed to pass legislation establishing a year-round $\mathrm{NO}_{\mathrm{x}}$ control program by a single vote, prompting Governor Rowland to initiate an administrative rulemaking on the subject. These initiatives create an additional opportunity to incorporate renewable set-asides into the trading mechanisms likely to accompany these "winter" $\mathrm{NO}_{\mathrm{x}}$ controls.

\section{Recent Legislative Initiatives to Reduce $\mathrm{NO}_{x}$ Emissions}

Most of the recent bills introduced in Congress to reduce $\mathrm{SO}_{2}$ emissions include provisions addressing $\mathrm{NO}_{\mathrm{x}}$. For example, the Acid Deposition Control Act (H.R. 657, H.R. 25, S.172) calls for capping emissions of $\mathrm{NO}_{\mathrm{x}}$ in the lower 48 states at 5.4 million tons per year for the years 2002-2004 and 3.0 million tons per year for 2005 on. Each allowance under the program would authorize one-half ton of $\mathrm{NO}_{\mathrm{x}}$ emissions during the summer ozone season and one ton of emissions the remainder of the year. The EPA would distribute allowances among the states but leave it to each state to decide how to allocate allowances among the various sources. Although the Acid Deposition Control Act does not include specific provisions to encourage renewable energy, states presumably would be free to develop an allocation scheme that includes renewables. A bill introduced by former Congressmen Rick Lazio (H.R. 4861), by comparison, would expressly regulate both combustion sources (25 MW or more) and wind, geothermal, solar thermal, or photovoltaic energy sources ( $5 \mathrm{~kW}$ or greater). The Clean Power Act would establish a 2.75-million-ton per year cap and would expressly allocate allowances on an output basis. (See Appendix D for a summary of recent CAA cap-and-trade legislation.)

\section{Revisions to the Ozone Standard}

As the above summary suggests, recent state and EPA efforts to address interstate ozone pollution have resulted in the development of a complex web of federal and state regulations; these efforts have been further complicated by an ongoing dispute involving the EPA's recent revision to the NAAQS for ozone. In July 1997, after years of scientific research, the EPA replaced its existing one-hour primary ozone standard with a new eight-hour standard based on evidence linking ambient ozone concentrations permitted by the existing ozone standards to health problems. ${ }^{67}$ As with the particulate matter NAAQS revisions discussed in Section V below, the ozone NAAQS revisions were extremely controversial. Ultimately, the federal Court of Appeals in

\footnotetext{
6642 U.S.C. $\S 7416$.

${ }^{67}$ For many years, the ozone standard was 12 parts per million (ppm) measured over one hour. The EPA replaced the pre-1997 onehour primary ozone standard with an eight-hour standard at a level of $0.08 \mathrm{ppm}$ calculated based on the three-year average of the annual fourth-highest daily maximum eight-hour average of ozone concentrations measured at each monitor within an area.
} 
American Trucking Association v. U.S. Environmental Protection Agency remanded both standards back to the EPA for further review. ${ }^{68}$ Although the court left the new ozone standards in place, it concluded that the standards could not be enforced. Consequently, the EPA was left scrambling to reinstate the old one-hour ozone standard that it had largely revoked after the new standard was adopted. The U.S. Supreme Court heard arguments on appeal of the American Trucking decision in early November 2000. A decision is expected by July 2001.

\section{Other $\mathrm{NO}_{\mathrm{x}}$ Regulations}

\section{Regional Haze/Particulate}

Until now, this report has focused on the regulation of $\mathrm{NO}_{\mathrm{x}}$ as an ozone precursor. However, emissions of $\mathrm{NO}_{\mathrm{x}}$ also contribute significantly to other air pollution problems. As discussed in Section $\mathrm{V}, \mathrm{NO}_{\mathrm{x}}$ reacts with other pollutants in the air to form nitrates, a fine particulate that, along with sulfate particles, is a significant component of regional haze. Many of the measures proposed to address regional haze involve restricting emissions from certain older steam electric power plants that are a significant source of $\mathrm{SO}_{2}$ and $\mathrm{NO}_{\mathrm{x}}$ and, by extension, regional haze. These measures are discussed in Section V of the report.

\section{Title IV Acid Rain Program}

Emissions of $\mathrm{NO}_{\mathrm{x}}$ also are specifically regulated under the Title IV acid rain program. Although the $\mathrm{NO}_{\mathrm{x}} \mathrm{SIP}$ call essentially superseded the Title IV requirements with respect to summertime $\mathrm{NO}_{\mathrm{x}}$ emissions (May through September) for electric utility and large industrial sources in the SIP call states, the regulations remain important for sources elsewhere in the country, and are the controlling limit on non-summer season $\mathrm{NO}_{\mathrm{x}}$ emissions in the northeastern states.

On the date a coal-fired utility unit becomes regulated under the Title IV acid rain program as an "affected unit," it also becomes an affected unit for purposes of the $\mathrm{NO}_{\mathrm{x}}$ emission limitations under Title IV. ${ }^{69}$ Title IV requires the EPA to set $\mathrm{NO}_{\mathrm{x}}$ limits for two groups of boilers: Group 1 and Group 2. Group 1 boilers include tangentially fired boilers and dry bottom wall-fired boilers other than units applying cell-burner technology. Group 2 boilers include cell burners, large cyclones, and wet bottom and vertically fired boilers. The emissions limits are implemented in two phases, with compliance with the Phase I limits required by January $1,1996,{ }^{70}$ and compliance with the Phase II limits by January $1,2000 .^{71}$

68175 F.3d 1027 (D.C.Cir. 1999), cert. granted, 120 S. Ct. 2003 (2000). The Court of Appeals concluded that CAA § 109 is unconstitutional because it "effects an unconstitutional delegation of legislative power" because the EPA "lacks any determinate criterion" for deciding where to set the standard for pollutants that have no known threshold for damaging health. The court remanded the standard back to the EPA to give it an opportunity to reinterpret the CAA to define more precisely where to draw the line in setting the NAAQS to protect public health.

${ }^{69}$ CAA $\S 407 ; 42$ U.S.C. $\S 7651 f$.

70 The EPA initially finalized the Phase I regulations on March 11, 1994 (59 Fed. Reg. 13538). However, a federal court vacated the regulations on the ground that the agency exceeded its authority by requiring the use of over-fire air technology rather than low $\mathrm{NO}_{\mathrm{x}}$ burners, as specified in the statute. Alabama Power v. U. S. Environmental Protection Agency, 40 F.3d 450 (D.C. Cir. 1994). The EPA promulgated final standards in response to the decision on April 13, 1995. 60 Fed. Reg. 18751. See 40 C.F.R. Part 76.

${ }^{71} 61$ Fed. Reg. 67112 (Dec. 19, 1996). Phase II requires additional emission reductions from Group 1 boilers. In addition, it sets limits for Group 2 boilers for the first time. 
In general, under the Title IV $\mathrm{NO}_{\mathrm{x}}$ program, each unit is expected to meet the emission limit appropriate to the particular type of boiler. However, the regulations allow each utility to average emissions from two or more boilers, such that overcontrol at one unit will allow another unit to emit above the emission limit. States are also allowed to petition the EPA to accept an emission cap-and-trade program as a substitute for compliance with Group 2 limits and incremental reductions required of the Group 1 boilers. This alternative may be allowed if the EPA finds that the cap-and-trade alternative will achieve lower total $\mathrm{NO}_{\mathrm{x}}$ emissions.

As noted above, the $\mathrm{NO}_{\mathrm{x}}$ control provisions of Title IV are important primarily for facilities not regulated under the $\mathrm{NO}_{\mathrm{x}}$ SIP call or other ozone reduction programs. Several of the CAA reform bills previously discussed would repeal the Title IV $\mathrm{NO}_{\mathrm{x}}$ requirements in favor of a nationwide $\mathrm{NO}_{\mathrm{x}}$ cap-and-trade program. 


\section{Section V-Visibility, Regional Haze, Particulate Matter, and Renewables}

\section{Introduction}

In recent years there have been several significant federal and state regulatory initiatives to address the related problems of visibility impairment in national parks and exposure to airborne PM. Most notably, Congress amended the CAA in 1990 to strengthen its visibility protection provisions. These efforts have occurred at a time of increased attention, particularly in western states, to the development potential of renewable energy. This section of the report describes the regulatory history of these developments. It also discusses the history and status of provisions of the CAA that specifically regulate PM.

As discussed below, the EPA's recently adopted regional haze regulations provide states with the option to implement an emission-trading program in lieu of requiring the installation of retrofit technologies on certain utility and other sources. These trading programs could be designed to create a role for renewables. In addition, the nine states in the Grand Canyon Visibility Transport Region have the option of adopting special rules that require them to work toward achieving specific goals for renewable energy generation. These and other provisions create opportunities for encouraging development of renewable energy.

\section{Background}

Emissions from industrial activities generally, and from fossil fuel-burning power plants in particular, have resulted in a significant decline in visual air quality in the form of regional haze. This haze is caused principally by the light-scattering effects of fine particles, such as sulfate and nitrates, formed in the atmosphere from $\mathrm{SO}_{2}$ and $\mathrm{NO}_{\mathrm{x}}$ emissions. Studies conducted by the National Park Service suggest that average visibility in the western United States is approximately one-half to two-thirds of the visual range that would exist without manmade air pollution; in most of the eastern United States, it is one-fifth of the range that would exist under natural conditions. ${ }^{72}$ To address the visibility problem, Congress specifically enacted visibility protection provisions ${ }^{73}$ designed to protect national parks and wilderness areas from visibility impairment ("plume blight" and haze) caused by manmade air pollution. These provisions, and their implementation, have evolved over time as the causes of visibility impairment are better understood.

Visibility protections were first included in the CAA in 1977. The 1977 Act established a broad goal calling for "the prevention of any future, and the remedying of any existing, impairment of visibility in mandatory Class I Federal areas which impairment results from manmade air pollution. ${ }^{, 74}$ Responsibility for achieving the goal of preventing or remedying visibility problems fell to the 35 states and 1 territory containing Class I Federal areas. These states were required to assess and remedy visibility impairment from new and existing sources and to develop long-term strategies to assure reasonable progress towards the national visibility goal as part of their SIPs. Until recently, however, the regulatory program was limited to controlling smoke plumes "reasonably

\footnotetext{
7264 Fed. Reg. 35714, 35715 (July 1, 1999) (citing National Park Service, Air Quality in the National Parks: A Summary of Findings from the National Park Service Air Quality Research and Monitoring Program, Natural Resources Report 88-1 (July 1988)).

73 CAA §§ 169A, 169B; 42 U.S.C. §§ 7491, 7492.

${ }^{74}$ CAA § 169A(a)(1); 42 U.S.C. § 7491(a)(1). The list of mandatory Class I Federal areas includes national parks exceeding 6000 acres, wilderness areas and national memorial parks exceeding 5000 acres, and all international parks that were in existence on August 7, 1977. Visibility has been identified as an important value in 156 areas, most of which are located in the West. See 40 C.F.R. Part 81, Subpart D.
} 
attributable" to a specific source or small group of sources ("plume blight"). ${ }^{75}$ The EPA specifically deferred action addressing regional haze impairment until monitoring techniques "provide[] more data on source-specific levels of visibility impairment, regional scale models become refined, and . . . scientific knowledge about the relationships between emitted air pollutants and visibility impairment improves." ${ }^{, 76}$

In the years that followed, the EPA and other agencies assembled significant additional information on the sources of regional haze, prompting Congress to regulate regional haze in wilderness areas as part of the 1990 CAA Amendments. Among other things, the CAA requires the EPA to take specific steps to improve information on haze by installing additional monitors and assessing improvements in visibility resulting from unrelated provisions of the CAA. ${ }^{77}$ Where the transport of pollutants from one state to another contributes to visibility impairment, the Act authorizes the EPA to establish "Visibility Transport Regions," headed by "Visibility Transport Commissions," which are responsible for assessing available data and issuing reports recommending measures to remedy visibility impairment. ${ }^{78}$ The Act also requires the EPA to adopt regulations to assure reasonable progress towards achieving national visibility goals ${ }^{79}$ and to specifically address visibility at the Grand Canyon National Park. The EPA's efforts involving the Grand Canyon set the stage for the agency's recently promulgated regional haze rule.

\section{Grand Canyon Visibility Transport Commission (GCVTC)}

Section 169B(f) of the CAA requires the EPA to establish a visibility transport commission for the region affecting visibility of the Grand Canyon National Park. ${ }^{80}$ The GCVTC, which is made up largely of political leaders from western states, issued its final report in 1996 after undertaking an extensive review of scientific, technical, and other information relevant to assessing visibility. ${ }^{81}$ The Report contains a series of recommendations to be used by the EPA as guidance for developing national strategies and rulemaking on visibility. These recommendations focus on air pollution prevention, stationary sources, mobile sources, road dust, emissions from Mexico, and fires, among other subjects.

Perhaps the most interesting feature of the GCVTC Report is its emphasis on pollution prevention and, in particular, renewable energy, as a means of addressing visibility impairment. The Report notes that "the West enjoys high potential for renewable energy production, especially electrical energy generation employing solar and wind power" and that the relative cost of renewables is declining. ${ }^{82}$ To encourage reliance on renewable energy sources, including wind, solar, geothermal, and biomass, the GCVTC supported establishing goals for

\footnotetext{
7540 C.F.R. § 51.300-.307 (1980).

7645 Fed. Reg. 80084, 80086 (Dec. 2, 1980).

77 CAA §§ 169B(a), (b); 42 U.S.C. §§ 7492(a), (b).

78 CAA §§ 169B(c), (d); 42 U.S.C. §§ 7492(c), (d).

${ }^{79}$ CAA $\S 169 B(e) ; 42$ U.S.C. $\$ 7492(e)$.

8042 U.S.C. $\$ 7492(\mathrm{f})$. The Grand Canyon Visibility Transport Region (GCVTR) includes nine states (Arizona, California, Colorado, Idaho, Nevada, New Mexico, Oregon, Utah, and Wyoming) and more than 200 tribal lands

81 Report of the Grand Canyon Visibility Transport Commission to the U.S. Environmental Protection Agency (June 1996) (hereinafter the "GCVTC Report"). Participants in the GCVTC included the governors of each state in the region (except Idaho), the leaders of four Indian tribes, and representatives of various federal agencies, who participated as ex officio members.

82 GCVTC Report, at 29.
} 
states in the Transport Region "to achieve annual additions in order that renewables will comprise $10 \%$ of the regional power needs by 2005 and $20 \%$ by 2015." 83 Progress toward these goals would be evaluated every five years in conjunction with regular reviews of emissions reductions and progress toward achieving the national visibility goal. The Report went on to note that incentives may be necessary to achieve the goal for renewables and recommended:

That spending and investment in energy research and development . . . be equalized among fossil fuel-based and renewable energy programs. The EPA should coordinate with the Department of Energy to achieve funding for the range of pollution prevention programs authorized by the Energy Policy Act and administered by the Department of Energy's Center of Excellence for Sustainable Development. All new power generation projects should include a percentage of renewables associated with them, in order to achieve regional renewable energy portfolio goals. ${ }^{84}$

To ensure that renewable energy and energy conservation play an appropriate role in remedying visibility impairment, the report includes other recommendations such as: (1) placing a high priority on pollution prevention by supporting education and innovative strategies for reducing per capita pollution; (2) modeling the effects of renewable energy and pollution prevention, including potential emissions reductions, visibility improvements, cost savings, and secondary benefits associated with renewables and energy efficiency; (3) developing economic incentives for pollution prevention efforts; (4) considering fees based on the quantity of pollution emitted, to encourage people and industry to reduce pollution in the most efficient manner possible, with the fees used to offset property or income taxes or provide financial assistance to pollution prevention projects; and (5) introducing "green labeling," including providing information to consumers about the characteristics of their sources of energy. ${ }^{85}$

\section{Regional Haze Rule}

The recommendations of the GCVTC are reflected in the final regional haze rule that the EPA issued in $1999 .{ }^{86}$ The rule, which will be implemented over a 60 -year period, requires states to develop goals and emission reduction strategies for improving visibility in all 156 mandatory Class I national parks and wilderness areas. Because the components of haze can travel long distances, the rule requires all 50 states and certain territories to participate. The western states in the GCVTR have the option of implementing either the basic regional haze regulations or regulations based on the recommendations of the GCVTC.

\footnotetext{
${ }^{83}$ GCVTC Report, at 31. A study by the Land and Water Fund of the Rockies entitled How the West Can Win (1996) cited in the GCVTC Report estimates that renewable energy could comprise 19\% of regional power needs by the 2015 deadline.

${ }^{84}$ GCVTC Report, at 31.

${ }^{85}$ Id. at $30-32$.

8640 C.F.R. §§ 51.308, .309; 64 Fed. Reg. 35714 (July 1, 1999).
} 
Unlike other CAA programs, the regional haze regulations are goal-oriented rather than prescriptive, leaving states with considerable discretion in designing and implementing a regional haze program. The final regulations require states to:

- Conduct visibility monitoring in mandatory Class I Federal areas and determine baseline conditions using a significantly expanded visibility-monitoring network. ${ }^{87}$

- Revise SIPs to assure reasonable progress toward the national visibility goal. The final rule does not specify what control measures the states should implement, nor does it establish specific targets for demonstrating "reasonable progress." Instead, states must establish goals for each Class I area to improve visibility on the haziest days and ensure that no degradation occurs on the clearest days, with the ultimate goal of reaching natural background conditions in 60 years. States will be required to determine baseline visibility conditions, track emissions, and visibility improvements (measured in deciviews) to assess progress toward achieving these goals. ${ }^{88}$

- Propose a long-term strategy to address visibility impairment. The long-term strategy must include specific enforceable measures that are sufficient to meet the state's reasonable progress goals. In developing their emission-reduction program, states should consider all types of manmade emissions, including those from mobile sources, stationary sources, small so-called "area sources" (such as residential wood stoves) and prescribed fires. ${ }^{89}$

- Determine which existing stationary facilities should install Best Available Retrofit Technology (BART). States must identify BART-eligible sources, analyze the air pollution-related impacts of installing BART and either establish emission limits based on BART or implement alternative measures such as an emissiontrading program that will achieve greater progress in visibility protection than implementing source-bysource BART controls. ${ }^{90}$ The list of BART-eligible sources includes specific types of stationary sources, including steam electric plants, placed in operation between 1962 and $1977 .^{91}$ The EPA intends to issue revised guidance to assist states in calculating BART.

- Adopt certain measures to assess potential visibility impacts of new or modified major stationary sources, including measures to notify Federal Land Managers of proposed new source permit applications. ${ }^{92}$

\footnotetext{
8740 C.F.R. $\S \S 51.305, .308(d)(4)$. The timetable for the SIP revisions required to implement the regional haze rule is linked to the designation of areas as attainment and nonattainment for $\mathrm{PM}_{2.5}$. As discussed below, additional equipment must be installed to monitor for $\mathrm{PM}_{2.5}$ to implement the EPA's revision of the NAAQS for PM. Once three years of data from the new monitors is available, the EPA will begin the designation process, which will, in turn, trigger deadlines under the visibility program.

8840 C.F.R. $\S \S 51.308(d)(1),(2)$

8940 C.F.R. $\S \S 51.306, .308(d)(3)$.

9040 C.F.R. $§ 51.308(\mathrm{e})$.

9140 C.F.R. § 51.301.

9240 C.F.R. $\S 51.307$.
} 
As part of this initial effort, states must develop, adopt, implement, and evaluate long-term strategies to cover an initial implementation period extending to 2018, with reassessment and revision of those strategies in 2018 and every ten years thereafter. (A timeline for implementing the first phase of the regional haze rule is attached as Appendix F.) States also must submit progress reports every five years documenting actual changes in visibility and emission reductions within the state.

States have the option of making individual SIP submissions or participating with other states in a regional planning effort to address visibility. ${ }^{93}$ States that elect to participate in regional planning must submit a plan demonstrating the state's ongoing participation and commitment to a regional planning process. The plan must address all areas in the state and demonstrate the need for regional planning by showing that emissions from their state are reasonably anticipated to contribute to visibility impairment in another state, or by showing that another state may contribute to visibility impairment in their state. The state plan must also include a detailed description of the regional planning process and a commitment by the state to submit a coordinated control strategy later. As indicated in Appendix F, participation in regional planning delays the requirement to submit a complete haze-control strategy for three years. Various industry groups have filed a lawsuit seeking to overturn the regional haze regulations.

As previously noted, the nine western states in the GCTVR have the option of implementing special regulations based on the recommendations of the GCVTC Report to satisfy their obligations under the regional haze rule. ${ }^{94}$ Among other things, the GCVTR rule requires the SIP to include provisions for monitoring and reporting $\mathrm{SO}_{2}$ emissions to determine whether five-year milestones in emission reductions have been achieved. If an applicable milestone is not met, the state must activate a market-trading program in accordance with criteria and procedures included in the SIP. The SIP must also include provisions for assessing stationary sources of PM and $\mathrm{NO}_{\mathrm{x}}{ }^{95}$

Consistent with the GCVTC Report, the regional haze regulations also contain specific provisions to encourage pollution prevention generally, and renewable energy in particular. Among other things, the regulations require any SIP submitted under the program to include:

A description of the programs relied on to achieve the State's contribution toward the Commission's goal that renewable energy will comprise 10 percent of the regional power needs by 2005 and 20 percent by 2015, and a demonstration of the progress toward achievement of the renewable energy goals in the years 2003, 2008, 2013, and 2018. This description must include documentation of the potential for renewable energy resources, the percentage of renewable energy associated with new power generation projects implemented or planned, and the renewable energy generation capacity and production in use and planned in the State. ${ }^{96}$

If the state cannot meet its renewable energy goals, the report must describe the measures implemented and explain why achieving the renewable energy goal was not feasible. The state also must include the following in the SIP: (1) an initial summary of its existing pollution prevention programs, including an inventory of its

\footnotetext{
9340 C.F.R. $\S 51.308(c)$.

9440 C.F.R. § 51.309.

9540 C.F.R. § 51.309(d)(4).

9640 C.F.R. § 51.309(d)(8)(vi).
} 
renewable energy capacity as of 2002 and the state's anticipated contribution toward meeting the renewable energy goals above; (2) programs to provide incentives to reward efforts that go beyond compliance or encourage early reductions, or both; (3) programs to preserve and expand energy conservation efforts; and (4) projections of short- and long-term emission reductions, visibility improvements, cost savings, and other benefits associated with renewable energy, energy conservation, and other pollution prevention efforts. ${ }^{97}$ These provisions addressing renewable energy are found only in the GCVTR section of the regulations; the broader regional haze regulation does not specifically address renewables.

Responsibility for implementing the regional haze program in the GCVTR states rests with the Western Regional Air Partnership (WRAP), the successor to the GCVTC, which is responsible for submitting recommendations for implementing a regional haze program in the GCVTR to the EPA. Among other things, the WRAP must reach consensus among the GCVTC states on regional $\mathrm{SO}_{2}$ emissions milestones and on the basic elements of the "backstop" emission-trading program, which must be implemented in the event the voluntary measures contemplated by 40 CFR $\S 51.309$ do not achieve the necessary emission reduction milestones. The WRAP issued a final report summarizing the elements of the backstop trading program in September 2000. The report, entitled Voluntary Emissions Reduction Program for Major Industrial Sources of Sulfur Dioxide in Nine Western States and a Backstop Market Trading Program, calls for the backstop trading program to be implemented within one year after a five-year emission reduction milestone is exceeded. States may also activate the program in 2013 if it appears that the 2018 milestone will not be reached. The report contains detailed procedures for allocating allowances among states and sources. With respect to renewables, the report calls for renewable sources that begin operation after October 1, 2000, to receive 2.5 tons of $\mathrm{SO}_{2}$ allocations per $\mathrm{MW}$ of installed nameplate capacity per year. A source that begins operation prior to the program trigger (i.e., prior to the date when the backstop trading program becomes effective) will receive allocations for each year it operated. Thus, allowances for renewables will not be set aside in advance but will instead be awarded retroactively. Sources beginning operation after the trigger date will receive allowances from the new source set-aside and an additional 2.5 allowances per MW of capacity from the reducible portion of the allocation to other sources. The term "renewable energy resource" means electricity generated by wind, solar, geothermal, landfill gas, biomass sources, and new low-impact hydropower. The term biomass includes agricultural, food, and wood wastes only.

The WRAP Backstop Trading Report merely represents recommendations to the EPA and the GCVTR states concerning the appropriate parameters of a trading program. The states and tribes in the region must work together over the next several years to finalize the complete package of strategies recommended by the GCVTC and will make final decisions by December 2003 regarding whether they plan to participate in the backstop trading program.

9740 C.F.R. $\$ 51.309$ (d)(8). States electing to adopt the recommendations of the GCVTC Report to satisfy their obligations under the regional haze program must also include in their SIP provisions that address clean-air corridors, mobile source programs, and programs related to fire and to dust emissions from paved and unpaved roads. 


\section{Particulate Matter}

Fossil fuel-fired electric utilities are a significant source of PM in the atmosphere. PM is a generic term for a broad class of chemically and physically diverse substances that exist as discrete particles, either liquid droplets or particles. PM originates from a variety of sources, both natural and manmade. It can be emitted directly or forms in the atmosphere by transformations of gaseous emissions such as sulfur oxides $\left(\mathrm{SO}_{\mathrm{x}}\right), \mathrm{NO}_{\mathrm{x}}$, and VOCs. PM is strongly associated with chronic lung and heart disease, and, as noted above, it causes regional haze conditions. Like ground-level ozone, PM can travel long distances, causing damage hundreds or thousands of miles beyond its point of emission.

PM is one of six criteria contaminants for which NAAQS have been set. ${ }^{98}$ Accordingly, each state must include in its SIP the measures it will implement to attain and maintain the NAAQS for PM in the state. ${ }^{99}$ Prior to the 1990 Amendments, the CAA merely established deadlines for areas to attain compliance with the PM NAAQS without specifying how those deadlines were to be reached. Consequently, states were left with considerable discretion in developing programs to achieve and maintain compliance with the standard. In 1990, the continued failure of many nonattainment areas to achieve the PM NAAQS prompted Congress to amend the CAA to establish stricter requirements for PM nonattainment areas. Under the 1990 Amendments, nonattainment areas are classified as "moderate" or "serious" depending on the extent of the PM problem. Each state with one or more areas thus designated must implement specific measures as part of its SIP, with stricter measures required in "serious" PM nonattainment areas. ${ }^{100}$

To ensure that the NAAQS reflect current science, the CAA requires the EPA to review each NAAQS every five years. ${ }^{101}$ This process has led the EPA to revise the basis for the PM NAAQS several times since the standards were first developed. Originally, the PM standards were expressed as a limit on total suspended particulate. As additional research on the adverse health effects of small particles emerged, the EPA changed the standard to limit particles with an aerodynamic diameter of less than or equal to 10 microns $\left(\mathrm{PM}_{10}\right)$. Ten years later, the EPA again revised the standard at the same time it revised the existing ozone standard, ${ }^{102}$ this time adding standards for $\mathrm{PM}_{2.5}-\mathrm{PM}$ with an aerodynamic diameter less than or equal to 2.5 microns, ${ }^{103}$ the EPA also revised the basis for the pre-existing $\mathrm{PM}_{10}$ standard. ${ }^{104}$ To implement the new $\mathrm{PM}_{2.5}$ standard, the EPA is required to undertake extensive ambient air quality monitoring to help it and the states determine which areas do not meet the new NAAQS and the location of major sources of $\mathrm{PM}_{2.5}{ }^{105}$ This monitoring is crucial to implementing the regional haze program, which is triggered by the designation of areas as attainment,

\footnotetext{
9840 C.F.R. $\S 50.6$.

99 CAA § 110; 42 U.S.C. $\$ 7410$.

100 CAA $\S \S 188-190 ; 42$ U.S.C. $\S \S 7513-7513 b$.

101 CAA § 109(d); 42 U.S.C. § 7409(d).

10262 Fed. Reg. 38651 (July 18, 1997). See Section IV for a discussion of the revisions to the ozone NAAQS.

103 The regulations establish an annual standard for $\mathrm{PM}_{2.5}$ of 15 micrograms per cubic meter, based on the 3-year average of annual arithmetic mean $\mathrm{PM}_{2.5}$ concentrations from single or multiple community-oriented monitors; the regulations also establish a 24-hour standard of 65 micrograms per cubic meter, based on the 3-year average of the $98^{\text {th }}$ percentile of 24 -hour $\mathrm{PM}_{2.5}$ concentrations at each population-oriented monitor within an area.

104 The pre-existing 24-hour $\mathrm{PM}_{10}$ standard was revised based on the $99^{\text {th }}$ percentile of 24 -hour $\mathrm{PM}_{10}$ concentrations at each monitor within an area.

105 See 62 Fed. Reg. 38752 (July 18, 1997).
} 
nonattainment, and unclassifiable for $\mathrm{PM}_{2.5 \cdot}{ }^{106}$

Immediately following the adoption of the new PM and ozone standards, various states and industry groups brought suit seeking to overturn them. In a controversial decision, the federal Court of Appeals in American Trucking Association v. U.S. Environmental Protection Agency ${ }^{107}$ remanded both standards back to the EPA for further consideration. ${ }^{108}$ In so doing, the court vacated the revised $\mathrm{PM}_{10}$ standard; as a result, the existing $\mathrm{PM}_{10}$ standard continues to apply. In a subsequent decision, the court ruled that the $\mathrm{PM}_{2.5}$ standard should remain in place pending the remand to the EPA. The Supreme Court heard arguments in the American Trucking decision in early November 2000, and a decision is expected by July 2001.

Despite the judicial setback, it is likely that the EPA will establish an enforceable fine-particle standard in the future. The EPA's next five-year review of the standard is already underway and will be complete by 2002 . Assuming the EPA is be able to cure any lingering problems raised by the American Trucking decision in that rulemaking, states will have several years to develop SIPs containing control measures to achieve the new standard.

10640 C.F.R. $\S 51.308(b)$.

107175 F.3d 1027 (D.C. Cir. 1999), cert. granted, 120 S. Ct. 2003 (2000).

108 The court concluded that the construction of the CAA, upon which the EPA relied in promulgating the NAAQS, "effect[ed] an unconstitutional delegation of legislative power"-in other words, the EPA construed the provisions of the CAA dealing with the establishment of NAAQS so loosely that it effectively usurped the legislature's power. The court remanded the matter back to the EPA to give it an opportunity to articulate a more precise rationale for the new standards. Id. at 1037 . 


\section{Section VI — Greenhouse Gases and Renewables}

\section{Introduction}

Concern over air pollution initially focused on the local effects of air pollution sources on public health and the environment. In the 1980s, however, it became apparent that many air pollution problems, such as acid rain and ground level ozone, were regional in nature, with key pollutants traveling hundreds, if not thousands, of miles before being deposited. At the same time, evidence began to accumulate to suggest that air pollution was also having an impact on global temperature. The awareness that pollution could have long-range impacts was key to the development of public support for climate change policies. As the 1990s ended, climate scientists confirmed that global temperatures are rising and that this rise is attributable, in large part, to manmade emissions of so-called GHG - chiefly, $\mathrm{CO}_{2}$, methane, and nitrous oxide. Recently, a report by the U.S. Energy Information Administration suggested that world emissions of $\mathrm{CO}_{2}$ will increase by $40 \%$ from 1990 to $2010{ }^{109}$ If severe enough, increased global temperatures could cause widespread climate changes, leading to changes in rainfall patterns, rising sea levels, flooding, and drought. ${ }^{110}$

Consistent with the global nature of the problem, efforts to control emissions of GHGs have been largely international. As discussed below, a series of agreements signed in the 1990s have established a framework for reducing worldwide GHG emissions. This section of the report summarizes the status of international efforts to limit GHGs. It also discusses the history and status of domestic programs to address GHG emissions. As the discussion below shows, neither the international or the national GHG programs specifically establish a role for renewables. However, opportunities exist to develop market-based strategies for controlling GHGs generally and $\mathrm{CO}_{2}$, in particular, that will both directly and indirectly benefit developers of renewable energy.

\section{The Framework Convention on Climate Change}

The United Nations (UN) established the Intergovernmental Negotiating Committee on a Framework Convention on Climate Change (UN FCCC), which formulated the Climate Change Convention endorsed at the $1992 \mathrm{UN}$ conference on the Environment and Development in Rio de Janeiro. The Rio convention adopted a goal of stabilizing GHG concentrations but set no emission limits or timeframes within which to accomplish this goal.

Five years later, delegates from more than 160 nations met in Kyoto, Japan, to negotiate an agreement to reduce GHG emissions that would go beyond previously agreed to voluntary targets. After significant diplomatic maneuvering, the industrial nations, including the former eastern bloc nations, agreed to cut their collective GHG emissions to 5.2\% below 1990 levels during the 2008-2012 budget period (hereinafter the "Agreement"). ${ }^{111}$ Under the Agreement, each of the so-called "Annex I countries" was assigned a specific emission commitment, ranging from a 10\% increase in GHG from 1990 levels (Iceland) to an 8\% reduction (the European Union countries). ${ }^{112}$ Countries can achieve these targets either by implementing GHG reductions or by undertaking so-

\footnotetext{
109 U.S. Energy Information Administration, International Energy Outlook 2000, Rep. No. IEO 2000 (Apr. 2000).

110 In 1995, the Intergovernmental Panel on Climate Change, a UN-appointed panel of 2,500 of the world's leading climate scientists issued a report that concluded "the balance of evidence . . . suggests a discernable human influence on the global climate" and that a $60 \%$ to $80 \%$ cut in GHGs will ultimately be needed to avert serious climate disruptions. J.T. Houghton et al., eds. Climate Change 1995: The Science of Climate Change, Contribution of Working Group I to the Second Assessment Report of the Intergovernmental Panel on Climate Change (Cambridge, U.K.: Cambridge University Press, 1996).

${ }^{111}$ UN FCCC, "Kyoto Protocol to the United Nations Framework Convention on Climate Change" (Dec. 10, 1997). GHGs covered by the Agreement include $\mathrm{CO}_{2}$, methane, nitrous oxide, and three synthetic substitutes for chlorofluorocarbons - hydroflourocarbons, perfluorocarbons, and sulfur hexafluoride.

112 Agreement, Art. 3, Annex B.
} 
called "carbon sequestration projects"-reforestation and other similar activities that involve planting trees to absorb $\mathrm{CO}_{2}$. The Agreement does not establish any targets for developing countries. ${ }^{113}$

To ensure that parties meet their emission-reduction commitments, the Agreement requires each Annex I country initially to submit to the conference's technical subcommittee the data necessary to establish its GHG baseline. ${ }^{114}$ Thereafter, each country must submit an annual GHG emissions inventory beginning the first year after the country ratifies the Agreement, as well as any supplementary information necessary to demonstrate compliance with its commitments under the Agreement. ${ }^{115}$ An expert review team will review the information and assess the country's compliance status. ${ }^{116}$

The Agreement specifically identifies "research on, and promotion, development and increased use of, new and renewable forms of energy" as one of many options for achieving the goals and emission limits of the Agreement. ${ }^{117}$ However, it does not specify how governments must achieve their GHG emission targets; it merely identifies policy options, including emission trading and promotion of renewable energy that might be implemented. Countries will have a wide range of options to meet their national emission targets.

The Agreement describes a number of emission-trading options, all of which are intended to provide participating nations with flexibility in meeting their emission obligations.

- International emissions trading. The agreement allows nations with emissions targets to trade GHG allowances. Using this mechanism, countries with low-cost $\mathrm{CO}_{2}$ emission-reduction opportunities (such as those with older inefficient power plants) can recover part of the cost of control by selling any emission reductions above those necessary to achieve their own commitments to other countries. This enables both participants to meet their commitments under the Agreement at the lowest possible cost. Guidelines governing the verification, reporting, and accountability of emission reductions must be developed to ensure that the reductions subject to trading did, in fact, occur and that they are maintained. ${ }^{118}$ Developing renewable energy resources for the electricity sector will clearly contribute toward a nation's ability to meet targets. The key issue is whether national emission-trading regimes will reward renewable energy development for this effect or whether renewables will essentially provide these benefits for free.

- Joint implementation among developed countries. Countries with emissions targets may obtain credit toward their targets through project-based emission reductions in other Annex I countries. Both the private and public sectors may participate in these activities. ${ }^{119}$ There seems to be no question that renewable energy

\footnotetext{
113 Since the Agreement was signed, several developing countries, including Argentina and Kazakhstan, have announced that they intend to take on binding emission targets for the 2008-2012 period. U.S. EPA, Fact Sheet on the Kyoto Protocol: The U.S. View (Oct. 1999).

114 Agreement, Art. 3.

115 Agreement, Art. 7.

116 Agreement, Art. 8.

117 Agreement, Art. 2, ๆ 1(a)(iv).

118 Agreement, Art. 6.

119 Agreement, Art. 4. To evaluate different approaches to joint implementation, the United States instituted a pilot program in 1994 known as the U.S. Initiative on Joint Implementation. This program encourages investments by U.S. entities (generally private companies) in projects to reduce GHG outside the United States. Proposed projects are evaluated by a multi-agency panel against a series of nine criteria, most of which focus on measuring and verifying reductions. Although participants do not receive formal credit for emissions reductions achieved as a result of approved pilot projects, they may receive public recognition for their GHG reduction efforts; in addition, it is possible that these projects may be eligible for credit once the Agreement is implemented. Through March 1998, initiative officials had reviewed proposals for 97 projects and had accepted 32 of them, roughly half of which involved projects
} 
development could participate in joint implementation projects, if the sponsoring governments provide either cost-sharing or other incentives to draw renewables into the process.

- Clean development mechanism (CDM). The CDM will allow developed countries to use certified emissions reductions from project activities in developing countries to meet their GHG reduction targets. ${ }^{120}$ Using the CDM, a company in a developed country could participate in a renewable energy project in a developing country, such as the construction of a wind farm, which reduces GHG emissions in the developing country. Such an arrangement would benefit both the company (which may gain marketable emission credits for sale or for its own use in meeting emission-reduction obligations imposed by its home nation) and the project host country that receives technology that creates employment and allows sustainable growth in electric power production. Certified emission reductions achieved starting in the year 2000 can count toward compliance with the first budget period, providing companies in developed countries with an "early reduction" incentive to undertake such projects immediately. Implementation of the CDM will be supervised by an "executive board" appointed by the Conference of the Parties. ${ }^{121}$

\section{Current Status of the Agreement}

The adoption of the Agreement by participants was merely the first step in a long process toward reducing global GHG emissions. The Agreement opened for signature in March 1998. To become effective, it must be ratified by at least 55 countries, incorporating at least $55 \%$ of the total $1990 \mathrm{CO}_{\mathrm{s}}$ emissions of Annex I countries. ${ }^{122}$ From March 1998 to March 1999, 84 countries signed the Agreement, indicating their acceptance of the text and their intent to ratify. Countries that did not sign during that period may become parties by acceding to the treaty later. Although several countries already have ratified the treaty, many more are awaiting the outcome of negotiations on the details of implementing the Agreement.

In the United States, ratification will require the advice and consent of the Senate, which has thus far opposed the Agreement, enacting legislation prohibiting federal agencies from spending funds on implementing it. ${ }^{123}$ President Clinton has indicated he will not submit the Agreement to the Senate for approval "without the meaningful participation of key developing countries in efforts to address meaningful climate change." 124

\footnotetext{
to reduce $\mathrm{CO}_{2}$ emissions by planting trees or engaging in other similar projects to capture GHG already emitted. GAO, Climate Change: Information on the U.S. Initiative on Joint Implementation (June 1998). Other countries, including the Netherlands and Norway, have implemented similar pilot programs.

120 Agreement, Art. 12.

121 Agreement, Art. 12, \ 4.

122 Agreement, Art. 25.

123 Making Appropriations for Energy and Water Development for Fiscal Year Ending September 30, 2000, Pub. L. No. 106-60 (1999).

124 U.S. EPA, Fact Sheet on the Kyoto Protocol: The U.S. View (Oct. 1999).
} 
The Agreement establishes only a broad framework for achieving GHG emission reductions. Obviously, it cannot be properly implemented until the mechanisms for certain key elements, such as international emission trading, $\mathrm{CDM}$, and carbon sequestration are developed. In the two years following the Kyoto meeting, the Conference of the Parties met in Buenos Aires, Argentina, and a year later in Bonn, Germany, to advance implementation of the Agreement. However, these meetings addressed primarily technical issues. The Conference of the Parties recently met at the Hague to resolve the more difficult issues. These issues include:

- Limits on flexible mechanisms. The most pressing dispute among potential signatories involves caps on using the flexible mechanisms of the Agreement. The European Union has argued strongly that countries should not be allowed to achieve more than $50 \%$ of their commitment to cut GHG emissions through flexible mechanisms such as international emission trading and CDM. By comparison, the United States and certain other countries, such as Canada and Australia, have argued against any such caps. Efforts to resolve this dispute thus far have been unsuccessful. The stakes of this dispute for renewables are high. If no limits are imposed on using trading to meet targets, there is a risk that no viable market for GHG credits from renewables will emerge. Countries will simply purchase low-cost surplus credits from nations that have a windfall of surplus credits due to favorable baseline conditions.

- Role of developing countries. Key members of the U.S. Senate have criticized the Agreement because it does not establish binding emission limits for developing nations, many of whom have expressly rejected calls for even voluntary limits. A report recently issued by the Energy Information Administration (EIA) indicates that energy use (and, by extension, GHG emissions) in developing countries is increasing at a faster rate than in developed countries. ${ }^{125}$ The United States has advocated strongly that poorer but fast-growing countries, such as India and China, should be subject to limits. Recently, certain small island nations and some African and Latin American countries joined the United States in advocating emission reductions for developing countries, either because the countries are particularly threatened by the impact of global warming or because they believe they could benefit financially or otherwise by participating in emissiontrading or other similar programs.

- Land-use activities. The Agreement allows participants to take credit for reductions in GHG attributable to activities such as reforestation that absorb $\mathrm{CO}_{2}$. The Intergovernmental Panel on Climate Change is expected to issue a final report outlining the results of its study on the impact of such activities on $\mathrm{CO}_{2}$ levels in the atmosphere. This report, entitled Special Report on Land Use, Land Use Changes, and Forestry, should help participants resolve key issues relating to land use and GHG, including what activities, other than reforestation, afforestation, and deforestation, should count in national emission budgets; what kind of monitoring is required to verify that a particular land use is offsetting emissions; and how nations can ensure that emission offsets are not reversed.

- Emission trading, CDM, joint implementation, compliance. Participants at the Sixth Conference of the Parties worked to develop mechanisms for implementing the key flexibility provisions of the Agreement. In addition, they attempted to develop a compliance system that will address such difficult issues as what penalties should be assessed if nations fail to meet their commitments under the Agreement and who will monitor the emission reductions and assess penalties. An important objective for the United States and the renewable energy industry is to ensure that a streamlined process will be developed by which renewable energy facilities can qualify to receive an emission-reduction credit.

Numerous government and non-government organizations are devoted to tracking developments under the Agreement, most of which maintain extensive web sites. ${ }^{126}$

${ }^{125}$ U.S. Energy Information Agency, International Energy Outlook 2000, Rep. No. IEO 2000 (Apr. 2000).

${ }^{126}$ Several web sites of interest are: The United Nations Framework Convention on Climate Change - www.unfccc.int; Pew Center for Climate Change - www.pewclimate.org; and Center for Clean Air Policy - www.ccap.org. 
The issues listed above must be resolved by the parties before the Agreement can be implemented. Once the key elements of the various implementation strategies are defined, each participating country must develop its own program for achieving the GHG emission reductions specified in the Agreement. In the United States, for example, Congress could pass legislation creating an emission-trading program for $\mathrm{CO}_{2}$ with the goal of achieving some or all of the emission reductions required under the Agreement. This program would have to be consistent with the framework established internationally to satisfy U.S. obligations under the Agreement.

In anticipation of reaching consensus on key aspects of implementing the Agreement, the World Bank announced the creation of the "Prototype Carbon Fund," which will use money from industrialized nations to invest in cleanenergy projects in developing countries. The fund will offer "independently verified and certified" emission reduction credits to companies or countries that contribute money. Although the fund began operation immediately, the World Bank has indicated that it will change the way it operates to meet any requirements established at the Sixth Conference of the Parties.

\section{Clean Air Act Provisions Directed Toward Global Warming}

To date the federal CAA has not aggressively addressed the issue of climate change; however, it includes provisions that reflect congressional recognition of the issue and could form the basis for later regulation.

Most of the statutory provisions directed at global warming thus far have been targeted at improving monitoring and assessment of GHG emissions. Prior to the 1990 amendments to the CAA, Congress mandated a comprehensive study addressing the impact of fossil-fuel combustion, coal conversion, and synthetic fuel activities on $\mathrm{CO}_{2}$ levels, assessing the economic and physical impacts of such activities, and making recommendations regarding possible future research. ${ }^{127}$ Congress thereafter requested additional reports on the health and environmental effects of climate change and an examination of policy options to stabilize current levels of GHG emissions. ${ }^{128}$ With the 1990 amendments, Congress added several study and informationgathering provisions, the most significant of which requires electric generating power plants to monitor $\mathrm{CO}_{2}$ emissions and make reports to the EPA. ${ }^{129}$ The EPA uses this data to compute each unit's aggregate $\mathrm{CO}_{2}$ emissions; this information is then incorporated into a database and made available to the public. Under the CAA, the EPA also is required to: (1) conduct studies on inventories of methane emissions from various sources and to prepare a report on methane emission-reduction strategies ${ }^{130}$ and (2) assign a "global warming potential value" to each substance listed for control under the stratospheric ozone protection provisions of CAA Title VI. ${ }^{131}$

\section{Clinton Administration GHG Initiatives}

Beginning in 1993, after the United States ratified the UN Framework Convention on Climate Change, the administration launched its "Climate Change Action Plan" implementing a series of initiatives to reduce GHG. To date, most of the programs have focused on improving energy efficiency and reducing $\mathrm{CO}_{2}$ emissions through voluntary efforts. Examples of energy-efficiency programs include improved energy-efficiency standards for

\footnotetext{
127 Energy Security Act $§ 711,42$ U.S.C. § 8911 (1980).

128 Fiscal Year 1987 Continuing Resolution Authority. The EPA released its report entitled "The Potential Effects of Global Climate Change on the United States" in December 1989. EPA-230-05-89-051.

129 CAA $\S 412 ; 42$ U.S.C. $\S 7651 \mathrm{k}$.

130 Pub. L. No. 101-549, § 603 (1990) codified in note accompanying 42 U.S.C. § 7671b.

131 CAA $\S 602(\mathrm{e}) ; 42$ U.S.C. $\S 7671 \mathrm{a}(\mathrm{e})$.
} 
appliances, various "Energy Star" programs to encourage energy efficient building construction; various products, including transformers; and the "Green Lights" program to encourage building owners to install highefficiency lighting systems. The administration also has developed programs to reward facilities that reduce $\mathrm{CO}_{2}$ emissions with various forms of public recognition. ${ }^{132}$

These early efforts to encourage GHG reductions have met with modest success. More recently, the administration proposed the "Climate Change Technology Initiative," a five-year, \$6.3 billion program of tax incentives and investments focusing on energy efficiency and renewable energy technologies. In addition, several new initiatives have been introduced that are targeted specifically at encouraging the development of renewable energy:

- Bioenergy. In 1999, President Clinton signed Executive Order 13134 to accelerate the development of biobased industries, with the goal of tripling use of bioenergy and bioproducts in the United States by $2010 .{ }^{133}$

- Wind Powering America. This Department of Energy (DOE) initiative seeks to supply 5\% of electricity in the United States through wind technologies by $2020 .^{134}$

- Brightfields. DOE recently announced a program to use former industrial sites contaminated with toxic waste for producing solar energy.

In addition, a recent Executive Order calls for federal agencies to invest in renewable energy through applications of solar, wind, geothermal, and biomass technologies at federal facilities and through the purchase of electricity from renewable energy sources. ${ }^{135}$

\section{Recent Federal Legislative Proposals on Climate Protection}

Over the last few years, several legislative initiatives have been introduced relating to GHG emissions. For the most part, these initiatives focus on providing credit to companies that voluntarily reduce their GHG emissions. Section 1605(b) of the Energy Policy Act of 1992 allows GHG emitters to report emission reductions or offsets achieved through measures such as fuel switching, tree planting, or energy efficiency to the federal EIA. This information may then be used to credit organizations with GHG reductions if reductions ever become mandatory. Although hundreds of companies have registered reductions with the EIA, ${ }^{136}$ the program has been criticized because it contains no standards concerning what reductions can be registered. Moreover, many companies have been reluctant to implement GHG reduction projects fearing that any reductions achieved will not be credited

\footnotetext{
132 See U.S. EPA, United States: Taking Action on Climate Change (Oct. 1999).

133 The Executive Order: (1) establishes a permanent council of key agencies to develop a coordinated research program on bioenergy; (2) instructs the council to review major agency regulations and programs to ensure they effectively promote the use of bioenergy and bioproducts; and (3) directs the Departments of Energy and Agriculture to establish a "National Bio-based Products and Bioenergy Coordination Office" to manage the preparation of interagency budgets and to provide a starting point for anyone interested in bioenergy.

134 The program seeks to meet its goals by accelerating research, development, and deployment of wind technologies through education and partnerships with states and localities, as well as by encouraging federal agencies to employ wind technologies.

135 Exec. Order No. 13123 (1999).

136 In 1998, 187 U.S. companies and other organizations reported that they had undertaken 1,507 projects that achieved GHG emission reductions and carbon sequestration equivalent to 212 million metric tons of $\mathrm{CO}_{2}$. The emission reductions reported for these projects usually were measured by comparing an estimate of actual project emissions with an estimate of what emissions would have been had the project not been implemented. Energy Information Administration, Voluntary Reporting of Greenhouse Gases 1998, Report No. DOE/EIA-0608(98) (Jan. 25, 2000).
} 
when the Agreement is implemented. To address these and other concerns, several bills have been introduced in Congress to give companies that cut GHG emissions credit that would be usable in any future domestic program for controlling GHG. Legislation introduced by the late Senator John Chafee in March 1999 (S. 547), for example, would allow various federal and state agencies to enter into emission-credit agreements with companies in return for emission cuts. In addition, companies could receive credit for actions they took between 1991 and 1998 with satisfactory verification. A business would receive Greenhouse Gas Reduction Credits if it "takes an action that reduces greenhouse gas emissions." The credits could be used in any future domestic program to mitigate GHG emissions. ${ }^{137}$ A similar, albeit slightly more restrictive, bill was introduced later that year in the House. ${ }^{138}$

These bills have been criticized by key opponents of the Agreement, who perceive them as an inappropriate step toward implementation. Environmental groups, while supporting the goal of encouraging early reductions, have argued that these bills would reward companies for reductions that have already occurred and thus would not create a strong incentive to achieve future emission reductions. They also expressed reservations about rewarding carbon sequestration activities until the scientific review of the relative impact of forestry and agricultural projects on $\mathrm{CO}_{2}$ levels is complete. With respect to renewables, S.547 is unclear on whether electricity generation from renewables qualifies for the early-reduction program; the bill appears to limit eligibility for credits to the owners of facilities that emit greenhouse gases. However, the bill could be amended to state that renewable energy project developers could earn credits directly, without the need to work through a utility or fossil fuel-fired source.

These preliminary efforts raise several important questions that must be answered when developing an earlyreduction program. The first question is how the emission baseline-the level of emissions from which reductions would be made - is established. Policy makers must decide whether the baseline should be based on a company's actual GHG emission level or on GHG emissions per unit of output, the approach favored by most businesses. A related question is whether businesses must perform better than their industry sector does on average to earn credit. Other key questions include who owns the credit and whether emission reductions should be reported at the facility or company-wide level. Also, policy makers must resolve whether reductions registered with the EIA under the 1992 Energy Policy Act should be "certified" and if so, under what circumstances.

More generally, several of the emission-trading bills introduced in the most recent session of Congress have included provisions limiting $\mathrm{CO}_{2}$ emissions. For example, the Clean Smokestacks Act discussed in earlier sections would require fossil fuel-fired power plants to reduce collective $\mathrm{CO}_{2}$ emissions to 1990 levels by 2005 . Another bill introduced by former Congressman Rick Lazio (H.R. 4861) would establish a cap-and-trade program for $\mathrm{CO}_{2}$ emissions that specifically includes a role for renewables. (See Appendix D for a summary of recent CAA cap-and-trade legislation.) As discussed in Section VII below, other legislation that would reduce GHG and other emissions has been introduced in the context of energy reform.

\footnotetext{
137 For more information on early actions for climate change see Robert C. Nordhaus and Stephen C. Fotis, Early Action and Global Climate Change: An Analysis of Early Action Crediting Proposals, from the Pew Center for Global Climate Change, at <www.pewclimate.org $>$.

138 Like S.547, H.R.2520 provides credit for voluntary emission reductions. However, the bill includes a notification mechanism that would limit the number of credits that could be acquired. In addition, unlike S. 547, the House legislation caps the proportion of credits that can be awarded for "carbon sequestration" projects. It also requires third-party independent verification that an emission reduction program is bona fide.
} 


\section{Emerging State Programs}

States are often the laboratory for innovative pollution-control policies that are later adopted at the national level. Although no $\mathrm{CO}_{2}$ cap-and-trade programs have yet emerged at the state level, a wide variety of inventory, early reduction, and other modest GHG programs are under consideration. For example, 30 states are currently developing Climate Action Plans. A recent example is the New Jersey "Greenhouse Gas Action Plan." Released in December 1999, the plan aims to reduce state GHG emissions by 3.5\% below 1990 levels by 2005 . The state plan does not include a mandatory cap on emissions but relies primarily on a series of incentives and market mechanisms to promote renewables and energy efficiency, including a renewable portfolio standard, system benefits charge, and net metering for small wind and solar facilities. It also includes policies to promote recovering and using landfill methane gas and to promote alternative fueled vehicles.

\section{Current Status of GHG Reduction Efforts in the United States}

As the above summary suggests, although the United States has undertaken some modest efforts to reduce GHG emissions, comprehensive changes have not been implemented. A UN report on implementation efforts in the United States indicated that baseline GHG emissions were increasing at a faster rate than originally anticipated due largely to higher than expected economic growth and lower than expected fuel prices. At the same time, the effect of the administration's initiatives on GHG emissions was smaller than expected, primarily because Congress failed to fully fund many of the administration's GHG reduction programs. ${ }^{139}$ Although the UN report noted that the administration has since proposed several new initiatives, the United States continues to rely heavily on voluntary programs to achieve GHG reductions. These measures arguably are not sufficient to meet the country's climate change commitments under the Agreement.

139 UN FCCC, United States of America: Report on the In-Depth Review of the Second Communication of the United States of America (May 12, 1999). 


\section{SECTION VII-Alternatives for Encouraging Renewable Energy}

\section{Introduction}

To date, Congress and the EPA have not relied extensively on the CAA as a vehicle for encouraging development of renewable energy sources. Although beginning in 2000, renewables can be expected to get a boost from the acid rain cap-and-trade program, the CRER set-aside under Title IV is the only CAA program implemented thus far that specifically targets renewable energy. Several other federal and state air-quality programs discussed above also contain provisions intended to promote renewable energy. In most cases, however, the programs are in their infancy; as a result, it is too early to judge their success.

Greater progress in encouraging the development of renewable energy sources has been made in conjunction with energy deregulation. In the past, state utility commissions and legislatures encouraged renewable energy development with a variety of planning requirements and incentives. With deregulation, both the federal government and states have been exploring ways to ensure an increasing role for renewables. In some cases, these strategies require utilities to subsidize renewable energy development directly through funds collected from a "system benefits charge" (SBC) ${ }^{140}$ on retail electric sales. In other cases, legislatures have required implementation of renewable portfolio standards (RPS) or emission performance standards (EPS), which are designed to encourage renewables development by requiring utilities to meet minimum renewable power generation quotas and emission standards, respectively. Although to date these mechanisms have been developed in the context of energy deregulation, they could readily be incorporated into state clean air regulations or in legislation to amend the federal CAA. ${ }^{141}$

The survey of the CAA and other programs found in Sections III-VI of this report provides a useful starting point for crafting statutory and other changes to benefit renewable energy. This section summarizes the key issues and pitfalls that must be addressed to develop a program that encourages the participation of renewables. Section VII concludes with an overview of the various types of programs that have been or could be implemented to encourage renewable energy development, including renewable energy set-asides, output-based allowance allocation, allowance auctions, renewable portfolio standards, system benefits charges, and emission performance standards, among others. Section VIII of the report discusses specific changes to existing CAA and other programs that could be implemented and the benefits and barriers associated with each change.

\section{Key Issues in Including Renewables}

In redesigning the CAA and related state programs to encourage the development of renewable energy sources, there are several broad issues that must be considered. These issues are summarized briefly below:

- Who can participate? Several critics have suggested that the CRER program failed to promote renewables, in part, because it limited participation to utilities. Independent producers of renewable energy - the group with the greatest incentive for ensuring the successful development of renewable energy-were not included in the program. Any program to encourage renewables must answer several questions:

\footnotetext{
140 System benefits charges also are referred to as societal benefits charges or public benefit funds. For consistency purposes, this report will refer to such charges as system benefits charges.

141 As recently as June 2000, the states in the Northeast Ozone Transport Commission (OTC) announced their intention to study SBCs, EPSs and other similar mechanisms as part of a long-term strategy to reduce ozone levels in the Northeast. See Memorandum of Understanding Among the States of the Ozone Transport Commission Regarding the Development of Specific Control Measures to Support Attainment and Maintenance of the Ozone National Ambient Air Quality Standards (June 1, 2000).
} 
(1) What is a renewable energy source? Although most people would agree that solar, wind, geothermal, and some forms of biomass generation should be included in any renewable energy program, the situation is less clear for biomass combustion and hydropower, which emit less pollution than conventional fossil fuels but nevertheless raise environmental concerns. Nuclear energy, although relatively "clean" from an air perspective, poses other significant environmental and safety problems.

(2) To whom is the program targeted (producer, retailer, consumer)? System benefits charge funds provide assistance directly to the renewable energy producer. By comparison, carbon taxes can either be imposed on the polluter or on the energy consumer. RPS and EPS can be imposed on either energy generators or electricity retailers. In designing a program to encourage renewable energy, there are practical and political costs and benefits associated with targeting each of the various links in the energy production chain.

- How does the program affect the energy market? The acid rain allowance program represents an attempt to reduce $\mathrm{SO}_{2}$ emissions by harnessing market forces. Rather than establishing one-size-fits-all control requirements, Title IV leaves it to each facility to decide how to meet its emission limitations (purchasing allowances, installing additional controls, and shutting down). The program alternatives discussed below each address, in different ways, the failure of the market to fully initialize pollution costs into electricity prices and the impact of that failure on the development of renewables. Several of these programs, such as set-asides, RPS and SBC, are designed specifically to encourage participation in the marketplace by renewables. Other strategies, such as output-based allocation schemes, encourage renewable participation primarily by ensuring that the cost of energy in the marketplace better reflects the environmental impacts of production.

- What is the role of government in implementing the program? Intimately tied to the question of what impact the program has on the energy market is government's role in the program. At one end of the spectrum are alternatives, such as SBC and, to a lesser extent, renewable set-asides, which involve government directly in deciding what renewable energy projects are funded. At the other end of the spectrum are carbon taxes, which ostensibly limit government to the task of tax collection, leaving the market to decide what projects proceed. In addition, different programs require different levels of government involvement in day-to-day administration. The role of government, both administratively and politically, is key to assessing program alternatives for promoting renewable energy.

- What are the political implications of the program? The political viability of any program to encourage renewables is obviously crucial in deciding what option(s) to pursue. From an economic perspective, many have argued that carbon taxes are the most economically efficient method of ensuring that society makes smart energy choices; politically, however, they are extremely unpopular in the United States (as are most new taxes). Other alternatives, such as output-based allocation strategies, could benefit technologies such as nuclear or waste-to-energy facilities, promoting opposition from environmental groups. These types of political considerations must be assessed in evaluating the various policy options available to promote renewables.

- Federal vs. state approach. Programs to promote renewables can be implemented at both the federal and state level. Perhaps the chief advantage of federal strategies is that they ensure uniformity across state lines. Many of the programs discussed below to encourage renewables could result in increased energy prices, at least in the short term. As a result, states may be reluctant to pursue them fearing that they may be competitively disadvantaged relative to other states without such programs. Federal strategies, by comparison, have a different set of disadvantages, including a potential disconnect between the air-quality problems of concern and the location of renewable energy development. States and regions have different air-quality problems and renewable energy potential based on meteorological and other conditions. The clean air benefits of a national program to promote renewables thus may be unevenly distributed across the country. A national program may have difficulty addressing this phenomenon. 
In deciding whether to pursue a federal or state strategy for promoting renewables, several logistical concerns should also be considered. Most of the programs discussed below would require legislative changes if implemented at the federal level, a potentially daunting prospect. By comparison, many state legislatures have delegated relatively broad powers to regulators for developing and implementing environmental programs; these powers can be tapped to create programs encouraging renewables. It may, however, be simpler to develop a single federal program than to negotiate with 50 states to implement similar programs.

- Program-by-program vs. integrated approach. For the most part, the CAA addresses different air pollution problems separately. For example, separate emissions-trading programs have been or may be developed for $\mathrm{SO}_{2}$ (under the Title IV acid rain program and, potentially, the regional haze program), $\mathrm{NO}_{\mathrm{x}}$ (under the various federal and state $\mathrm{NO}_{\mathrm{x}}$ budget trading programs and, potentially, the regional haze program) and $\mathrm{CO}_{2}$ and other GHGs (under programs to address global warming). In general, the greater the number of programs, the greater the potential administrative difficulties. Ultimately, small renewable producers may be discouraged from participating in multiple programs simply because the administrative costs do not justify the financial benefits. Moreover, in the case of renewable energy, the revenue enhancement potential of a pollutant-by-pollutant approach is low relative to a more integrated, multi-pollutant approach. ${ }^{142}$ Any proposal to encourage renewables must consider the costs and benefits of relying on a single vs. multipollutant approach.

\section{Clean Air Act Program Alternatives for Encouraging Renewable Energy}

Below is a summary of several broad program alternatives that could be pursued under the CAA to promote renewable energy. These alternatives either are already part of one or more CAA programs (e.g., renewable energy set-asides and supplemental environmental projects) or are contemplated by CAA policy makers.

\section{Renewable Energy Set-Aside}

\section{Description}

As discussed above, one alternative for encouraging participation of renewables is to "set aside" for renewable energy sources a portion of emission allowances awarded under a "cap-and-trade" program. Such set-asides were used in the CRER program and have been adopted by several northeastern states as part of their $\mathrm{NO}_{\mathrm{x}}$ reduction programs under the OTC MOU. Experience with the CRER program suggests, however, that set-asides may not be an effective mechanism for promoting renewables unless they are properly designed. Valuable guidance concerning the key components of a renewable set-aside program can be found in EPA's Guidance on Establishing an Energy Efficiency and Renewable Energy (EE/RE) Set-Aside in the NO $O_{x}$ Budget Trading Program (hereinafter "EE/RE Guidance") discussed briefly in Section IV. Although intended to address only set-asides under the $\mathrm{NO}_{\mathrm{x}}$ Budget Trading Program developed to implement the EPA's SIP call, the criteria outlined in the guidance are relevant to any allowance set-aside program.

Ideally, set-asides can achieve several goals, including: (1) reducing the total long-term economic cost of meeting an emission cap; (2) promoting energy efficiency and renewable energy by providing a catalyst for investment in these technologies; and (3) reducing emissions of collateral contaminants (such as $\mathrm{CO}_{2}$ ) not directly regulated under the program. As experience with the CRER program suggests, however, whether these goals are realized will depend on how the program is designed. For purposes of the $\mathrm{NO}_{\mathrm{x}}$ Budget Trading Program, the EPA recommended that states create an $\mathrm{EE} / \mathrm{RE}$ set-aside of between $5 \%$ and $15 \%$ of a state's total $\mathrm{NO}_{\mathrm{x}}$ budget for electricity generation units. ${ }^{143}$

${ }^{142}$ D. Wooley, Renewable Energy Policy Project (REPP), A Guide to the Clean Air Act for the Renewable Energy Community, at 1924 (2000).

143 EE/RE Guidance, at 12. As noted in Section IV, the $\mathrm{NO}_{\mathrm{x}}$ Budget Trading Program has two components: (1) an electricity budget, 
The EPA's EE/RE Guidance identifies several key elements to consider in determining the number of allowances to include in an EE/RE program, including: (1) who and what is eligible for allowances; (2) whether and how to focus on "new" projects; (3) length of award; and (4) how to address over- and under-subscription to the allowance pool. ${ }^{144}$ These elements are discussed briefly below:

- Who and what is eligible for set-aside allowances. As the EPA noted in the EE/RE Guidance, the goal of the set-aside program is to "ensure that the incentives provided through the set-aside allowances will be most closely linked to the party that has assumed responsibility for undertaking the efficiency or renewable action and who therefore deserves the credit for the associated emissions reduction." 145 The types of projects eligible for allowances should be limited to those that reduce or displace electricity use. In the case of renewables, eligible projects generally would include projects that meet increased electricity demand through construction of new renewable energy sources. Specific set-aside eligibility criteria include:

- Project reduces or displaces electricity load from core electricity generating source in the region;

- Is not required by federal regulation;

- Is not/will not be used to generate compliance or permitting credits otherwise in the SIP;

- Is in operation in the year(s) for which it will receive allowances;

- Is measured and verified. ${ }^{146}$

- Focusing awards on "new" projects. Set-aside programs should be designed to encourage actions that would not otherwise occur. For this reason, renewable generation that pre-existed the creation of the policy should not be eligible to receive emission credits under the set-aside. ${ }^{147}$

- Length of award. EE/RE projects typically provide environmental benefits that extend far beyond one year. In establishing a set-aside program, regulators must balance the length of the stream of allowances awarded to a project with the ability to maintain a sufficient number of allowances over time to provide an incentive for new projects. Under the $\mathrm{NO}_{\mathrm{x}}$ Budget Trading Program, the EPA recommends awarding allowances for at least three years, while verifying energy savings and displacements annually. ${ }^{148}$

- Adjusting size of set-aside. Set-aside pools may be under- or over-subscribed. Regulators must develop strategies for allocating allowances when there are too many (or too few) allowances available. When a pool is over-subscribed, the EPA recommends awarding allowances on a first-come, first-served basis; when a pool is under-subscribed, the EPA recommends reallocating excess allowances among current participants.

which restricts emissions from large, fossil fuel-fired stationary boilers and other similar units; and (2) a fuel budget based on emissions allowable from certain large industrial combustion sources. The EPA specifies that the EE/RE set-aside must come from the pool of allowances available to sources that generate electricity to ensure that using these allowances will not cause a state to exceed its budget. EE/RE set-aside allowances are not intended for actions that reduce or displace on-site fuel use but are intended, instead, to reward actions that result in a reduction in electricity generation at a core source or in supplanting the use of electricity from the grid. $I d$. at 5 .

${ }^{144} \mathrm{EE} / \mathrm{RE}$ Guidance, at 12.

145 Id. at 16.

146 In addition, consistent with the requirements of the $\mathrm{NO}_{\mathrm{x}}$ Budget Trading Program, the EPA also requires that the project reduce or displace energy during the summer ozone season. Id. at 19-20.

147 Id. at 23-24.

${ }^{148} I d$. at $27-28$. 
- Long term, regulators must develop strategies for readjusting the size of the set-aside based on participation rates. $^{149}$

\section{Benefits}

At least in theory, set-asides should provide a financial incentive for investing in renewable energy sources by compensating them monetarily for the environmental benefits they provide. Under a set-aside program, renewable energy producers would receive allowances that they can then sell to fossil fuel-fired electricity generators. Although most set-aside programs target a single contaminant, it may be preferable in the long term to establish a multi-pollutant set-aside program because replacing conventional electricity generation with renewables results in reductions in multiple pollutants. Encouraging renewable energy through set-aside programs has other benefits as well:

- Experience/political popularity. To date, efforts to encourage renewables under the CAA have focused primarily on set-aside programs. Policymakers thus are relatively comfortable with the concept of set-asides. Additionally, experience exists to provide lessons on the importance of such elements as low transaction costs and appropriate incentives. Other strategies, such as output-based allowance allocation, are still largely untried and may be politically unpopular among conventional electricity generators.

\section{Barriers}

- Size of emissions cap. Set-aside programs will work well only if the cap is sufficiently stringent to require significant emission reductions. As discussed in Section III above, the CRER program failed in part because $\mathrm{SO}_{2}$ allowance prices and the costs of conventional control alternatives were so low that the incentive offered by the CRER was insufficient to attract utility investment to renewables. Although legislation has been introduced to reduce the $\mathrm{SO}_{2}$ cap still further, it is unclear whether the political will exists to lower it far enough to make set-aside programs for renewables financially meaningful.

- Allocating credits. Any policy maker hoping to adopt a set-aside program must resolve the difficult question of how to allocate allowances among conventional fossil plants and how many to "set aside" for renewables. For obvious reasons, this decision is politically charged, making it difficult to achieve the optimal solution from an economic perspective.

- Double counting. Several critics have criticized set-aside programs, charging that they lead to "double counting." For example, a utility that invests in renewable energy to displace fossil power could receive multiple forms of compensation under a set-aside program: first by receiving special marketable allowances from the set-aside pool, and second by lowering emission-control costs and thus freeing up allowances directly awarded to it that it can either sell or use. Furthermore, the utility may gain green-marketing revenue from selling the output of the renewable generator. This "double counting" problem could be addressed by utilizing output-based allowance allocation methods to distribute both regular and set-aside allowances, and by limiting or preventing generators receiving allowances from participating in other programs such as RPS or green marketing. However, double counting is only a problem if the incentives enjoyed by the generator are higher than needed to encourage the investment in renewables or until the cost of those incentives exceeds the public benefits derived from renewable energy. It is not uncommon for renewable generation (or fossil fuel for that matter) to receive several forms of economic incentives (e.g., production tax credits exist side -by side with state RPS, SBC, and R\&D support). Where there is competition to supply renewables, all of these incentives should lower the price of renewables in the market. Until renewables achieve stand-alone competitiveness, the receipt of multiple forms of public policy benefits is not a problem. Long term, the other benefits (tax credits, system benefits charges, etc.) can be adjusted downward, while

${ }^{149} I d$. at 29-30. 
leaving set-asides in place to give renewables a direct method of competing to provide clean air resources against other air-pollution-control options.

\section{Renewable Output-Based Allowance Allocation}

\section{Description}

To date, the CAA and state programs typically have relied on set-asides to ensure a role for renewables in emission-trading programs. The difficulties associated with set-asides have prompted many to propose alternative allocation schemes that attempt to incorporate the air pollution benefits of renewables more directly into the emission-trading process by more directly relating emissions (and emission allowance allocations) to electric power output. Under currently operating emission trading programs, the government caps emissions from all regulated units at a specified level and then allocates emission allowances to pollution sources based on various factors, including the type of fuel burned and political considerations. The government then "sets aside" a portion of the total allowances for renewable energy sources. These set-aside allowances are allocated among participating renewable energy sources in accordance with criteria established by statute or regulation.

By contrast, under an "output-based allocation" approach, government also would cap overall emissions of one or more contaminants from electric generating facilities but permission to emit the contaminants (i.e., allowances or credits) would be awarded to participating electric generating facilities by applying a uniform emission rate to the amount of electricity they generate (lbs./MWh). The uniform emission rate would be derived by dividing the projected level of total electric output from participating generation by the desired tonnage cap. Ideally, the output-based system would award credits to both fossil fuel and renewable energy sources. Under this approach, to meet their emission limits, coal-burning and other "dirty" facilities would be initially in credit/allowance deficit and would be required to acquire allowances from other cleaner-burning facilities, including renewable energy producers who would have a surplus of allowances. Thus, this system would automatically provide renewable energy sources with a revenue stream that makes them relatively more cost-effective, without arbitrary limits on the amount of allowances set aside for renewables or a government role in awarding the allowances to qualified applicants.

To date, no major federal or state emission trading programs have allocated allowances on an output basis. As previously noted, however, states implementing programs to satisfy the $\mathrm{NO}_{\mathrm{x}}$ SIP call regulation have the option to allocate allowances under their voluntary emission-trading programs on an output basis; in May, the EPA issued guidance to assist them in this effort. In addition, beginning in 2008, the EPA intends to allocate allowances to sources limiting emissions under CAA $\S 126$ on an output basis. The chief obstacle to these efforts is the lack of data on emission generation necessary to allocate allowances among regulated sources. Other benefits and barriers to an output-based allocation approach are summarized below.

\section{Benefits}

- Market efficiency. At least in theory, the chief benefit of an output-based allocation approach is that it establishes a stable and long-term mechanism for ensuring that the market recognizes the environmental benefits of renewable energy relative to conventional fossil fuel-fired plants (assuming renewables are included in the allowance program). By allocating allowances based solely on output, renewables receive credits based on the amount of power they generate, which they can then sell to other electric generating facilities, providing renewables with a valuable revenue stream. New renewable energy facilities would have an advantage over new fossil fuel-fired plants because they would not require any emission credits to operate. 
- Simplicity. Output-based allocation systems arguably would be easier to administer than conventional setaside programs. Once the cap is set, the decision regarding how allowances are allocated would be left largely to the market. Government agencies would not be required to address the difficult issues concerning set-asides discussed above, such as the size of the set-aside pool, what types of entities and projects should be eligible for allowances, whether and how to focus on "new" projects and other related issues. Renewable energy facility owners could participate with minimal reporting and transaction costs.

\section{Barriers}

- Political concerns. The chief barrier to developing an output-based allowance program is political. Faced with the prospect of having to acquire large quantities of emission credits from natural gas and, to a lesser extent, renewable generators, coal- and oil-burning facilities are likely to lobby hard against any emission trading scheme that allocates credits based solely on output. States may find it difficult essentially to force a shift in wealth from coal and oil to gas-fired and renewable electricity generators.

- Nuclear. Any output-based allocation scheme that includes renewables would have to address the difficult issue of whether nuclear energy and waste-to-energy plants should be allocated allowances on the same terms as renewables. Nuclear plants, like renewables, generate power without directly emitting $\mathrm{SO}_{2}, \mathrm{NO}_{\mathrm{x}}$, and other by-products of fossil-fuel combustion. Under an unrestricted output-based scheme, nuclear plants would be awarded credits that they could then sell to conventional plants. Most environmentalists would object strongly to any emission-trading program that awarded credits to nuclear energy; obviously, the nuclear energy industry would argue strongly in favor of such credits. However, a logical case can be made for treating nuclear power and waste-to-energy plants differently from renewables in an output-allocation program. Renewables do not have the radioactive and toxic emissions and long-term radioactive and combustion waste disposal problems that are connected to nuclear energy and mass-burn garbage facilities. It is also doubtful that the economics of nuclear and waste-to-energy facilities would be significantly affected by eligibility for emission allowances. Consequently, including them in an output-based allowance allocation will essentially create a windfall for these industries with no compensating public benefit. Renewables, by contrast, are a potentially large new generation source for the nation the output of which would likely increase with air quality-related incentives.

- Lack of information. As noted above, a significant short-term obstacle to pursuing output-based allocation strategies is the absence of generation reporting and aggregation methods for smaller dispersed renewable generators as well as methods for allocating credits to combined heat and power and steam/electric generators. These problems are not, however, insurmountable, and the EPA is currently addressing these and other data-related issues.

\section{Allowance Auction}

\section{Description}

Both input- and output-based allowance allocation schemes "rely on existing patterns of economic activity (electricity production or fuel use) to determine the distribution of initial allowances among sources. Sources receive free allowances in proportion to their past or projected polluting activity." ${ }^{\prime 50}$ As noted above, however, successfully implementing such schemes depends on various political and other factors that cannot always be controlled. As an alternative, several policy makers have suggested that the government cap emissions of one or more pollutants and then auction the allowances needed to operate under the cap to the highest bidders. As an alternative, the federal government and/or states could allocate a portion of allowances among sources using

${ }^{150}$ Center for Clean Air Policy, Recognizing Efficiency and Renewable Energy under a Cap and Trade Program, p. 45 (July 1999). 
an input- or output-based approach and then auction the remainder. The revenues from the auction could then be used to offset other taxes or to pursue other policy objectives, such as promoting renewable energy.

As noted in Section III, allowance auctions have been implemented on a limited basis under the Title IV $\mathrm{SO}_{2}$ trading program. ${ }^{151}$ To date, however, no state or federal program has relied solely or in large part on auctions to allocate allowances. As with other allowance allocation strategies, this approach has several benefits and barriers.

\section{Benefits}

- Economic efficiency. Perhaps the chief benefit of allowance auctions is that they are economically efficient. Auctions allow the market to decide the value of allowances, reducing transaction costs; they also allow new sources the same access to allowances as existing ones.

- Revenue potential. Revenues from the auction could be used to offset existing taxes; they could also be applied to promote the development of renewable energy sources and/or energy efficiency projects either by encouraging research and development and other similar programs or by providing direct cash awards to renewable energy projects.

\section{Barriers}

- Operational uncertainty. From a facility perspective, the chief disadvantage of an auction-based allocation system is the perceived lack of certainty concerning the award of allowances. Unlike an input- or outputbased allocation system, an auction-only system would not ensure that facilities obtain the allowances they need to operate. This uncertainty may complicate long-term planning by facilities. This problem arguably could be mitigated by auctioning allowances well in advance of the year in which they are needed.

- Political concerns. Auctions arguably function as a tax on pollution that is paid by those facilities that require allowances to operate. Any such system is likely to be opposed by those facilities - such as coal and oil-fired fossil fuel plants - that will require the greatest number of allowances to operate. Natural gas-fired plants could even oppose the system if they feel threatened either by the increased costs associated with purchasing allowances or by the possible uncertainties associated with relying solely on the marketplace to acquire allowances.

\section{Emission/Generation Performance Standards}

\section{Description}

EPS (also known as Generation Performance Standards) establish minimum standards of environmental performance (usually expressed in pounds or tons of emissions per units of electricity sales-e.g., tons/MWh of sales) for generators or retail suppliers of electricity. The goal of the EPS is to impose the same minimum emission standards on all suppliers and thus "level the environmental playing field." Because renewables are non-emitting or low emitting sources of electric generation, an EPS encourages electricity retailers to include renewables in the mix of generation supplies it procures to meet the EPS requirement. NESCAUM, an organization composed of state air officials, recently issued an EPS model rule to provide a template for state regulations implementing minimum environmental performance standards for retail suppliers of electricity. The model rule and associated background documents provide a useful framework for examining the EPS concept. ${ }^{152}$

151 CAA § 416; 42 U.S.C. § 7651o. Regulations establishing the Special Allowance reserve are set forth at 40 C.F.R. § 73.27 ; see 58 Fed. Reg. 3590 (Jan. 11, 1993).

152 NESCAUM, Emission Performance Standards Model Rule Background Information Document (Dec. 1999). The model rule and background materials can be found at www.nescaum.org. 
The NESCAUM model rule applies to entities licensed by the state to supply electricity to retail customers. Under the rule, retailers must supply an "electricity product" to the state that meets emission standards established for three air contaminants: $\mathrm{NO}_{\mathrm{x}}, \mathrm{SO}_{2}$, and $\mathrm{CO}_{2}{ }^{153}$ To determine compliance, the retailer must demonstrate that the weighted average annual emission rate for the total portfolio of electricity sold in the state (measured in lbs./MWh) is less than or equal to the EPS for each of these contaminants. This calculation requires information about both the amount of electricity supplied by each generation source assigned to the portfolio and the emissions characteristics of each of those resources. Ideally, this information should be available from a centralized and independent source, such as the independent system operator (ISO). If the product portfolio exceeds the EPS for one or more pollutants, the retail supplier must fully offset the excess emissions in the following year.

The NESCAUM proposal identifies numerous issues that must be addressed in developing an EPS program. Key issues are discussed briefly below:

- Regulated entity: suppliers vs. generators. Although most air pollution control programs are targeted at electricity generators, deregulation means that increasing amounts of power are generated outside state borders. As a result, the NESCAUM model rule targets electricity retailers who must be licensed by the states they service and can, therefore, be required to comply with EPS requirements.

- Types of sources regulated. In developing its model rule, NESCAUM considered whether to include all electric generation resources or just fossil resources. The group elected to include all types of resources, concluding that this approach would: (1) make the program consistent with RPS and information disclosure requirements, facilitating coordinated implementation of these programs; (2) promote greater fuel diversity and provide retail suppliers with greater flexibility in achieving compliance; and (3) reduce the likelihood that overall emissions would increase over time, thus providing greater environmental protection. NESCAUM deferred to individual states in deciding whether to include unconventional generation resources such as cogeneration, landfill gas, and waste-to-energy facilities.

- Contaminants regulated/setting emission standards. In developing an EPS program, policy makers must decide what contaminants to regulate; in particular, whether to limit the program to the more commonly regulated, well understood byproducts of combustion such as $\mathrm{NO}_{\mathrm{x}}, \mathrm{SO}_{2}$ and $\mathrm{CO}_{2}$ or whether to expand the program to include other contaminants or other, broader environmental impacts. In addition, policy makers must consider what geographic area to use to determine EPS levels. Standards set for the Northeast alone would likely be stricter than those set over a broader geographic area, because existing northeastern power plants are generally cleaner than those in the Midwest and South. Another consideration in establishing emission standards is whether to cap emissions or to rely on rate-based standards expressed in terms of an allowable quantity of emissions per quantity of electricity generated, the approach adopted by NESCAUM. Although an output-based approach means that total emissions of regulated contaminants may increase over time, it avoids the need for allocating emissions among retailers, an extremely complex and politically sensitive process. ${ }^{154}$

\footnotetext{
153 The model rule proposes the following standards for the three listed contaminants: $\mathrm{NO}_{\mathrm{x}}, 1 \mathrm{lb} / \mathrm{MWh} ; \mathrm{SO}_{2} 4 \mathrm{lbs} / \mathrm{MWh}$ and CO $1100 \mathrm{lbs}$./MWh. Although several states that have developed EPS call for regulation of carbon monoxide (CO), the model rule defers regulation of this contaminant pending further study. With respect to mercury, the model rule sets the EPS at the actual emission rate for the short term.

154 The NESCAUM background report includes a detailed discussion of the assumptions underlying each emission standard contained in the model rule. In setting the standards for $\mathrm{NO}_{\mathrm{x}}$ and $\mathrm{SO}_{2}$, the group generally was guided by the most stringent limits required by regulation under the OTC MOU and Phase II acid rain programs, respectively. The $\mathrm{CO}_{2}$ standard reflected 1996 emissions and generation in the United States. The group declined to set standards for CO and mercury primarily because of a lack of information. NESCAUM Report, at 23-28.
} 
- Information systems. To implement an EPS program, regulators must have data on generation (which units ran and how much power they generated) and emissions (quantity of pollutants emitted from each unit). Key to any EPS is an information system linking the source of electricity with retail sales. In the long term, this information will be used in systems being developed by state and regional ISOs. In the interim, policy makers must rely on other sources of information concerning generation. With respect to emissions data, sources regulated under the acid rain program and state $\mathrm{NO}_{\mathrm{x}}$ budget programs must monitor emissions of $\mathrm{SO}_{2}$ and $\mathrm{NO}_{\mathrm{x}}$ using CEMS and report the results. For other sources and contaminants not monitored under this program, policy makers must decide what type of information they will require to verify emissions to determine compliance with the EPS.

- Trading/banking. NESCAUM rejected proposals to allow intra-company and inter-company trading between product portfolios and banking of excess emissions below the EPS for use in later years because of the additional regulatory and administrative complexity of setting up such systems and the uncertainty surrounding development of crucial regional information systems. However, policy makers may wish to consider these alternatives in developing an EPS program.

Several states in the Northeast and elsewhere have enacted legislation requiring or authorizing the adoption of EPS. ${ }^{155}$ However, these programs have yet to be implemented. Therefore, it is too early to assess their relative success or failure.

\section{Benefits}

- Market competitiveness. EPS will improve the relative competitive position of renewables by making their "environmental friendliness" a commodity. Retailers faced with the need to demonstrate compliance with the EPS are more likely to turn to existing renewable energy sources or to encourage development of new ones.

\section{Barriers}

- Not guaranteed boost for renewables. Unlike RPS and SBCs discussed below, EPSs are not specifically targeted at encouraging development of renewable energy sources. Whether EPS will serve as a catalyst for renewable energy projects will depend largely on market conditions.

- Clean conventional fuels retain competitive advantage. Depending on how the EPS program is structured, retailers may be able to achieve compliance with the EPS simply by switching to cleaner conventional fuels. Currently, the price differential between electricity and renewable sources is relatively large; therefore, the most cost-effective alternative for achieving compliance with an EPS is likely to be natural gas. The lower the EPS for the individual contaminants, the more attractive renewable energy would likely become. It may be difficult politically to set the EPS low enough to make renewable energy a cost-effective alternative to cleaner conventional fuels, at least in the short term.

- "Leakage" or "gaming" issues. Because it is physically impossible to track the source of a given electron, any EPS program may experience problems with "leakage" or "gaming"-suppliers demonstrating compliance on paper but obtaining power in ways that are inconsistent with the policies underlying the EPS program. For example, a retail supplier serving multiple states could designate relatively cleaner resources in his portfolio for the EPS-implementing state without any effect on the overall mix of generation sources. According to NESCAUM, this problem can be addressed, at least in part, by enlarging the size of the market covered by the EPS and by developing comprehensive information management systems to support

\footnotetext{
155 These states include Connecticut, Massachusetts, New Jersey and Vermont, among others. See NESCAUM Report, at 4-5.
} 
compliance. In addition, the NESCAUM model rule proposes to assign default emission values where the origins of power cannot be identified. Although these measures may reduce the likelihood of gaming, the problem can never be eliminated.

\section{Supplemental Environmental Projects and Enforcement}

\section{Description}

Facilities entering agreements settling environmental violations with the EPA or the Department of Justice may agree to perform a "supplemental environmental project" (SEP) to offset a portion of their penalties. One alternative for promoting renewables is to allow utilities and others settling CAA and other environmental violations to agree to construct or promote renewable energy projects under the EPA's policy. In a recent settlement with a Colorado utility, for example, the EPA approved as a SEP a program that required the utility to pay a premium for wind power as a substitute for a portion of its penalty. This provision will require the utility to construct a new wind turbine to meet the demand.

The EPA has issued guidance on the approval of SEPs that sets forth the types of projects that are permissible as SEPs, the penalty mitigation appropriate for a particular SEP, and the terms and conditions under which they may become part of a settlement. ${ }^{156}$ Among other things, the guidance makes clear that there must be a nexus between the violation and the proposed project. Construction of new renewable capacity presumably would be approved as a SEP only in settlement of alleged CAA violations.

\section{Benefits}

- Implementability. The EPA and the Department of Justice currently have broad authority to approve supplemental environmental projects when settling environmental enforcement actions. This alternative thus can be implemented immediately. By comparison, all of the other alternatives discussed require legislative and/or regulatory action.

\section{Barriers}

- Limited scope. The fact that SEPs are triggered by enforcement, in itself, limits opportunities to promote renewables. Moreover, the number of renewable projects that can be approved as SEPs is necessarily limited by the need to show a nexus between the violation and the project. Thus, although the renewables industry can propose new projects as SEPs to settle CAA violations, it cannot hope to rely on SEPs to provide a meaningful boost to renewables and should pursue other alternatives.

156 EPA Supplemental Environmental Projects Policy (May 1, 1998). 


\section{Non-Clean Air Act Program Alternatives for Encouraging Renewable Energy}

Thus far, this report has discussed alternatives for promoting renewable energy traditionally contemplated under the CAA. As noted earlier in this section, however, there are many other alternatives for promoting renewables, such as RPS, SBCs, and pollution taxes or charges that, while not currently part of the CAA, nevertheless could be incorporated into the Act either alone, or as part of a larger program to encourage development of renewable energy. These alternatives are discussed briefly below.

\section{Renewable Portfolio Standard}

\section{Description}

RPS attempt to encourage the development of renewable energy sources by requiring electricity generators or retailers (depending on how the program is designed) to demonstrate that a certain percentage of their power has been generated by renewable sources. To ensure market efficiency, RPS programs ideally should authorize the creation of renewable energy credits (RECs) for each kilowatt-hour ( $\mathrm{kWh}$ ) of electricity generated. Under this scheme, electricity generators/retailers would be required to demonstrate, through ownership of RECs, that they have supported the amount of renewable energy generation required by the RPS. For example, if the RPS is set at $5 \%$ and a REC is produced for each MWh of renewable generation, then a generator that sells $100,000 \mathrm{kWh}$ in a given year would need to possess 5,000 RECs at the end of that year. Like emission allowances, the RECs would be fully tradable. Thus, generators would have the option of producing their own renewable power (and generating their own RECs), entering into a contract with a renewable power generator to purchase RECs, or simply acquiring RECs through brokers.

As with emission credits, the government's role in the RPS process is relatively limited. Among other things, the government is responsible for: (1) establishing the RPS; (2) certifying the RECs generated by renewable power producers; (3) assessing each year whether regulated entities have RECs sufficient to meet their obligations under the RPS; and (4) assessing penalties for noncompliance, including fines and/or offsets. Ideally, an RPS should increase over time with the goal of encouraging continued development of renewable energy sources. ${ }^{157}$

There are several key factors that must be considered in designing a RPS program, including:

- Defining "renewables." Ideally, renewables should be defined for purposes of RPS to include only technologies that are environmentally sound, that represent a small fraction of the current resource base, and that need market support. Such a definition would include wind, solar, biomass, and geothermal resources. Certain state programs limit RPS to specific types of renewables such as solar power. However, this approach arguably interferes with the efficient functioning of the market.

- Setting the standard and rate of increase. The level of the standard should begin at, or very near, current levels of renewables (as defined) and rise gradually from that point. Intermittent larger increases in the RPS should be avoided because they will likely result in "boom and bust" cycles.

- Sunset date. The RPS should be "self-sunsetting"-meaning that the RPS policy sunsets when the price of RECs falls to zero, signifying that renewables are fully competitive and integrated into the market.

\footnotetext{
157 Numerous analyses of RPS have been prepared. Papers of potential interest include: N. Rader, The Mechanics of a Renewables Portfolio Standard Applied at the Federal Level (Sept. 1997), which can be found at www.econet.org/awea.
} 
- Cost containment. Under certain circumstances, the market may not generate RECs sufficient to meet the needs of generators. This problem can be addressed by setting a cap on the price generators must pay for credits that is higher than the marginal price of credits, but significantly lower than the penalty. If a generator cannot find credits at the cap price or below, the administering agency would issue "proxy" credits at the cap price. The agency would then use the money generated through the sale of "proxy" credits to purchase real credits in the market, lowest prices first, until the funds are expended. This method would ensure that the cost of RPS compliance will not exceed a specified level. ${ }^{158}$

Numerous states have adopted RPS either by statute or by regulation, typically as part of efforts to restructure the electric industry. ${ }^{159}$ In addition, over the years, RPS has been included in many major federal restructuring bills. These programs differ significantly in several important respects, including the size of the renewable requirement, whether or not the program authorizes REC trading, the types of facilities covered, and whether the standards apply to generators or retailers. ${ }^{160}$

\section{Benefits}

- Market stability. A properly designed RPS system will help create a certain, stable market for renewables, enabling them to negotiate long-term contracts and financing and to lower renewable power costs.

- Improved competitiveness. In addition to improving market stability, RPS will improve the economic competitiveness of renewable energy sources in other ways. First, large generation companies will be looking for ways to drive down the cost of renewables to reduce their RPS compliance costs. This will prompt them both to invest directly in renewables and to search out other ways of providing cost-effective renewable power. Second, unlike the one-time competition for funds contemplated by system benefits charges, discussed below, projects must continually compete to keep a place in the market created by the RPS, encouraging ongoing innovation and improvements. Third, the RPS, like emission trading, allows each generator to identify its own least cost solution to compliance, improving market efficiency.

- Administrative simplicity. Unlike system benefits charges, discussed below, RPS do not involve the government in selecting projects and distributing funds, a process which can be bureaucratic, inefficient, and politically charged.

- Targeted directly at renewables. RPSs are one of the only market-based strategies designed specifically to improve market stability and efficiency for renewables. Other strategies, such as output-based allocation and emission performance standards, apply more broadly. Their success as a mechanism for improving the market for renewables depends largely on the cost of renewables relative to conventional fossil fuel-fired plants.

158 Rader, at 3-4.

159 As of Spring 2000, eight states had adopted RPS: Connecticut, Maine, Massachusetts, Nevada, New Jersey, Pennsylvania, Texas, and Wisconsin. To date, however, only Maine has implemented the program, although several other states are well along in their implementation efforts. Credit trading has been implemented in Texas and is being considered by several other states. See K. Porter and R. Wiser, A Status Report on the Design and Implementation of State Renewable Portfolio Standards and System Benefits Charges (May 2000) (hereinafter "RPS/SBC Status Report"). A summary of state RPS programs also can be found in M. Kushler and P. Witte, American Council for an Energy Efficient Economy, A Review and Early Assessment of Public Benefit Policies Under Electric Restructuring Volume 1: A State-by-State Catalog of Policies and Actions (May 2000) (hereinafter "ACEEE Report"). A summary of provisions as of August 2000 can be found at the ACEEE web site at www.aceee.org/briefs/mktabl.htm. Additional information on RPS and other state incentive programs can be found in the National Database of State Incentives for Renewable Energy (DSIRE), which is available on the web at www.ncsc.ncsu.edu/dsire.htm.

160 See RPS/SBC Status Report, at p.2, Table 1 for a summary of existing state RPS policies. 


\section{System Benefits Charge}

\section{Description}

As part of the restructuring of the electric industry, many states have implemented an SBC to encourage efficiency and renewable energy projects. ${ }^{161}$ SBCs typically are levied on electricity sales at a specified rate per $\mathrm{kWh}$ of energy generated. These SBCs are used to create a funding source for public policy initiatives that are not adequately addressed by competitive markets. Programs typically funded by SBCs include research and development, energy efficiency, and renewable energy projects. In New York, for example, a charge of approximately one-tenth of a cent is levied against energy retailers for each $\mathrm{kWh}$ sale. The proceeds from this charge - about $\$ 78$ million per year in New York - are placed in a fund managed by the state. The fund manager then makes these funds available to energy-efficiency service providers or renewable energy developers in the form of grants, production incentives, or technical assistance. Recent projects funded by the SBC in New York include approximately $30 \mathrm{MW}$ of wind power and numerous energy efficiency projects.

Although efforts to date have focused on implementing SBCs as part of the restructuring process, they could readily be included as an element of federal or state programs to reduce emissions of key contaminants such as $\mathrm{NO}_{\mathrm{x}}$ and $\mathrm{CO}_{2}$. For example, a state could decide to target $\mathrm{SBC}$ funds to areas where emission reductions are needed to achieve national or state air quality goals. As noted in Section IV, for example, the states in the OTC currently are exploring $\mathrm{SBCs}$ as an alternative for reducing $\mathrm{NO}_{\mathrm{x}}$.

\section{Benefits}

- Targeted directly at renewables and specific air-quality problems. The chief benefit of SBCs is that they guarantee the development of renewables regardless of market conditions. At least in the short term, they may provide an essential catalyst for developing more cost-effective renewable energy alternatives. Similarly, the use of SBC funds can be targeted to reduce specific pollutants and, in some cases, may be targeted toward areas with persistent pollution problems.

\section{Barriers}

- Administrative inefficiency/political considerations. SBCs arguably are less efficient than emission credits, RPS, and other market-based mechanisms for encouraging renewable development. The money generated by SBCs typically is distributed by government agencies that must account for how the money is allocated and spent. Under certain circumstances, the distribution process can become bureaucratic and inefficient. In addition, the allocation process may be subject to political pressures.

161 States that have implemented SBCs as of Spring 2000 include California, Connecticut, Delaware, Illinois, Massachusetts, Montana, New Jersey, New Mexico, New York, Oregon, Pennsylvania, Rhode Island, and Wisconsin. Approximately half of these states have begun to distribute SBC funds to renewables projects. See RPC/SBC Status Report, p. 2, Table 2, for a summary of existing state SBC programs. See also ACEEE Report for a summary of state SBC programs. 


\section{Pollution Taxes or Charges}

\section{Description}

Conventional fossil fuel-fired power plants have a significant advantage over renewables because one important "cost" of operating - air pollution - is borne not by the generator but by society as a whole. Several of the strategies discussed previously, such as EPS, attempt to remedy this problem by requiring fossil plants to somehow pay the cost of the pollution they generate. Economists have suggested achieving this result more directly by imposing a "pollution tax." 162 Under this approach, a tax would be levied based on the quantity of carbon in fuel, which is a useful surrogate for the quantity of pollution produced by burning fossil fuels. To prevent possible economic problems associated with higher taxes generally, most proposals call for offsetting carbon taxes with reductions in traditional taxes such as income and/or sales taxes.

\section{Benefits}

- Improved economic efficiency. Perhaps the chief benefit of carbon taxes is that they improve market efficiency by forcing generators and consumers to pay the cost of pollution, rather than allowing the "price" to be paid by society generally in the form of dirty air. Properly designed, a carbon tax could lead to greater energy efficiency and increased reliance on renewable energy as the market searches for cleaner sources of electricity.

- Minimal government involvement. Once the carbon tax is developed and implemented, the government's role would be limited to collecting the tax. By comparison, virtually all of the other alternatives for encouraging renewables discussed above require a continuing government role either in monitoring "compliance" (in the case of allowance set-asides, RPS, or EPS) or in actually deciding what projects to finance (in the case of SBC).

\section{Barriers}

- Political unpopularity. Higher fuel taxes (indeed higher taxes of any kind) are extremely unpopular in the United States. Unless the offsetting reductions in other taxes are significant and the economic and environmental benefits of the program properly explained, carbon taxes will be extremely difficult to sell politically.

- Economic dislocation. Unless properly designed, the imposition of a carbon tax could lead to short-term economic dislocations as businesses with high energy needs struggle, perhaps unsuccessfully, to cope with higher energy prices. This impact arguably could be lessened by implementing any such taxes gradually and by providing transition assistance in the form of rebates for energy efficiency or renewable energy projects, retraining assistance for workers and other measures. Some economists have raised concerns that carbon taxes may, in the long run, adversely affect our competitiveness relative to other markets.

- Regressivity. A carbon tax would likely be regressive because the poor pay a larger percentage of their income in energy costs, both directly and indirectly. This problem could be addressed through "revenue recycling"-reducing income or other taxes to offset the regressivity caused by the carbon tax.

\footnotetext{
162 Various studies have been done assessing pollution taxes. See Tellus Institute, Ecological Tax Reform: Carbon Taxes with Tax Reductions in New York (June 1997) (prepared in cooperation with the Pace University Energy Project, Pace University, White Plains, NY).
} 


\section{Recent Legislative Initiatives}

Numerous bills have been introduced recently with the express goal of encouraging the generation of "clean power" under the CAA. Many of these bills would establish emission limitations on $\mathrm{SO}_{2}, \mathrm{NO}_{\mathrm{x}}$, and other pollutants from new and existing fossil fuel-fired power plants. They would also establish emission performance standards, RPS, and other programs discussed above intended expressly to encourage development of renewable energy sources. For example, the Clean Power Act of 1999 (H.R. 2980), sponsored by Representative Thomas Allen, would establish emission limitations on mercury, $\mathrm{SO}_{2}$, and $\mathrm{NO}_{\mathrm{x}}$ emissions from fossil fuel-fired power plants; it would also establish an EPS for $\mathrm{CO}_{2}$ emissions beginning in 2004. A related bill, known as the Clean Power Plant and Modernization Act of 1999 (S.1949), would also establish a minimum combustion heat rate efficiency and require existing grandfathered sources to comply with new source review standards under Title I of the CAA. The Fair Energy Competition Act (H.R. 2569), sponsored by Representative Frank Pallone, would establish EPS for various pollutants; it would also require establishment of a public benefits fund to support renewable energy sources and a RPS. A similar bill sponsored by Senator James Jeffords (S.1369), known as the Clean Energy Act of 1999, would also authorize the EPA to establish EPS for various pollutants; like H.R. 2569, it calls for the creation of a public benefits fund and RPS. These bills are in addition to legislation discussed in Sections III-VI (and summarized in Appendix D), that call for new, stricter emissions cap-and-trade programs. 


\section{Section VIII — Specific Recommendations for Program Reform}

\section{Introduction}

Section VII of the report summarized, in some detail, various generic environmental regulation mechanisms that have been or could be implemented to help encourage the development of renewables at either the federal or state level, including allowance set-asides, output-based allowance allocation programs, allowance auctions, RPS, SBCs, EPS, pollution taxes or charges, and supplemental environmental projects. This section will examine various opportunities to apply these mechanisms to promote renewables in the context of the CAA, focusing on the most promising policy alternatives involving the four programs discussed in Sections III-VI of the report$\mathrm{SO}_{2}$ and acid rain (Section III); $\mathrm{NO}_{\mathrm{x}}$ and ozone (Section IV); PM, visibility, and regional haze (Section V); and GHG and climate change (Section VI). For each program, the report will follow the format used in the previous section, summarizing the benefits and barriers of each alternative. In addition, it will suggest strategies for implementation, assuming the alternative merits pursuit. The section will conclude with a brief summary of the factors that would need to be considered in developing a multi-pollutant emission trading program and the impact of such a program on renewables.

This section of the report focuses primarily on alternatives that we believe pose the greatest opportunity for success, both from a practical and political perspective. Obviously, alternatives other than those recommended below could be pursued to promote renewable energy. It is important to bear in mind, however, that any program resulting in the substitution of renewable energy sources for fossil fuel-fired sources inevitably will result in the reduction of harmful air emissions other than those specifically targeted by the program. Thus, successfully implementing even a few well-chosen programs to promote renewables could have clean air benefits well beyond those specifically targeted by the program.

In discussing the various programs below, we have focused primarily on amending existing cap-and-trade and other programs currently found in the CAA. However, the program changes discussed below could readily be combined with other programs, such as RPS, EPS, and SBCs discussed in the previous section.

\section{Title IV Acid Rain Program}

\section{Introduction}

The Title IV acid rain program is arguably the most mature attempt to harness market forces to address air pollution. This maturity makes it an attractive target for renewables because both government and industry are familiar with the program and are more likely to understand and be comfortable with the types of changes that would be necessary to promote renewable development. Possible alternatives that should be explored are set forth below.

- Option 1: Tightening the existing $\mathrm{SO}_{2}$ cap (increasing the price of allowances and improving the competitive position of renewables).

- Option 2: Establishing an improved allowance set-aside program for renewables to replace the CRER.

- Option 3: Phasing out the existing allowance program in favor of an output-based allowance allocation system that includes renewables.

- Option 4: Phasing out the existing allowance program in favor of an allowance auction system. 
- Option 5: Combining an improved $\mathrm{SO}_{2}$ allowance allocation for renewables with a similar system for other pollutants emitted from power plants.

In today's political climate, we believe that Options 1 and 2 represent the most viable alternatives for revising the federal CAA and boosting opportunities for renewables, at least in the short term. At a time when environmental regulations are often criticized for being unduly complicated and expensive to implement, the existing acid rain allowance program generally has been hailed as a success by industry, government, and the environmental community. Indeed, as previously noted, several bills have been introduced in Congress to lower the $\mathrm{SO}_{2}$ cap still further-no doubt a reflection of the widespread belief that the program has resulted in significant reductions in $\mathrm{SO}_{2}$ emissions at much lower costs than expected.

Although output- and auction-based allowance allocation schemes (Options 3 and 4) represent an economically viable alternative to set-asides, political and practical considerations may make such schemes difficult to implement, at least in the short term. In the long term, policy makers should consider pursuing a multi-pollutanttrading scheme (Option 5) consistent with the proposal outlined below. A properly designed multi-pollutant scheme would better reward renewables for the air pollution benefits they bestow while minimizing transaction costs.

\section{Option 1: Tightening the Existing $\mathrm{SO}_{2}$ Cap}

\section{Description}

In general, the lower an emissions cap under a cap-and-trade program, the higher the cost of allowances; the higher the cost of allowances, the more attractive renewables are as a compliance alternative. Accordingly, any strategy to promote renewables under the acid rain program should include a reduction in the $\mathrm{SO}_{2}$ cap. As discussed in Section III, several bills have been introduced in both the House of Representatives and the Senate to reduce the $\mathrm{SO}_{2}$ cap as part of a broader emissions-trading proposal. These bills adopt very different approaches to reducing $\mathrm{SO}_{2}$ emissions. The Clean Smokestacks Act sponsored by Representative Henry Waxman (with 116 cosponsors) requires power plants to reduce $\mathrm{SO}_{2}$ emissions by $75 \%$ from 1997 levels by 2005. The bill does not specify how these reductions are to be achieved but instead leaves it to the EPA to promulgate regulations. Presumably, the EPA would be free to pursue any strategy, within reason, to achieve the necessary emission reductions, including those, such as allowance set-asides, that would benefit renewables. Because the EPA is more likely than Congress to be aware of (and sympathetic to) the air quality benefits posed by renewables, the approach embodied in the Waxman bill may present significant opportunities for the renewables industry, particularly if language referring to allowance allocations for renewables were added to the bill.

Other legislation introduced to date calls for reducing $\mathrm{SO}_{2}$ emissions by decreasing the value of the allowances already issued under the Title IV acid rain program by $50 \%$ to $75 \%$. In other words, as of a particular date, each allowance would be worth one-half ton of $\mathrm{SO}_{2}$ rather than one ton. Under this approach, the emissions reductions would occur solely within the framework of the existing program. As noted above, renewables presumably would benefit from this approach to the extent that higher allowance costs make renewables more attractive economically. However, this legislation does not contain any provisions intended specifically to encourage renewables, at least as applied to $\mathrm{SO}_{2}$ emissions, nor does it grant the EPA broad discretion to develop its own regulations. ${ }^{163}$ Any provisions, such as the development of a new set-aside program or an expanded auction program, would require legislative changes.

\footnotetext{
163 The Clean Power Act, sponsored by former Congressman Rick Lazio, would specifically address renewables under a $\mathrm{NO}_{\mathrm{x}}$ cap-
} and-trade program; however, no similar provisions are included for $\mathrm{SO}_{2}$. 


\section{Benefits}

- Political support. Perhaps the biggest advantage of reducing the $\mathrm{SO}_{2}$ cap is that proposals advocating this approach already have significant support in both houses of Congress. As previously noted, more than 126 members of the House of Representatives have endorsed one or more of the various bills introduced to reduce the cap beyond levels required by the existing program.

\section{Barriers}

- May not provide sufficient "boost." As noted above, the current acid rain program does not establish a role for renewables, except under the now-expired CRER program. Reducing the cap alone may not increase production costs for conventional sources enough to make wind, solar, and biomass generation fully competitive. The benefit would primarily be enjoyed by lower emitting fossil generation, particularly natural gas combined cycle generation. Therefore, as noted above, in addition to reducing the cap, it will also be necessary to change Title IV to allow renewable sources to acquire allowances (through a set-aside or other similar program) or to participate in the program in other ways. Lowering the cap may, however, provide a long-term benefit to some renewables if the cost of compliance for fossil plants rises at the same time as the cost of production of renewables falls - reducing the time before renewables become competitive. Because renewables need near-term support to expand and achieve production efficiencies, a set-aside is an appropriate complement to lowering the emission cap.

\section{Option 2: Establishing an Improved Renewables Set-Aside Program}

\section{Description}

The CRER program represented a limited attempt by Congress to encourage renewables development by setting aside a portion of allowances for energy efficiency and renewable energy programs. One option for promoting renewables is to propose a new renewable set-aside program, either alone or in conjunction with a reduction in the $\mathrm{SO}_{2}$ cap, discussed above. ${ }^{164}$ Possible elements of the new program include the following:

- Quantity of allowances. Set aside 5\% of total $\mathrm{SO}_{2}$ allowances by 2003 (growing to10\% by 2013) for allocation to renewable energy developers.

- Type of project. Consistent with the recommendations outlined in Section VII, allowances should be awarded only for new renewable projects.

- Eligible participants. The CRER program limited participation to utilities. Any new program should open up participation in the allowance program to anyone sponsoring a "new" renewable project that meets the program criteria and eliminate least-cost planning and utility income neutrality eligibility requirements.

- Length of award. Currently, the costs of renewable energy are high relative to conventional fuels. To address this cost differential, any new allowance set-aside program should award allowances to projects for at least five years and preferably 10 years, with the longer time for projects that have high up-front costs. A longer time frame will provide projects with the type of steady revenue stream necessary to attract financing and ensure the initial success of the project. As technology improves and renewable energy projects become increasingly commonplace, the length of time set-asides are awarded should be reduced.

\footnotetext{
164 As an alternative, it has been suggested that the EPA "reinterpret" the existing CRER legislation to allow issuance of the approximately 260,000 credits remaining from the original CRER allocation. Assessing whether the EPA has the authority to adopt such a policy is beyond the scope of this report.
} 
- Transaction costs. The procedures for applying for set-aside credits should be as simple as possible to minimize transaction costs. In particular, any set-aside program should include a streamlined procedure for awarding credits to simple renewable projects, such as windmill farms, with commonly recognized and easily calculated emission reduction benefits.

\section{Benefits}

- See discussion of set-asides in Section VII above.

\section{Barriers}

- $\quad$ See discussion of set-asides in Section VII above.

Option 3: Phasing Out the Existing Allowance Program in Favor of an Output-Based Allowance Allocation System that Includes Renewables

\section{Description}

The current acid rain program awards allowances to renewables on a set-aside basis. Long term, however, the renewables industry could benefit from adopting an output-based allowance allocation system (Option 3 ) that expressly includes renewables. As with the options previously discussed, this change would require legislation amending the CAA.

\section{Benefits}

- Market efficiency. As discussed in Section VII, the chief benefit of an output-based allocation approach is that it more efficiently rewards cleaner generating facilities, such as renewables, for the air pollution benefits they generate. Credits are awarded based solely on the quantity of electricity generated, without regard to fuel type.

- Simplicity. Advocates argue that output-based allocation systems will be easier to administer than conventional systems because the decision regarding how allowances are allocated is left to the market. The government's role is limited to setting the emission cap, monitoring energy output, and ensuring that each generator holds sufficient allowances in relation to the quantity of emissions generated.

\section{Barriers}

- Lack of information. As discussed above, regulators currently lack the information on electric generation output needed to set up an output-based allocation mechanism. However, this information should be available shortly.

- Political concerns. Allocating allowances based on electricity generated will inevitably cause a shift in wealth to cleaner sources at the expense of "dirty" ones. Fossil fuel producers and utilities would lobby hard against any such program unless they can be convinced that it will not cripple them economically. An outputallocation system would also invite controversy over allocating credits to nuclear power, further complicating the picture politically. Opposition by oil- and coal-fired utilities could be reduced by restricting participation in an output-based allocation scheme for $\mathrm{SO}_{2}$ to major $\mathrm{SO}_{2}$ emitters and renewables. Currently, Title IV allocates allowances to oil- and coal-fired electric generators because they are the only fossil fuel-fired units that emit $\mathrm{SO}_{2}$ in significant quantities. The CAA could be amended to award allowances to such sources and to renewables on an output basis (allowances per MWh of generation). This approach would involve a much smaller shift of wealth than an output-based approach applied to all generators. This proposal would, 
of course, first have to overcome the historic preference of Congress in Title IV for allocations of $\mathrm{SO}_{2}$ credits based on historic heat input data.

\section{Option 4: Phasing Out the Existing Allowance Program in Favor of an Allowance Auction System}

\section{Description}

Currently, a small percentage of $\mathrm{SO}_{2}$ allowances are allocated by auction. Several policy makers have suggested replacing the current heat input-based allocation scheme with one that relies solely on auctions.

\section{Benefits}

- See discussion of auctions in Section VII above.

\section{Barriers}

- See discussion of auctions in Section VII above.

\section{Option 5: Combining an Improved $\mathrm{SO}_{2}$ Allowance Allocation for Renewables with a Similar System for Other Pollutants Emitted from Power Plants}

See discussion of multi-pollutant trading below.

\section{Strategies for Implementing}

As the above summary suggests, there is already considerable momentum in Congress to reduce the $\mathrm{SO}_{2}$ cap, an important element of any revisions to the CAA intended to boost renewables. To take advantage of this momentum, the renewables industry should consider implementing the following strategy:

- Reach out to environmental groups and regulators to explain the air quality and other benefits of renewable energy and enlist their support for measures, such as renewable energy set-asides, that will specifically benefit renewables.

- Educate decision-makers on the need to replace the 1990 Amendment's CRER provisions to provide some type of ongoing $\mathrm{SO}_{2}$ allowance allocation for renewables.

\section{Ozone and Nitrogen Oxides Controls}

\section{Introduction}

There are several obstacles to ensuring that renewables play a significant role in existing programs to limit $\mathrm{NO}_{\mathrm{x}}$ emissions. First, as discussed in Section IV above, neither the federal $\mathrm{NO}_{\mathrm{x}}$ Budget Trading Program nor the Northeast $\mathrm{NO}_{\mathrm{x}} \mathrm{MOU}$ specifically require the establishment of set-asides or other mechanisms to encourage participation by renewables. Although both the EPA and the OTC have issued guidance encouraging such programs and established guidelines for their implementation, to date only a few states have adopted renewable set-asides. Consequently, the opportunities for renewables to participate in $\mathrm{NO}_{\mathrm{x}}$ trading are severely limited. This problem can be remedied only by revising state emission-trading regulations one-by-one, or by amending the act to give the EPA authority to require participation by renewables or to otherwise encourage their participation. 
Another problem facing renewables is the sheer complexity of the regulatory scheme governing $\mathrm{NO}_{\mathrm{x}}$ emission reductions. As discussed above, the CAA regulates $\mathrm{NO}_{\mathrm{x}}$ as an ozone precursor under a variety of programs; the programs operate in addition to the various state programs adopted to implement the Northeast MOU. Although the criteria and standards for these programs are similar in many key respects, subtle and not-so-subtle differences between the programs significantly complicate compliance. Moreover, $\mathrm{NO}_{\mathrm{x}}$ also is regulated at the federal level as an acid rain and regional haze precursor, further complicating the already difficult task of understanding and conforming the various $\mathrm{NO}_{\mathrm{x}}$ control programs.

Possible alternatives for encouraging renewables under existing CAA programs for $\mathrm{NO}_{\mathrm{x}}$ include:

- Option 1: Encouraging states to address renewables under existing programs established by the Northeast OTR under its existing MOU

- Option 2: Encouraging states to address renewables under trading programs to be implemented under the $\mathrm{NO}_{\mathrm{x}}$ SIP call.

- Option 3: Addressing renewables under the CAA $\S 126$ petition regulations.

- Option 4: Establishing a national or regional $\mathrm{NO}_{\mathrm{x}}$ cap-and-trade system with a mandatory renewable setaside.

- Option 5: Combining a $\mathrm{NO}_{\mathrm{x}}$ allowance allocation for renewables with a similar system for other pollutants emitted from power plants.

As set forth below, we believe that Options 1 and 2 are both feasible in the short term. Unfortunately, the potential impact of these alternatives is limited for two reasons: (1) the programs are limited geographically; and (2) any changes must be implemented on a state rather than national level. Option 3 is even more limited geographically because the scope of the Section 126 orders is narrower than the $\mathrm{NO}_{\mathrm{x}}$ SIP call; unlike the MOU and SIP call programs, however, the Federal $\mathrm{NO}_{\mathrm{x}}$ Budget Trading regulations adopted under CAA § 126 will be implemented federally. As also discussed below, the EPA has indicated a willingness to address renewables under this program, at least in the long term. With respect to Option 4, there is some momentum in Congress to develop a $\mathrm{NO}_{\mathrm{x}}$ cap-and-trade program similar to the Title IV acid rain program. This alternative could significantly benefit renewables, particularly if the trading program includes a renewable set-aside. ${ }^{165}$ However, another $\mathrm{NO}_{\mathrm{x}}$ trading program could significantly complicate the regulation of $\mathrm{NO}_{\mathrm{x}}$ particularly in those states already covered by one or more existing $\mathrm{NO}_{\mathrm{x}}$ trading programs. Perhaps a better alternative to a federal $\mathrm{NO}_{\mathrm{x}}$ trading program is to actively pursue a multi-pollutant-trading scheme that would more efficiently reward the multi-pollutant benefits offered by renewables.

\section{Option 1: Addressing Renewables in the OTR Under the Existing MOU}

\section{Description}

States in the OTR are required to implement a cap-and-trade program to reduce $\mathrm{NO}_{\mathrm{x}}$ emissions. In the short term, state regulations implementing the MOU could be amended specifically to establish a role for renewables in those states that have not already done so. In the long term, further reductions in $\mathrm{NO}_{\mathrm{x}}$ could be required that would make renewables a more "valuable" alternative relative to other emission reduction strategies. Additional

\footnotetext{
${ }^{165}$ Using an output-based allocation approach would be more difficult for $\mathrm{NO}_{\mathrm{x}}$ than $\mathrm{SO}_{2} . \mathrm{NO}_{\mathrm{x}}$ is emitted from coal, oil, and natural gas-fired generators; as a result, the wealth shift associated with adopting an output-based allocation approach for $\mathrm{NO}_{\mathrm{x}}$ would be larger, making such a program more politically problematic.
} 
programs also could be developed (set-asides, RPS, and SBCs) specifically to encourage development of renewables. As previously discussed, the OTC currently is exploring these options and expects to issue a final assessment by winter 2002 .

\section{Benefits}

- Basic programs already exist that contemplate role for renewables now or in future. A basic cap-andtrade mechanism is already in place in the northeastern states. As discussed above, several states in the OTR have already developed set-aside and other programs to encourage renewables. Under these circumstances, the northeastern states may be relatively comfortable with the emission-trading process and may be amenable to tinkering with their existing programs to encourage renewables. Long term, provisions governing renewables could be included in model rules developed to implement additional $\mathrm{NO}_{\mathrm{x}}$ reductions contemplated by the most recent MOU signed in June 2000. This would ensure that all states executing the MOU include renewables as a $\mathrm{NO}_{\mathrm{x}}$ reduction strategy.

\section{Barriers}

- Limited geographic scope. Participation in the trading program is limited to states in the Northeast OTR (excluding Virginia).

- Limited season. The program only requires $\mathrm{NO}_{\mathrm{x}}$ reductions in the five-month summer period when ozone levels tend to be highest. Although several states in the OTR have indicated that they intend to require $\mathrm{NO}_{\mathrm{x}}$ reductions year round, it is unclear how widespread those requirements will be.

- State focus. Each state in the Northeast OTR is responsible for developing its own $\mathrm{NO}_{\mathrm{x}}$ control program and for deciding what role, if any, renewables will play in achieving ozone reductions. As discussed in detail in Section IV, to date, only a few states have specifically addressed renewables under this program. At least short term, any efforts to encourage renewables must focus on individual state programs.

\section{Option 2: Encouraging States to Address Renewables Under Trading Programs to be Implemented Under the $\mathrm{NO}_{x}$ SIP Call}

\section{Description}

As discussed in Section IV above, the EPA has established a model trading rule under the SIP call. The rule does not specify a mandatory mechanism for allocating allowances among sources, although it does contain a "recommended" $\mathrm{NO}_{\mathrm{x}}$ allowance allocation methodology that focuses on heat input while acknowledging some of the benefits of an output-based approach. Under the $\mathrm{NO}_{\mathrm{x}}$ Budget Trading Program, states are free to allocate allowances among sources as they see fit and thus to set aside a portion of allowances for renewables.

\section{Benefits}

- $\quad$ Broader geographic scope. The $\mathrm{NO}_{\mathrm{x}}$ SIP call essentially expands the reach of seasonal $\mathrm{NO}_{\mathrm{x}}$ controls beyond the northeastern states into the Midwest and South (currently, 19 states are covered by the $\mathrm{NO}_{\mathrm{x}}$ SIP call). These states, like those in the Northeast, will have the option to adopt emission trading and renewables set-asides as part of their compliance programs (initially due in late 2000, although opportunities to add renewable set-asides will occur at several later stages). 


\section{Barriers}

- $\quad$ State implementation. As in the OTC option discussed above, this option requires each state to develop its own regulations, significantly complicating program advocacy and implementation.

\section{Option 3: Addressing Renewables Under the CAA § 126 Petition Regulations}

As discussed in Section IV, the EPA has adopted the Federal $\mathrm{NO}_{\mathrm{x}}$ Budget Trading Program for 392 sources required to limit emissions under CAA $\S 126$. Although this mandatory program does not currently establish a role for renewables, the EPA has indicated that it may include renewables when it switches to an output-based allowance allocation scheme in 2008.

\section{Benefits}

- Federally implemented. Unlike the OTC and SIP call programs, the CAA § $126 \mathrm{NO}_{\mathrm{x}}$ allowance program is being implemented by the EPA rather than the states. As a result, efforts to encourage the creation of a role for renewables can focus on the EPA.

\section{Barriers}

- Limited participation. Participation in the program is limited to the 392 facilities identified in the rulemaking (although new facilities may be added if the EPA grants additional petitions). This severely limits the potential impact of any efforts to encourage renewables under the program.

\section{Option 4: Establishing a National or Regional $\mathrm{NO}_{x}$ Cap-and-Trade System with a Renewable} Set-Aside

\section{Description}

As an alternative to the options above, renewable producers could attempt to convince Congress to adopt legislation establishing a national emission trading and set-aside program for $\mathrm{NO}_{\mathrm{x}}$ to control both annual and seasonal $\mathrm{NO}_{\mathrm{x}}$ emissions. As previously noted, several of the bills introduced in Congress to address utility emissions have included provisions establishing a cap-and-trade program for $\mathrm{NO}_{\mathrm{x}}$ in addition to proposals to reduce the cap for $\mathrm{SO}_{2}$.

\section{Benefits}

- Nationwide scope. A national cap-and-trade program would ensure that all states are required to implement $\mathrm{NO}_{\mathrm{x}}$ trading and emission reduction programs in place of the voluntary trading option applicable in the OTAG region.

\section{Barriers}

- Duplicate programs and regional nature of underlying pollution problems. As noted above, states in the Northeast, in particular, are currently subject to multiple $\mathrm{NO}_{\mathrm{x}}$ trading programs. A national or broad regional program to control annual and seasonal $\mathrm{NO}_{\mathrm{x}}$ emissions would need to be layered on top of the recently created seasonal controls in certain northeastern states. Congress may be justifiably reluctant to impose additional trading requirements on facilities in these states. The design of any national trading program also would need to take account of the different regional impacts of $\mathrm{NO}_{\mathrm{x}}$ emissions on health and ecosystems. Long term, the better approach may be to combine $\mathrm{NO}_{\mathrm{x}}$ set-asides or direct allocation systems for 
renewables with similar programs for other pollutants (including $\mathrm{SO}_{2}$ and $\mathrm{CO}_{2}$ ) to reduce transaction costs and ease participation by the renewables industry.

\section{Option 5: Combining a NO $\mathrm{N}_{x}$ Allowance Allocation for Renewables with a Similar System for Other Pollutants Emitted from Power Plants}

See discussion of multi-pollutant trading program below.

\section{Strategies for Implementing}

As the above summary suggests, the greatest short-term potential for renewables with respect to $\mathrm{NO}_{\mathrm{x}}$ exists at the state level, under the OTC and SIP call trading programs. As a preliminary matter, therefore, it is crucial to conduct a complete inventory of existing state programs to identify any existing provisions addressing renewables and to monitor their implementation. In addition, the renewables industry should develop model proposals for encouraging renewables (including model set-asides, RPS, and other provisions). In the longer term, it is important to begin to popularize the idea of a national mandate for state $\mathrm{NO}_{\mathrm{x}}$ set-asides .

\section{Visibility Impairment and Particulate Matter}

\section{Introduction}

Visibility impairment and particulate matter exposure are largely caused by the same pollutants that are regulated by the acid rain and ground level ozone programs $-\mathrm{NO}_{\mathrm{x}}$ and $\mathrm{SO}_{2}$. As discussed above, visibility impairment occurs when these contaminants react to form nitrate and sulfate particles, respectively, both of which are key components of PM pollution. In developing a program to address visibility and particulate concerns, policy makers have three broad options, each with distinct advantages and disadvantages.

- Option 1: Adopting state or federal programs specifically targeted at controlling PM through cap-and-trade programs.

- Option 2: Including a renewable set-aside or other renewable incentives as part of upcoming guidance on the emission trading alternative to BART under the regional haze program.

- Option 3: Pursuing renewable energy alternatives under the GCVTC portion of the regional haze regulations.

For the reasons set forth below, Options 2 and 3 present the best opportunities to promote renewables in the context of PM and regional haze.

\section{Option 1: Adopting State or Federal Programs Specifically Targeted at Controlling PM}

\section{Description}

As noted in Section V, PM is emitted from a variety of sources. In many cases, PM is emitted directly as particulate from industrial sources. However, $\mathrm{PM}$ also is created when certain gases, including $\mathrm{NO}_{\mathrm{x}}$ and $\mathrm{SO}_{\mathrm{x}}$, react in the atmosphere. State regulators could adopt programs, such as a PM cap-and-trade system, directly targeting emissions of PM; at least theoretically, Congress could amend the CAA to establish such a program nationwide. 


\section{Benefits}

- Emission reductions. Utilities are a significant source of both direct PM emissions and of gases that react to create PM. As a result, any emission-trading program targeted at PM and its precursors could create significant opportunities for renewables, assuming the caps are set low enough.

\section{Barriers}

- Timing. Implementing the new $\mathrm{PM}_{2.5}$ standard has been slowed by the American Trucking decision; as a result, the earliest any new SIP submissions would likely be required is the latter part of this decade. In the absence of any requirement to revise their SIPs, states are unlikely to pursue innovative PM-control strategies that incorporate renewables. Moreover, until the initial $\mathrm{PM}_{2.5}$ monitoring effort is completed, it will be difficult to judge whether the PM nonattainment problem is widespread enough to be a driver for renewables. This monitoring data should be available by the middle of 2001 .

\section{Option 2: Establishing Renewable Incentives as Part of Emission Trading Alternative to BART Under Regional Haze Program}

\section{Description}

As previously noted, states have the option of either adopting emission limits based on BART or implementing alternative measures, such as an emission-trading program, that will allow much greater flexibility to achieve the necessary emission reductions. Federal support for a flexible cap-and-trade program could be linked with a request to include a renewable set-aside as a component of each state's system. This approach would be similar to that adopted by states implementing $\mathrm{NO}_{\mathrm{x}}$ controls to address ozone nonattainment concerns. These provisions ultimately would be incorporated into the first visibility SIPs. ${ }^{166}$

\section{Benefits}

- Nationwide potential. Although most of the Class I areas targeted by the regional haze program are located in the West, the regulations apply nationwide to address pollutant transport. Thus, unlike the $\mathrm{NO}_{\mathrm{x}}$ SIP call and OTC programs discussed above, the regional haze trading program could potentially apply nationwide.

\section{Barriers}

- State implementation. As in the $\mathrm{NO}_{\mathrm{x}}$ programs discussed above, implementing the trading program is left to the states, which have considerable discretion regarding the type of program they implement.

Option 3: Pursue Renewable Energy Alternatives Under the GCVTC Portion of the Regional Haze Regulations

\section{Description}

Although neither Congress nor the EPA has clearly embraced renewable energy as a solution to the nation's regional haze problem, the seeds have been planted in the GCVTR regulations. As noted above, the GCVTR alternative sets goals for renewable energy use in the GCVTR and requires states to monitor compliance with those goals. If the states fail to achieve these goals, they must implement an emission-trading program. The

\footnotetext{
166 As indicated in Appendix E, the first SIP submissions will not be due until approximately 2004-2006, one year after the EPA designates $\mathrm{PM}_{2.5}$ areas as attainment, nonattainment, or unclassifiable.
} 
proposed backstop trading program submitted to the EPA by the WRAP in September would award 2.5 tons of $\mathrm{SO}_{2}$ allocations per MW of installed nameplate capacity per year to renewable sources.

\section{Benefits}

- Momentum. Unlike other trading programs, the GCVTR regulations and WRAP proposal specifically address renewables. Assuming these elements are implemented, the program should provide a modest boost for the renewable industry.

\section{Barriers}

- Limited geographic scope. Participation in the GCVTC program is limited to the nine states in the region.

\section{Strategy for Implementing}

The visibility program is still in its preliminary stages. As a result, there are numerous opportunities to shape the program so as to promote renewables. As noted in Section V above, the EPA intends to issue final BART guidance shortly; the EPA will likely follow with guidance concerning emission trading and other programs that can be implemented as BART substitutes. The renewable industry should participate in the development and review of these documents to ensure that their interests are addressed. With respect to the GCVTR, the WRAP has issued its guidance on the "backstop" emission-trading program that includes allowances for renewables. The renewables industry should review this proposal carefully to ensure that a workable trading program is implemented in the region.

\section{Greenhouse Gases}

\section{Introduction}

In many ways, the regulation of GHG is the most difficult subject addressed in this report. Previous sections have addressed policies concerning pollutants that are primarily local or regional in scope. The topic of GHG controls is inherently more complex because of its international dimensions. This is not to say, however, that national, state, or even local governments are unimportant in climate change policy. On the contrary, while there are several important objectives to be achieved for renewables in international negotiations, most of the opportunities to promote renewables through climate change polices will arise at the national level. Thus, in the United States, federal and state energy and environmental officials will likely be the ones to design and implement climate change requirements.

Any effort to promote renewables through regulating $\mathrm{CO}_{2}$ and other GHGs must reconcile two arguably competing concerns. First, GHGs, in particular $\mathrm{CO}_{2}$, are emitted in significantly greater quantities than the other contaminants addressed thus far in this report. Studies suggest that programs to regulate $\mathrm{CO}_{2}$ offer perhaps the greatest opportunity to promote renewables. For example, one recent analysis suggests that properly structured markets for tradable GHG credits are likely to have a revenue enhancement potential at least double that of other pollutants. Unfortunately, political fallout from the international climate change negotiations has inhibited discussion of $\mathrm{CO}_{2}$ controls domestically. As discussed in Section VI above, several key Congressional leaders are strongly opposed to the recent international agreement on GHG, to the point of enacting a ban on the use of federal funds for any GHG programs. However, some of this political opposition seems to be disappearing, as both presidential candidates in the 2000 election endorsed multi-pollutant reduction bills regulating electric power plants that included $\mathrm{CO}_{2}$ reductions. ${ }^{167}$

167 See, e.g., http://www.gerogebush.com/Media/PDFs/NaturalEnergyPolicy.pdf. 
With these two broad considerations in mind, we have identified several program alternatives for promoting renewables through the regulation of GHG emissions.

- Option 1: Developing streamlined mechanisms for emission trading, CDM and joint implementation programs.

- Option 2: Improving national and international awareness of the potential benefits of renewable energy and the opportunities for promoting renewables through various programs (RPS, EPS, SBCs).

- Option 3: Restricting either international emission trading of $\mathrm{CO}_{2}$ or reliance on carbon sequestration to boost renewables, or both.

- Option 4: Adopting a cap-and-trade program for $\mathrm{CO}_{2}$.

For the reasons set forth below, we believe that Options 1 and 2 present the best opportunities at the international level to boost renewables. Long-term, the financial benefits to renewables of a $\mathrm{CO}_{2}$ trading program justify pursuing Option 4, despite the strong opposition in some quarters to the regulation of $\mathrm{CO}_{2}$. These options are discussed in detail below.

\section{Option 1: Developing Streamlined Mechanisms for Emission Trading, CDM and Joint Implementation Programs/Option 2: Improving National/International Awareness of Benefits of Renewables and Opportunities for Promoting Renewables}

\section{Description}

Renewable energy projects tend to be small relative to conventional fossil fuel-fired power plants. Their small scale makes them extremely sensitive to administrative and other similar "costs." It is, therefore, crucial that any emission trading or other program developed during the international negotiation process be streamlined enough to make participation by small-scale projects feasible and cost-effective. During international negotiations, this means that the United States and representatives of the renewables industry should advocate strongly for the development of a streamlined mechanism by which renewables could be "certified" for eligibility to receive tradable credits in any international CDM or other trading program.

More generally, the renewables industry should become more involved in influencing current climate change negotiations. Although participants are generally aware that renewables present a clean alternative to conventional fossil fuel-fired plants, there appears to be a perception that renewables are too limited, in terms of size and geography, to ever serve a large share of the energy market. This perception must be addressed if renewables are to assume a significant role in strategies to reduce GHG emissions.

\section{Barriers}

- Complexity of negotiation process. Perhaps the chief barrier to boosting renewables at the international level is the sheer unwieldiness of the international negotiation and implementation process. The negotiations involve dozens of committees and hundreds of participants, each with different interests and agendas. Understanding the negotiation process, let alone participating, is a difficult proposition. Moreover, the international negotiations are only one small component of the implementation process. As noted above, the actual programs to reduce GHG will be implemented at the national level, presumably in conformance with the broad outlines established internationally. 


\section{Option 3: Restricting International Emission Trading of $\mathrm{CO}_{2}$ and/or Reliance on Carbon Sequestration to Boost Renewables}

\section{Description}

As with any emission-trading program, a key factor in boosting renewables is ensuring that the cap is low enough to allow renewables to become more competitive relative to other options, such as placing additional controls on conventional fossil plants. In the climate change arena, the emission goals already have been set. However, concerns have arisen about the unrestricted use of emission trading to help achieve these goals. As noted in Section VI, several countries, including Russia and the Ukraine, received relatively generous emission allowances, in large part because their economies collapsed after the 1990 baseline date, leaving them with actual emissions well below their GHG emission-reduction target. These excess emissions could be sold on the open market to countries looking for inexpensive alternatives for achieving their own emission reduction goals. In addition, as discussed in Section VI, countries have the option of pursuing "carbon sequestration" projects such as planting forests to meet their GHG goals. One alternative for boosting renewables is to promote restrictions on the use of emission trading and carbon sequestration as compliance alternatives. These restrictions would force countries to pursue alternatives, such as construction of renewable energy projects, to achieve their GHG reduction goals.

\section{Barriers}

- Administration opposition. Politically, it would be extremely difficult for the renewables industry to advocate restrictions on the use of trading and other flexible mechanisms. From the outset, representatives of the United States have pushed hard for both carbon sequestration and unrestricted trading. Thus, the renewables industry would have difficulty finding allies within the Administration that would support these alternatives.

- Transaction costs. Restricting emission trading of $\mathrm{CO}_{2}$ would increase transaction costs and complicate efforts to develop a streamlined system for certifying credits from renewable energy projects. It could also have unintended consequences that harm renewables. For example, renewable energy developers may be reluctant to participate in a CDM project if it is unclear whether the emission reductions generated could be freely traded.

\section{Option 4: Adopting a Cap-and-Trade Program for $\mathrm{CO}_{2}$}

\section{Description}

Congress could enact legislation authorizing a cap-and-trade program for $\mathrm{CO}_{2}$ in the United States similar to those being implemented for other pollutants. In the alternative, states could assume responsibility for adopting a similar program. At least one of the bills introduced in Congress to expand emission trading (H.R. 4861) includes a $\mathrm{CO}_{2}$ cap-and-trade program.

\section{Benefits}

- Revenue potential. As noted above, $\mathrm{CO}_{2}$ is emitted in larger quantities from fossil fuel-fired plants than any other pollutant. As a result, the revenue potential for renewables under a cap-and-trade or other similar market-based program is considerable. 


\section{Barriers}

- Political opposition. As noted above, there is considerable opposition in Congress to any program regulating GHGs. Despite this opposition, bills have been developed or introduced that propose to cap $\mathrm{CO}_{2}$ emissions, suggesting that there is some potential for such legislation to succeed. In addition, both presidential candidates have endorsed multi-pollutant reduction bills that include $\mathrm{CO}_{2}$.

- Non-criteria status. Unlike the other pollutants discussed, no NAAQS for $\mathrm{CO}_{2}$ has been established. This fact means that states are not compelled to demonstrate compliance with a $\mathrm{CO}_{2}$ standard to fulfill their obligations under the CAA, eliminating an important incentive for states to develop programs to address $\mathrm{CO}_{2}$ emissions.

\section{Strategies for Implementing}

Any strategy for promoting renewables at the international level depends on two factors: knowledge and advocacy. Renewable advocates must track the international negotiations and identify opportunities to advocate on behalf of the industry. Specific avenues to pursue include tracking international climate change negotiations to increase understanding of the process and to identify opportunities to advocate for renewables and identifying groups or individuals who are already involved in the climate change negotiations and providing them with information and/or proposals to improve the opportunities for renewables.

At the national level, the renewables industry should pursue developing a market-based $\mathrm{CO}_{2}$ trading program in light of the significant revenue potential such a program offers. As with the other programs discussed, the first step is to review and evaluate current proposals.

\section{Multi-Pollutant Program}

\section{Introduction}

Until now, the discussion of recommended strategies has focused primarily on changes to individual pollutant control programs at the federal or state level. An alternative strategy is to transcend this "pollutant-by-pollutant" approach by establishing a multiple pollutant credit allocation system. Under this approach, an emissionallowance program, whether traditional or output-based, would address emissions of multiple contaminants. The program would include a specific role for renewables, in the form of set-asides or other mechanisms, such as a RPS or EPS.

\section{Benefits}

- Full recognition of environmental benefits of renewables. As previously suggested, existing allowance programs have not yet advantaged renewables, in part because the financial benefits associated with awarding allowances to renewables for a single contaminant are insufficient to offset the higher up-front costs for such facilities or are too small to justify the administrative resources needed to participate. A multipollutant allowance system would more fully recognize and compensate the environmental costs avoided by substituting renewable for conventional electric generation.

- Simplicity. If all of the various emission-trading programs currently in existence or contemplated are fully implemented, compliance with the various programs may become extremely difficult. These high administrative costs may ultimately discourage renewables from participating. A multi-pollutant emissiontrading regime implemented in place of multiple single-pollutant programs would be much simpler to administer. 
- Elimination of "waste." The existing multi-program approach has been criticized by some in industry as wasteful. Facilities in the Northeast confronted by the need to install $\mathrm{SO}_{2}$ controls to satisfy their obligations under the acid rain program are now faced with additional obligations under the OTC MOU and, potentially, under the SIP call and 126 petition requirements. Long term, additional requirements may be implemented to limit GHG emissions. In many cases, the cumulative costs of complying with these separate requirements are greater than if the various programs were coordinated. For renewables, a coordinated program means that all of the environmental benefits are realized at once, making such projects more cost-effective at the outset.

\section{Barriers}

- Eliminating existing programs. Once adopted, regulations frequently assume a life of their own. As a result, it may be difficult to eliminate the existing single pollutant trading schemes in favor of a more efficient multi-pollutant one. Difficulties in phasing out existing programs may discourage policy makers from pursuing this alternative approach. Adopting a multi-pollutant scheme in addition to the existing programs could lead to dissatisfaction with emission trading, or with trading generally, if multiple programs lead to administrative burdens, higher costs, and other problems.

- Role of $\mathrm{CO}_{2}$. Renewables arguably would realize the greatest environmental benefit from a multi-pollutanttrading scheme that includes $\mathrm{CO}_{2}$. As previously discussed, however, any program that includes $\mathrm{CO}_{2}$ could prove controversial in Congress, at least in the short term.

\section{Program Elements}

In keeping with the benefits and barriers outlined above, a model multi-pollutant-trading program could include the following basic components:

- Cap on emissions of $\mathrm{SO}_{2}, \mathrm{NO}_{x}$, and possibly $\mathrm{CO}_{2}$. The program would cap emissions from electric generating facilities at a level sufficiently below current emission levels to provide significant air quality benefits and to create an improved market for renewables.

- Establish allowance set-aside or a direct output allocation for renewables. If an allowance set-aside is chosen, initially at least $5 \%$ of all allowances should be set aside for renewable energy projects. This figure should increase gradually as the program matures.

- Create a simplified mechanism for allocating allowances to renewables. To encourage participation by renewables, any program should include simple formulae for allocating emission allowances to common renewable projects such as wind farms and solar projects.

- Prohibit inter-pollutant trading. A common objection to multi-pollutant programs is that the environmental impacts of various contaminants differ. This concern can be addressed by managing each pollutant separately and prohibiting the substitution of emission credits for different pollutants.

- Include other program alternatives. To further encourage renewables, any multi-pollutant-trading program should be implemented in tandem with other programs, such as an RPS. The RPS would ensure the development of at least some minimum level of renewable generating capacity; the multi-pollutant emissiontrading component would introduce additional flexibility for regulated entities and would serve to popularize renewables as a compliance option. 
- Consider integrating federal emission trading programs. As noted above, a new multi-pollutant-trading program could complicate compliance unless the number of existing trading programs is reduced. Although Congress is unlikely to revise the CAA to prohibit states from pursuing emission trading as an option for SIP compliance, Congress may be willing to better integrate the various federally administered programs.

Although this report is focused on how renewable energy can participate in CAA cap-and-trade programs, energy efficiency could participate in largely the same way. There are a number of circumstances in which renewable energy and energy efficiency can be combined or packaged, both for enhanced environmental value and improved investment payback. This is particularly true for large corporate, governmental, or institutional electric consumers. Clean air credit allocation and award systems for renewables should anticipate and encourage such packaging by making it easy for vendors and customers to seek clean air credits for combined renewable and efficiency investments.

\section{Strategies for Implementing}

Industry, regulators, and even some environmental groups agree that a multi-pollutant-trading program presents the best opportunity for regulating emissions from utilities. As recently as this May, several members of the Senate Clean Air Subcommittee expressed an interest in the multi-pollutant approach. The chief obstacles to implementation are the difficulties associated with crafting a program that will satisfy all constituencies and integrating that program into the existing CAA. The first step toward implementing a multi-pollutant program is to review and evaluate existing proposals. Several proposals have been circulated in recent years that address multiple pollutants. These proposals should be reviewed: (1) to assess their possible impact on renewables, and (2) to determine their "political viability." This assessment can serve as a basis for developing legislation within the broad framework outlined above. 


\section{Section IX - Conclusion}

As this report makes clear, the existing CAA offers opportunities to promote renewable energy in conjunction with various state and federally administered programs such as the OTR emission-trading program, $\mathrm{NO}_{\mathrm{x}}$ SIP call, and regional haze program. The chief advantage of using these programs to boost renewables is that the necessary changes can be made administratively, without amending the CAA. In many cases, however, these programs are limited geographically; more importantly, the CAA does not mandate the inclusion of programs to encourage renewables in the regulations implementing these programs, leaving it to the discretion of either the EPA or the states, or both, to decide what role, if any, renewables will play. As a result, without pressure from advocates for renewable energy, it is possible that these programs will be implemented without addressing renewables.

It has been 10 years since Congress last amended the CAA, and pressure is mounting in Congress and elsewhere to amend the Act to address issues, such as global warming, that are not now covered by the Act. As discussed in greater detail above, several CAA bills introduced in Congress in recent sessions have included proposals to reduce the existing $\mathrm{SO}_{2}$ cap and to establish other emission trading programs that build on the success of the Title IV acid rain program. The time is thus ripe to advocate for changes to the CAA consistent with the options identified in Section VIII above that will allow renewables to participate fully in emission trading and other similar programs. 


\section{Appendix A}

\section{Summary of Key Clean Air Act Regulatory Developments}

\section{Title IV Acid Rain Program}

\begin{tabular}{|c|c|c|}
\hline SUMMARY & CITATION & COMMENT \\
\hline $\begin{array}{l}\text { Special allowance reserve. Regulations establishing special allowance } \\
\text { reserve making } 2.8 \% \text { of allowances available for auction to new sources, } \\
\text { including independent power producers. }\end{array}$ & $\begin{array}{l}58 \text { Fed. Reg. } 3590 \text { (Jan. } 11 \\
\text { 1993) (codified at } 40 \text { CFR § } \\
\text { 73.27). }\end{array}$ & \\
\hline $\begin{array}{l}\text { Allowance allocation and tracking. Procedures for allocating } \mathrm{SO}_{2} \\
\text { allowances among sources, tracking, holding, and transfer of allowances } \\
\text { and deduction of allowances for compliance and sale of allowances. }\end{array}$ & $\begin{array}{l}\text { 58 Fed. Reg. } 3590 \text { (Jan. 11, } \\
\text { 1993) (codified at } 40 \text { CFR Part } \\
\text { 73). }\end{array}$ & \\
\hline $\begin{array}{l}\text { Monitoring. Regulations establishing Title IV air emission-monitoring } \\
\text { requirements. }\end{array}$ & $\begin{array}{l}\text { 58 Fed. Reg. } 3717 \text { (Jan. 11, } \\
\text { 1993) (codified at } 40 \text { CFR Part } \\
\text { 73, Subpart E). }\end{array}$ & \\
\hline $\begin{array}{l}\text { Penalties. Regulations governing imposition of excess emissions } \\
\text { penalties. }\end{array}$ & $\begin{array}{l}\text { 58 Fed. Reg. } 3757 \text { (Jan. 11, } \\
\text { 1993) (codified at } 40 \text { CFR Part } \\
\text { 77). }\end{array}$ & \\
\hline $\begin{array}{l}\text { Permitting. Regulations establishing air permit program requirements } \\
\text { for Title IV sources. }\end{array}$ & $\begin{array}{l}\text { 58 Fed. Reg. } 3590 \text { (Jan. 11, } \\
\text { 1993) (codified at } 40 \text { CFR Part } \\
\text { 72). }\end{array}$ & \\
\hline $\begin{array}{l}\text { Conservation and Renewable Energy Reserve Program (CRER). } \\
\text { Regulations implementing allowance set-aside for energy efficiency and } \\
\text { renewable energy projects. }\end{array}$ & $\begin{array}{l}58 \text { Fed. Reg. } 3695 \text { (Jan. 11, } \\
\text { 1993) (codified at } 40 \text { CFR Part } \\
\text { 73, Subpart F). }\end{array}$ & \\
\hline
\end{tabular}




\section{Appendix A}

\section{Summary of Key Clean Air Act Regulatory Developments}

\section{Ozone and Nitrogen Oxide Requirements (CAA Titles I and IV)}

\begin{tabular}{|c|c|c|}
\hline SUMMARY & CITATION & COMMENTS \\
\hline $\begin{array}{l}\text { SIP call. Rulemaking finding that certain states in Ozone Transport } \\
\text { Assessment Group region are contributing to ozone nonattainment in } \\
\text { northeastern states and requiring reductions in } \mathrm{NO}_{\mathrm{x}} \text { emissions (SIP call), } \\
\text { including voluntary implementation of emission-trading program. }\end{array}$ & $\begin{array}{l}63 \text { Fed. Reg. } 57356 \text { (Oct. } 27 \text {, } \\
\text { 1998) (model trading rule } \\
\text { codified at } 40 \text { CFR Part 96). }\end{array}$ & $\begin{array}{l}\text { A federal court upheld the SIP call in a decision } \\
\text { earlier this year. See Appendix B. }\end{array}$ \\
\hline $\begin{array}{l}\text { Section } 126 \text { findings. Finding on CAA } \S 126 \text { petitions filed by four } \\
\text { northeastern states that specific facilities in } 12 \text { states and the District of } \\
\text { Columbia are contributing to ozone problems in the petitioning states and } \\
\text { establishing mandatory emission trading program. }\end{array}$ & $\begin{array}{l}65 \text { Fed. Reg. } 2554 \text { (Jan. 18, } \\
\text { 2000) (trading program } \\
\text { codified at } 40 \text { CFR Part 97). }\end{array}$ & $\begin{array}{l}\text { Other } 126 \text { petitions are currently pending before the } \\
\text { EPA. The } 126 \text { rulemaking has been challenged in } \\
\text { federal court. See Appendix B. }\end{array}$ \\
\hline $\begin{array}{l}\text { Title IV NO } \boldsymbol{O}_{\boldsymbol{x}} \text { standards. Regulation establishing Phase I limits on } \mathrm{NO}_{\mathrm{x}} \\
\text { emissions from certain types of boilers under Title IV acid rain program. }\end{array}$ & $\begin{array}{l}60 \text { Fed. Reg. } 18751 \text { (Apr. 13, } \\
\text { 1995) (codified at } 40 \text { CFR } \\
\text { Part 76). }\end{array}$ & \\
\hline $\begin{array}{l}\text { Title IV NO } \boldsymbol{O}_{\boldsymbol{x}} \text { standards. Regulation establishing Phase II limits on } \mathrm{NO}_{\mathrm{x}} \\
\text { emissions from certain types of boilers under Title IV acid rain program. }\end{array}$ & $\begin{array}{l}61 \text { Fed. Reg. } 67112 \text { (Dec. } 19 \text {, } \\
\text { 1996) (codified at } 40 \text { CFR } \\
\text { Part 76). }\end{array}$ & \\
\hline
\end{tabular}




\section{Appendix A}

\section{Summary of Key Clean Air Act Regulatory Developments}

\section{Visibility, Regional Haze, and Particulate Matter Programs}

\begin{tabular}{|l|l|l|}
\hline SUMMARY & CITATION & COMMENTS \\
\hline $\begin{array}{l}\text { Regional haze rule. Regulation requiring states to develop goals and } \\
\text { achieve emissions reductions to improve visibility in Class I national } \\
\text { parks and wilderness areas. }\end{array}$ & $\begin{array}{l}\text { 64 Fed. Reg. 35714 (July 1, } \\
\text { 1999) (codified at 40 CFR §§ } \\
51.300-.308)\end{array}$ & $\begin{array}{l}\text { Litigation challenging the regional haze rule is } \\
\text { pending. See Appendix B. }\end{array}$ \\
\hline $\begin{array}{l}\text { GCVTC rule. Regulation establishing optional alternative regional haze } \\
\text { program for states in the Grand Canyon Visibility Transport Region. }\end{array}$ & $\begin{array}{l}\text { 64 Fed. Reg. 35714 (July 1, } \\
\text { 1999) (codified at 40 CFR § }\end{array}$ & $\begin{array}{l}\text { States in GCVTR can implement standard regional } \\
\text { haze rule or alternative rule based on } \\
\text { Appendix C. } \\
\text { Appendations of GCVTC Report. See }\end{array}$ \\
\hline
\end{tabular}




\section{Appendix B}

\section{Status of Major Clean Air Act Litigation}

\begin{tabular}{|c|c|c|c|}
\hline CASE & ISSUES & HOLDING/STATUS & $\begin{array}{l}\text { IMPLICATIONS FOR } \\
\text { RENEWABLES }\end{array}$ \\
\hline $\begin{array}{l}\text { Michigan v. U.S. EPA, } \\
213 \text { F.3d } 663 \text { (D.C. Cir. 2000) - } \mathrm{NO}_{\mathrm{x}} \\
\text { SIP call }\end{array}$ & $\begin{array}{l}\mathrm{NO}_{\mathrm{x}} \text { SIP call regulations challenged } \\
\text { on various grounds, including: (1) } \\
\text { EPA failed to establish ozone } \\
\text { transport commission; (2) EPA's } \\
\text { scheme of uniform control is } \\
\text { arbitrary and capricious; and (3) } \\
\text { EPA impermissibly intruded on } \\
\text { statutory right of states to fashion } \\
\text { SIPs. Petitioners also challenged } \\
\text { inclusion of individual states in SIP } \\
\text { call. }\end{array}$ & $\begin{array}{l}\text { Court of Appeals rejected challenge, } \\
\text { with certain limited state-specific } \\
\text { exceptions. Stay of SIP call issued } \\
\text { by the court has been lifted and SIP } \\
\text { submissions were due October } 30 \text {, } \\
2000 \text {. States must implement SIP } \\
\text { call by May } 2004 \text { (extended from } \\
2003 \text { ). A petition for review has } \\
\text { been filed with the Supreme Court. }\end{array}$ & $\begin{array}{l}\text { EPA will resume implementation of } \\
\mathrm{NO}_{\mathrm{x}} \text { SIP call, which includes } \\
\text { voluntary emission trading program. } \\
\text { Program does not include specific } \\
\text { role for renewables although } \\
\text { opportunities exist at state level } \\
\text { where SIP call will be implemented. }\end{array}$ \\
\hline $\begin{array}{l}\text { Appalachian Power Co. v. U.S. EPA, } \\
\text { Civil Action Nos. } 99-1200 ; 00-1223 \\
\text { - State } 126 \text { petitions }\end{array}$ & $\begin{array}{l}\text { Actions address whether EPA has } \\
\text { authority to issue CAA } \S 126 \\
\text { rulemaking based on statutory } \\
\text { language of CAA and raise various } \\
\text { technical challenges to the } \\
\text { regulation. }\end{array}$ & $\begin{array}{l}\text { Court severed case into two parts, } \\
\text { one related to one-hour standard and } \\
\text { one related to eight-hour standard. } \\
\text { Briefing is underway related to one- } \\
\text { hour standard. Oral argument was } \\
\text { set for December } 15,2000 \text {. }\end{array}$ & $\begin{array}{l}\text { Petitioning states must implement a } \\
\text { mandatory emission trading program. } \\
\text { Although short-term the program } \\
\text { does not include re-newables, EPA } \\
\text { proposes to adopt an output-based } \\
\text { allowance allocation program } \\
\text { beginning in } 2008 \text { that could be } \\
\text { crafted to include renewables. }\end{array}$ \\
\hline
\end{tabular}




\section{Appendix B}

\section{Status of Major Clean Air Act Litigation}

\begin{tabular}{|c|c|c|c|}
\hline CASE & ISSUES & HOLDING/STATUS & $\begin{array}{l}\text { IMPLICATIONS FOR } \\
\text { RENEWABLES }\end{array}$ \\
\hline $\begin{array}{l}\text { American Corn Growers Ass' } n \text { v. } \\
\text { U.S. EPA, Civil Action No. 99-1348 } \\
\text { - Regional haze rule }\end{array}$ & Briefs not yet filed. & $\begin{array}{l}\text { Litigation on hold since Spring } 2000 \\
\text { pending EPA's response to request } \\
\text { for administrative reconsideration. } \\
\text { EPA is expected to deny petitions. }\end{array}$ & \\
\hline $\begin{array}{l}\text { American Trucking Association v. } \\
\text { U.S. EPA, } 175 \text { F.3d } 1027 \text { (D.C. Cir. } \\
\text { 1999), cert. granted, } 120 \text { S. Ct. } 2003 \\
\text { (2000) - Revised ozone and } \text { PM }_{2.5} \\
\text { standards }\end{array}$ & $\begin{array}{l}\text { Various industry groups challenged } \\
\text { EPA's authority to promulgate new } \\
\text { stricter } 8 \text {-hour standards for ozone } \\
\text { and new } \mathrm{PM}_{2.5} \text { standard on various } \\
\text { grounds. }\end{array}$ & $\begin{array}{l}\text { Court concluded that the construction } \\
\text { of CAA §109 relied on by EPA in } \\
\text { promulgating the NAAQS "effects an } \\
\text { unconstitutional delegation of } \\
\text { power" since EPA "lacks any } \\
\text { determinate criterion" for deciding } \\
\text { where to set standard. Court } \\
\text { remanded standard back to EPA to } \\
\text { give it an opportunity to reinterpret } \\
\text { the CAA to define more precisely } \\
\text { where to draw line in setting NAAQS } \\
\text { to protect public health. Court left } \\
\text { new ozone standard in place but } \\
\text { declared it could not be enforced; } \\
\text { PM }{ }_{2.5} \text { standard remained in place } \\
\text { pending remand to EPA. The } \\
\text { Supreme Court heard argument in the } \\
\text { case in November } 2000 \text { and is } \\
\text { expected to issue a decision next } \\
\text { year. }\end{array}$ & $\begin{array}{l}\text { The implications of the decision for } \\
\text { renewables are largely indirect. } \\
\text { States are implementing programs to } \\
\text { monitor for } \mathrm{PM}_{2.5} ; \text { long term, stricter } \\
\text { standards for both ozone and PM } \\
\text { present opportunities for renewables, } \\
\text { which may present an alternative to } \\
\text { controlling emissions of these } \\
\text { contaminants from other sources } \\
\text { through cap-and-trade programs and } \\
\text { other similar mechanisms. }\end{array}$ \\
\hline
\end{tabular}




\section{Appendix C}

\section{Key Federal/State/Regional Reports, Agreements, and Guidance Documents}

\section{Ozone and Nitrogen Oxide Requirements (CAA Titles I and IV)}

\begin{tabular}{|c|c|c|}
\hline TITLE & DESCRIPTION & COMMENT \\
\hline $\begin{array}{l}\text { Memorandum of Understanding Among the } \\
\text { States of the Ozone Transport Commission on } \\
\text { Development of a Regional Strategy Concerning } \\
\text { the Control of Stationary Sources of Nitrogen } \\
\text { Oxide Emissions (Sept. 24, 1994). }\end{array}$ & $\begin{array}{l}\text { Agreement among states in the Northeast Ozone } \\
\text { Transport Region (excluding Virginia) to } \\
\text { promulgate regulations to reduce summertime } \mathrm{NO}_{\mathrm{x}} \\
\text { emissions. }\end{array}$ & $\begin{array}{l}\text { The participating MOU states have adopted state } \\
\text { regulations implementing the MOU, including } \\
\text { emission-trading programs; several states have } \\
\text { included set-asides for renewables as part of their } \\
\text { trading programs. }\end{array}$ \\
\hline $\begin{array}{l}\text { Memorandum of Understanding Among the } \\
\text { States of the Ozone Transport Commission } \\
\text { Regarding the Development of Specific Control } \\
\text { Measures to Support Attainment and } \\
\text { Maintenance of the Ozone National Ambient Air } \\
\text { Quality Standards (June 1, 2000). }\end{array}$ & $\begin{array}{l}\text { Agreement among states in the Northeast Ozone } \\
\text { Transport Region to evaluate by Winter } 2002 \\
\text { specific ozone control measures, including system } \\
\text { benefits charges, environmental performance } \\
\text { standards, and renewable energy and energy } \\
\text { efficiency programs. }\end{array}$ & \\
\hline $\begin{array}{l}\text { EPA, Office of Atmospheric Programs, Guidance } \\
\text { on Establishing an Energy Efficiency and } \\
\text { Renewable Energy (EE/RE) Set-Aside in the } N O_{x} \\
\text { Budget Trading Program (Mar. 1999). }\end{array}$ & $\begin{array}{l}\text { Guidance summarizes the key elements of an } \\
\text { energy efficiency and renewable energy set-aside } \\
\text { under the emission-trading program offered as an } \\
\text { alternative for states regulated under the SIP call's } \\
\mathrm{NO}_{\mathrm{x}} \text { Budget Trading Program. }\end{array}$ & $\begin{array}{l}\text { Guidance is one of three documents the EPA } \\
\text { anticipates issuing to assist states in implementing } \\
\text { trading programs under the SIP call. }\end{array}$ \\
\hline $\begin{array}{l}\text { EPA, Developing and Updating Output-Based } \\
N O_{x} \text { Allowance Allocations (May } 8,2000 \text { ) }\end{array}$ & $\begin{array}{l}\text { Guidance focuses on technical issues associated } \\
\text { with implementing an output-based allocation } \\
\text { program under the } \mathrm{NO}_{\mathrm{x}} \text { SIP call, including } \\
\text { procedures for allocating allowances and obtaining } \\
\text { information to enable sources to update allocations } \\
\text { periodically. }\end{array}$ & $\begin{array}{l}\text { The EPA intends to use the output-based allocation } \\
\text { method beginning in } 2008 \text { under the CAA } \S 126 \\
\text { Federal } \mathrm{NO}_{x} \text { Budget Trading program. States also } \\
\text { have the option of adopting output-based approach } \\
\text { under SIP call. }\end{array}$ \\
\hline $\begin{array}{l}\text { EPA, Economic Incentive Program Guidance } \\
\text { (Sept. 1999) (DRAFT). }\end{array}$ & $\begin{array}{l}\text { Guidance outlines necessary components of } \\
\text { discretionary "economic incentive programs" such } \\
\text { as emission trading, emission averaging, "open } \\
\text { market trading," that may be implemented by states } \\
\text { to achieve emission reductions required to meet or } \\
\text { maintain compliance with NAAQS. }\end{array}$ & \\
\hline
\end{tabular}




\section{Appendix C}

\section{Key Federal/State/Regional Reports, Agreements and Guidance Documents}

\section{Visibility, Regional Haze, and Particulate Matter Programs}

\begin{tabular}{|l|l|l|}
\hline TITLE & DESCRIPTION & COMMENT \\
\hline $\begin{array}{l}\text { Report of the Grand Canyon Visibility Transport } \\
\text { Commission to the United States Environmental } \\
\text { Protection Agency (June 1996). }\end{array}$ & $\begin{array}{l}\text { Contains recommendations of GCVTC to be used } \\
\text { by the EPA as guidance in developing visibility } \\
\text { and regional haze strategies for states in the } \\
\text { GCVTR. }\end{array}$ & $\begin{array}{l}\text { The EPA included some of the recommendations } \\
\text { from the GCVTC's Report in its alternative } \\
\text { regional haze program for states in the GCVTR. }\end{array}$ \\
\hline $\begin{array}{l}\text { Western Regional Air Partnership (WRAP), } \\
\text { Major Industrial Sources of Sulfur Dioxide in } \\
\begin{array}{l}\text { Nine Western States and a Backstop Market } \\
\text { Trading Program (Sept. 29, 2000). }\end{array}\end{array}$ & $\begin{array}{l}\text { Identifies key elements of backstop emission- } \\
\text { trading program that must be implemented in the } \\
\text { event voluntary measures by states implementing } \\
\text { GCVTR visibility regulations do not achieve the } \\
\text { required visibility improvements. The report } \\
\text { includes specific provisions for allocating } \\
\text { allowances among sources and states, including } \\
\text { provisions addressing renewables. }\end{array}$ & \\
\hline
\end{tabular}




\section{Appendix C}

Key Federal/State/Regional Reports, Agreements and Guidance Documents

\section{Greenhouse Gas Reduction Programs}

\begin{tabular}{|l|l|l|}
\hline TITLE & DESCRIPTION & COMMENTS \\
\hline UN FCCC, Kyoto Protocol to the United Nations & $\begin{array}{l}\text { Agreement among developed countries to reduce } \\
\text { Framework Convention on Climate Change (Dec. } \\
\text { greenhouse gas emissions by specified percentages } \\
\text { during the 2008-2012 budget period. }\end{array}$ & $\begin{array}{l}\text { Agreement has not yet been ratified by United } \\
\text { States. Negotiations concerning key aspects of the } \\
\text { agreement are ongoing. }\end{array}$ \\
\hline
\end{tabular}




\section{Appendix D}

\section{Summary of Recent CAA Emission Trading Legislation}

\begin{tabular}{|c|c|c|c|c|}
\hline LEGISLATION & $\begin{array}{l}\text { SULFUR DIOXIDE } \\
\left(\mathrm{SO}_{2}\right) \text { PROVISIONS }\end{array}$ & $\begin{array}{l}\text { NITROGEN OXIDE } \\
\left(\text { NO }_{\mathbf{X}}\right) \text { PROVISIONS }\end{array}$ & $\begin{array}{l}\text { CARBON DIOXIDE } \\
\left(\mathrm{CO}_{2}\right) \text { PROVISIONS }\end{array}$ & OTHER \\
\hline $\begin{array}{l}\text { H.R. } 2900 \mathrm{IH}-\text { Clean } \\
\text { Smokestacks Act of } 1999 \\
\text { Sponsor: Waxman } \\
\text { Cosponsors: } 116 \\
\text { Introduced: } 9 / 21 / 99\end{array}$ & $\begin{array}{l}\text { Requires power plants to } \\
\text { reduce } \mathrm{SO}_{2} \text { emissions } 75 \% \\
\text { from } 1997 \text { levels by January } \\
2005 .\end{array}$ & $\begin{array}{l}\text { Requires power plants to reduce } \\
\mathrm{NO}_{x} \text { emissions } 75 \% \text { from } 1997 \\
\text { levels by January } 2005 \text {. }\end{array}$ & $\begin{array}{l}\text { Requires power plants to } \\
\text { reduce } \mathrm{CO}_{2} \text { emissions to } \\
1990 \text { levels by January } 2005\end{array}$ & $\begin{array}{l}\checkmark \text { Requires EPA to promulgate } \\
\text { regulations to achieve emission } \\
\text { reductions within } 2 \text { years of } \\
\text { enactment. } \\
\checkmark \text { Also restricts mercury } \\
\text { emissions. } \\
\checkmark \text { Requires older plants to } \\
\text { comply with NSPS and with } \\
\text { PSD and nonattainment NSR } \\
\text { requirements. }\end{array}$ \\
\hline $\begin{array}{l}\text { H.R. } 657 \text { - Acid } \\
\text { Deposition Control Act } \\
\text { Sponsor: Sweeney } \\
\text { Cosponsors: } 15 \\
\text { Introduced: } 2 / 19 / 99\end{array}$ & $\begin{array}{l}\text { Makes each existing } \\
\text { allowance worth } 1 / 2 \text { ton of } \mathrm{SO}_{2} \\
\text { beginning in } 2005 . \text { NOTE: } \\
\text { Reduces utility emissions of } \\
\mathrm{SO}_{2} \text { by } 50 \% \text { after } \\
\text { implementation of Phase II of } \\
\text { Title IV acid rain program. }\end{array}$ & $\begin{array}{l}\checkmark \text { Establishes } 48 \text {-state } \mathrm{NO}_{\mathrm{x}} \\
\text { allowance program; awards } \\
5,400,000 \text { allowances annually } \\
\text { for 2002-2004; } 3,000,000 \\
\text { allowances for } 2005 \text { onward. } \\
\text { NOTE: reduces utility emissions } \\
\text { of NO } \mathrm{x}_{\mathrm{x}} \text { by } 70 \% \text { from } 1990 \text { levels. } \\
\checkmark \text { Allowances authorize } 1 \text { ton } \\
\mathrm{NO}_{\mathrm{x}} \text { emissions from Oct-Apr; } 1 / 2 \\
\text { ton } \mathrm{NO}_{\mathrm{x}} \text { emissions from May- } \\
\text { Sep. } \\
\checkmark \text { Requires EPA to allocate } \\
\text { allowances among states in } \\
\text { accordance with share of total } \\
\text { electric power generated } \\
\text { nationwide. } \\
\checkmark \text { States must allocate allowances } \\
\text { among affected facilities or EPA } \\
\text { will step in. } \\
\checkmark \text { Establishes new source reserve } \\
(10 \% \text { of total allowances). } \\
\checkmark \text { Establishes allowance-tracking } \\
\text { and transfer system. }\end{array}$ & None & $\begin{array}{l}\checkmark \text { Repeals existing } \mathrm{NO}_{\mathrm{x}} \\
\text { provisions under Title IV acid } \\
\text { rain program. } \\
\checkmark \text { Requires EPA to develop } \\
\text { report "identifying objectives for } \\
\text { scientifically credible } \\
\text { environmental indicators } \\
\text { sufficient to protect sensitive } \\
\text { ecosystems" and to develop } \\
\text { additional regulations if existing } \\
\text { measures are deemed inadequate } \\
\text { to achieve goal of protecting } \\
\text { these ecosystems. } \\
\checkmark \text { Requires EPA to study } \\
\text { practicality of monitoring } \\
\text { mercury emissions from large } \\
\text { combustion units and to } \\
\text { promulgate regulations requiring } \\
\text { controls }\end{array}$ \\
\hline
\end{tabular}




\section{Appendix D}

\section{Summary of Recent CAA Emission Trading Legislation}

\begin{tabular}{|c|c|c|c|c|}
\hline LEGISLATION & $\begin{array}{l}\text { SULFUR DIOXIDE } \\
\left(\mathrm{SO}_{2}\right) \text { PROVISIONS }\end{array}$ & $\begin{array}{l}\text { NITROGEN OXIDE } \\
\left(\text { NO }_{\mathbf{X}}\right) \text { PROVISIONS }\end{array}$ & $\begin{array}{l}\text { CARBON DIOXIDE } \\
\left(\mathrm{CO}_{2}\right) \text { PROVISIONS }\end{array}$ & OTHER \\
\hline $\begin{array}{l}\text { S.172 - Acid Deposition } \\
\text { and Ozone Control Act } \\
\text { Sponsor: Moynihan } \\
\text { Cosponsors: } 11 \\
\text { Introduced: } 1 / 19 / 99 \\
\text { H.R. } 25 \text { - Same Title } \\
\text { Sponsor: S. Boehlert } \\
\text { Cosponsors: } 48 \\
\text { Introduced: } 1 / 19 / 99\end{array}$ & $\begin{array}{l}\text { Essentially identical to H.R. } \\
657 \text { (minor differences in } \\
\text { wordings). }\end{array}$ & $\begin{array}{l}\text { Essentially identical to H.R. } 657 \\
\text { with minor exceptions (different } \\
\text { schedule;; lower excess emissions } \\
\text { penalties). }\end{array}$ & None & $\begin{array}{l}\text { Essentially identical to H.R. } 657 . \\
\text { NOTE: There are minor } \\
\text { differences in dates between the } \\
\text { Senate and House versions. }\end{array}$ \\
\hline $\begin{array}{l}\text { H.R. } 4861 \text { - Clean Power } \\
\text { Act Sponsor: R. Lazio } \\
\text { Cosponsors: } 1 \text { Introduced: } \\
7 / 13 / 00\end{array}$ & $\begin{array}{l}\text { Makes each existing } \mathrm{SO}_{2} \\
\text { allowance worth 1/4 ton } \\
\text { beginning in } 2005 .\end{array}$ & $\begin{array}{l}\checkmark \text { Establishes } 48 \text {-state } \mathrm{NO}_{\mathrm{x}} \\
\text { allowance program; awards } \\
2,750,000 \text { allowances annually } \\
\text { beginning Jan. } 2005 \text {. } \\
\checkmark \text { Allowances authorize } 1 \text { ton } \\
\mathrm{NO}_{\mathrm{x}} \text { emissions from Oct-Apr; } 1 / 2 \\
\text { ton } \mathrm{NO}_{\mathrm{x}} \text { emissions from May- } \\
\text { Sept. } \\
\checkmark \text { Allowances distributed based } \\
\text { on each affected facility's share } \\
\text { of total output production. } \\
\checkmark \text { Establishes new source reserve } \\
(5 \% \text { of total allowances). } \\
\checkmark \text { Affected facility under program } \\
\text { includes } 25 \text { MW or greater } \\
\text { combustion facilities (including } \\
\text { those combusting biomass) and } \\
\text { facilities generating } 5 \mathrm{~kW} \text { or } \\
\text { greater using wind, geothermal, } \\
\text { solar thermal, or photovoltaic } \\
\text { energy. }\end{array}$ & $\begin{array}{l}\checkmark \text { Establishes } 48 \text {-state } \mathrm{CO}_{2} \\
\text { allowance program; awards } \\
1,914,000,000 \text { allowances } \\
\text { annually beginning Jan. } \\
2005 \text {. } \\
\checkmark \text { Allowances authorize } 1 \\
\text { ton } \mathrm{CO}_{2} \text { emissions. } \\
\checkmark \text { Allowances distributed } \\
\text { based on each affected } \\
\text { facility's share of total } \\
\text { output production. } \\
\checkmark \text { Establishes new source } \\
\text { reserve (5\% of total } \\
\text { allowances). } \\
\checkmark \text { Affected facility under } \\
\text { program includes } 25 \mathrm{MW} \text { or } \\
\text { greater combustion facilities } \\
\text { (including those combusting } \\
\text { biomass) and facilities } \\
\text { generating } 5 \mathrm{~kW} \text { or greater } \\
\text { using wind, geothermal, } \\
\text { solar thermal, or } \\
\text { photovoltaic energy. }\end{array}$ & $\begin{array}{l}\checkmark \text { Within } 1 \text { year of enactment } \\
\text { requires EPA to develop } \\
\text { regulations addressing } \\
\text { monitoring, allocation, } \\
\text { allowance transfer and tracking, } \\
\text { etc. } \\
\checkmark \text { Repeals existing } \mathrm{NO}_{\mathrm{x}} \\
\text { provisions under Title IV acid } \\
\text { rain program. } \\
\checkmark \text { Limits mercury emissions } \\
\text { from electric utilities. } \\
\checkmark \text { Requires establishment of } \\
\text { renewable portfolio standard if } \\
\text { total electricity supplied by } \\
\text { renewables is less than } 3 \% \text { in } \\
2004 \text {. Standard increases to } 6 \% \\
\text { in } 2010 . \text { Renewable energy } \\
\text { includes solar, wind, geothermal, } \\
\text { or biomass. } \\
\checkmark \text { Establishes net metering } \\
\text { provision. }\end{array}$ \\
\hline
\end{tabular}




\section{Appendix E}

\section{Map of Current Ozone Nonattainment Areas}

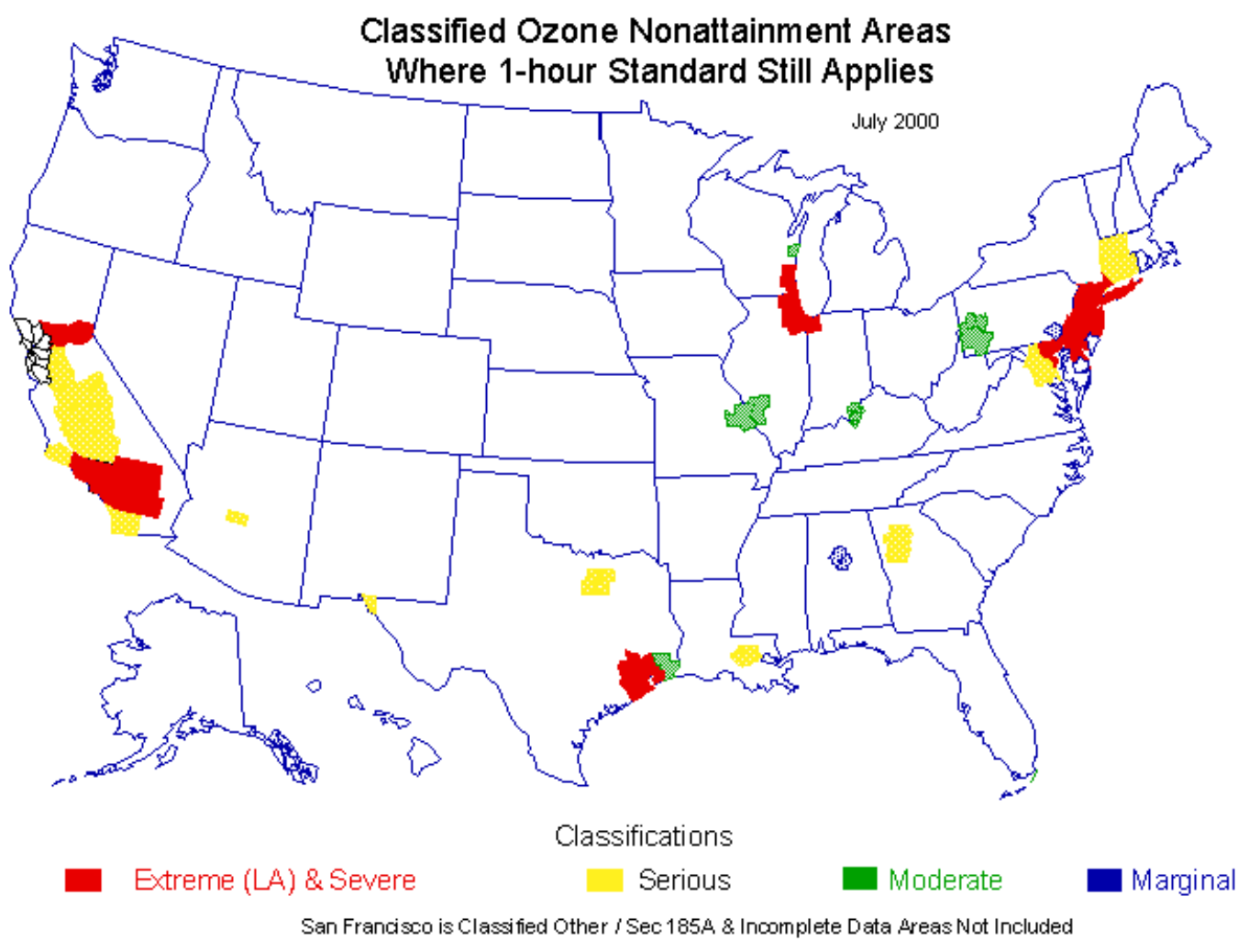




\section{Timeline for States to Implement EPA's Rule}

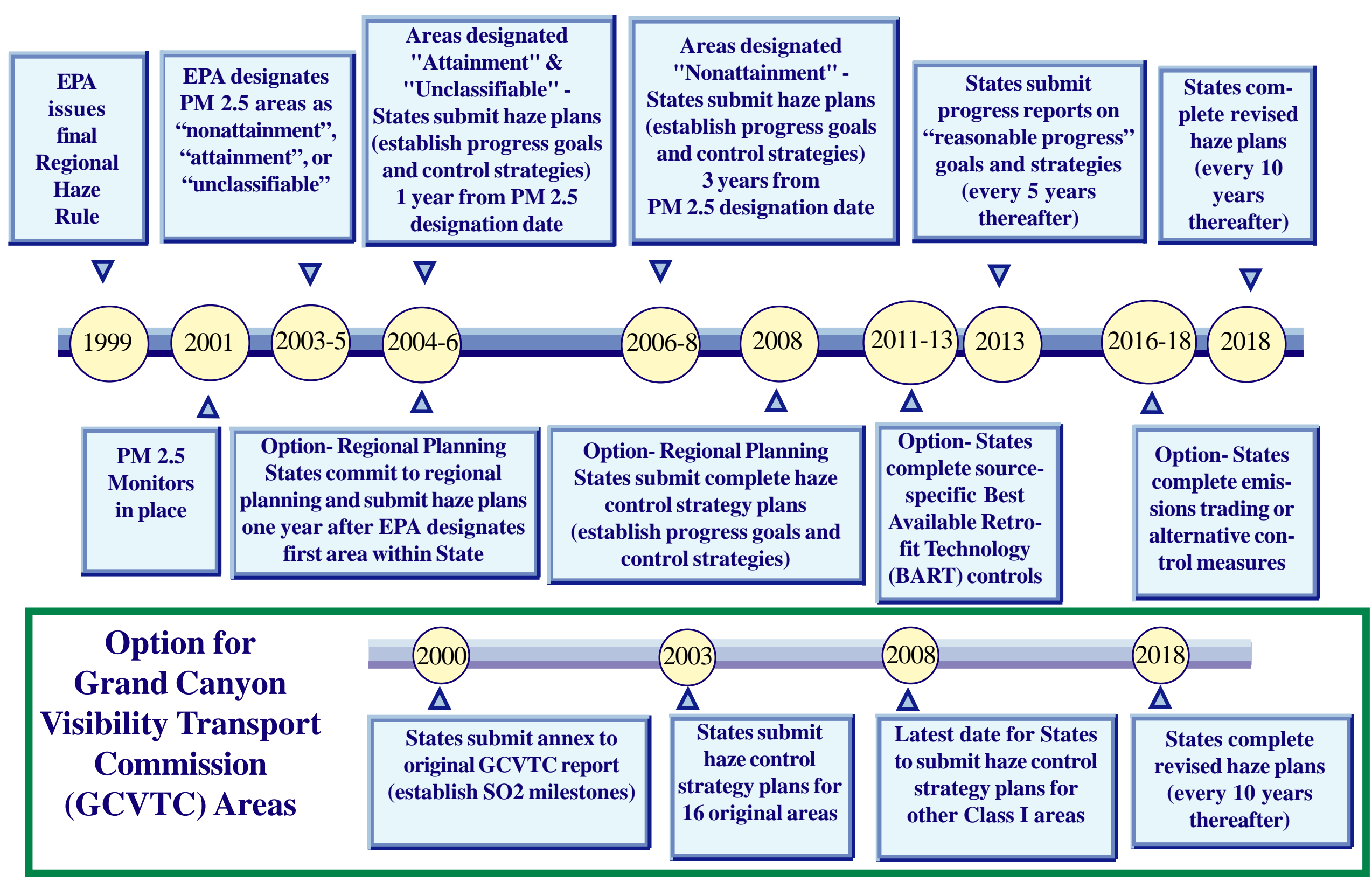




\section{Appendix G}

\begin{tabular}{|c|c|c|c|}
\hline Pollutant & $\begin{array}{l}\text { Emissions Allowance } \\
\text { Value (Dollars/Ton) }\end{array}$ & $\begin{array}{l}\text { Tons Avoided per MWh of } \\
\text { Renewable Energy }\end{array}$ & $\begin{array}{l}\text { Emissions Reduction } \\
\text { Value (Dollars/MWh) }\end{array}$ \\
\hline $\mathrm{CO}_{2}$ (low-cost allowance) & 5 & 0.6 & 3 \\
\hline $\begin{array}{l}\mathrm{CO}_{2} \text { (medium-cost } \\
\text { allowance) }\end{array}$ & 20 & 0.6 & 12 \\
\hline $\mathrm{CO}_{2}$ (high-cost allowance) & 60 & 0.6 & 36 \\
\hline $\mathrm{NO}_{\mathrm{x}}$ & 2,000 & 0.00075 & 1.5 \\
\hline $\mathrm{SO}_{2}$ & 200 & 0.006 & 1.2 \\
\hline \multicolumn{3}{|c|}{ Total value with low carbon allowance } & 5.7 \\
\hline \multicolumn{3}{|c|}{ Total value with medium carbon allowance } & 14.7 \\
\hline \multicolumn{3}{|c|}{ Total value with high carbon allowance } & 38.7 \\
\hline
\end{tabular}

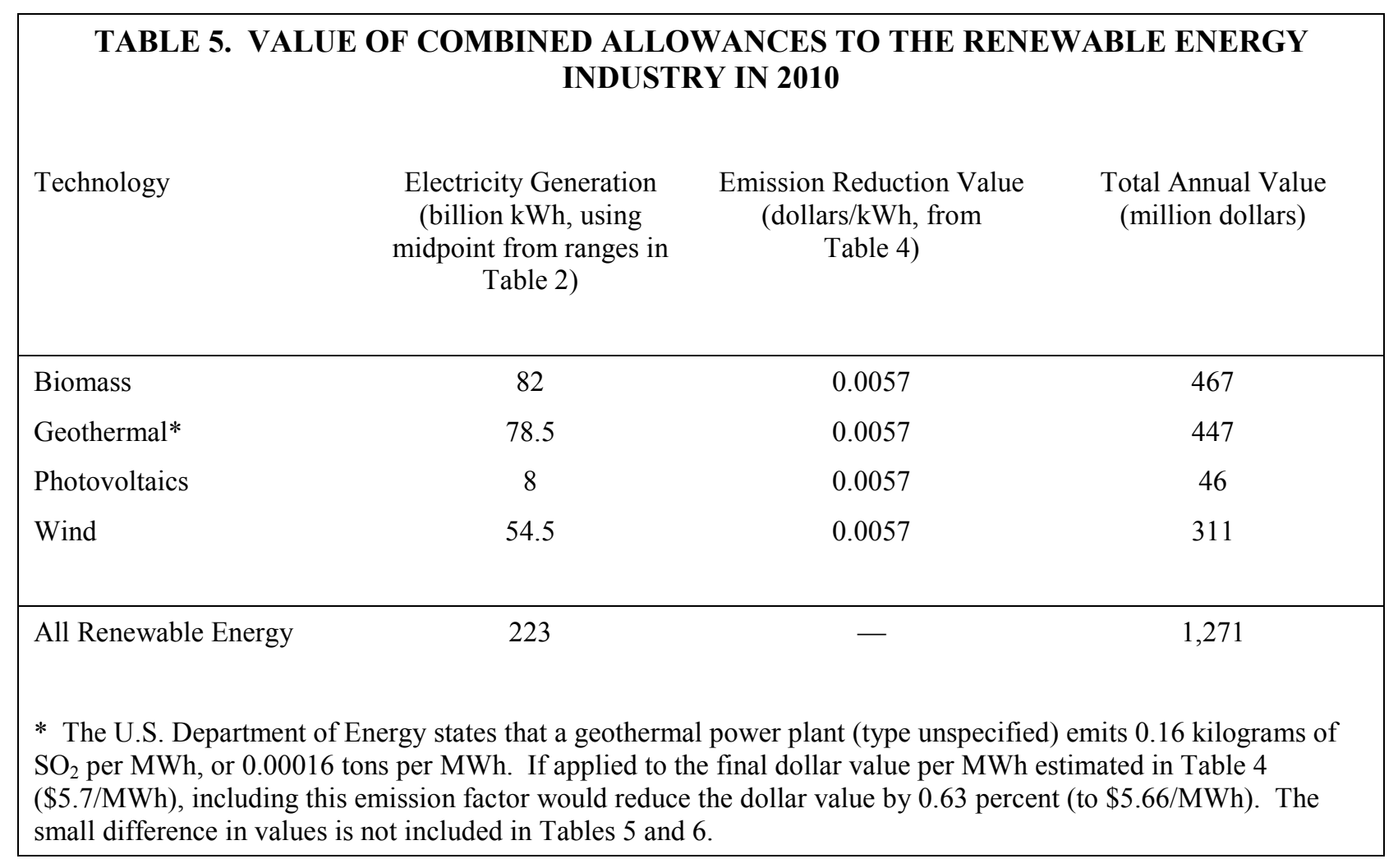

Source: D. Wooley A Guide to the Clean Air Act for the Renewable Energy Community Renewable Energy Policy Project Issue Brief \#15 (Feb. 2000). 


\section{Appendix G}

TABLE 6. ANNUAL REVENUE FOR RENEWABLE ENERGY FACILITIES ${ }^{a}$

\begin{tabular}{|c|c|c|c|c|}
\hline \multicolumn{5}{|c|}{ TABLE 6. ANNUAL REVENUE FOR RENEWABLE ENERGY FACILITIES ${ }^{a}$} \\
\hline Pollutant & $\begin{array}{l}\text { 20-MW Wind } \\
\text { Facility }\end{array}$ & $\begin{array}{l}\text { 20-MW Biomass } \\
\text { Facility }^{\mathrm{b}}\end{array}$ & $\begin{array}{l}\text { 20-MW Geothermal } \\
\text { Facility }\end{array}$ & $\begin{array}{l}\text { 20-MW Solar } \\
\text { Facility }\end{array}$ \\
\hline $\mathrm{CO}_{2}$ (low-cost allowance) & 189,746 & 419,328 & 497,952 & 104,832 \\
\hline $\begin{array}{l}\mathrm{CO}_{2} \text { (medium-cost } \\
\text { allowance) }\end{array}$ & 758,984 & $1,677,312$ & $1,991,808$ & 419,328 \\
\hline $\mathrm{CO}_{2}$ (high-cost allowance) & $2,276,951$ & $5,031,936$ & $5,975,424$ & $1,257,984$ \\
\hline $\mathrm{NO}_{\mathrm{x}}$ & 94,873 & 0 & 248,976 & 52,416 \\
\hline $\mathrm{SO}_{2}$ & 75,898 & 167,731 & 199,181 & 41,933 \\
\hline $\begin{array}{l}\text { Total with low carbon } \\
\text { allowance }\end{array}$ & 360,517 & 587,059 & 946,109 & 119,181 \\
\hline $\begin{array}{l}\text { Total with medium carbon } \\
\text { allowance }\end{array}$ & 929,755 & $1,845,043$ & $2,439,965$ & 513,677 \\
\hline $\begin{array}{l}\text { Total with high carbon } \\
\text { allowance }\end{array}$ & $2,447,722$ & $5,199,667$ & $6,423,581$ & $1,352,333$ \\
\hline Total for $\mathrm{NO}_{x}$ and $\mathrm{SO}_{2}$ only & 170,771 & 167,731 & 448,157 & 94,349 \\
\hline \multicolumn{5}{|c|}{$\begin{array}{l}\text { a Assumes a } 36.2 \% \text { capacity factor for wind and a Class } 4 \text { wind resource (a 20-MW wind facility produces } 63.2 \text { million } \mathrm{kWh} \\
\text { annually); a } 20 \% \text { capacity factor for residential C-Si PV in average insolation (20-MW of solar, in this case aggregated PV } \\
\text { installations, would produce } 35 \text { million kWh annually); a 95\% capacity factor for geothermal "flashed-steam" technology (a 20- } \\
\text { MW geothermal plant produces } 166 \text { million kWh annually); and an } 80 \% \text { capacity factor for direct-fired biomass in } 2010 \text { (a } \\
\text { 20-MW biomass plant produces } 139.8 \text { million kWh annually). }\end{array}$} \\
\hline \multicolumn{5}{|c|}{$\begin{array}{l}\mathrm{b} \text { It is assumed here that a biomass plant will emit enough } \mathrm{NO}_{\mathrm{x}} \text { to cancel out its value for that pollutant. However, advanced } \\
\text { biomass gasification combined-cycle systems are expected to emit very little } \mathrm{NO}_{\mathrm{x}}-0.0005 \text { tons/MWh; Margaret K. Mann and } \\
\text { Pamela L. Spath, Life-Cycle Assessment of a Biomass Gasification Combined-Cycle System, NREL/TP-430-23076 (Golden, CO: } \\
\text { National Renewable Energy Laboratory). }\end{array}$} \\
\hline $\begin{array}{l}\text { Source: Based on Electric P } \\
\text { Characterizations, EPRI TR }\end{array}$ & $\begin{array}{l}\text { esearch Institute } \\
6 \text { (Palo Alto, CA }\end{array}$ & $\begin{array}{l}\text { and U.S. Departm } \\
\text { 1997). }\end{array}$ & Energy, Renewable E & Technology \\
\hline
\end{tabular}

Source: D. Wooley A Guide to the Clean Air Act for the Renewable Energy Community Renewable Energy Policy Project Issue Brief \#15 (February 2000). 


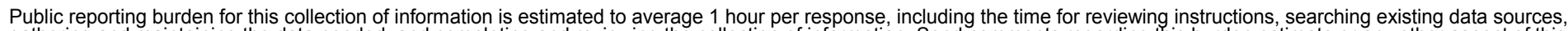

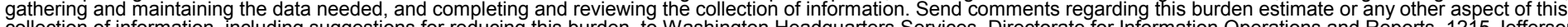

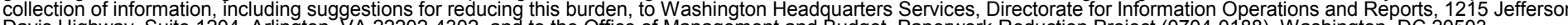
Davis Highway, Suite 1204, Arlington, VA 22202-4302, and to the Office of Management and Budget, Paperwork Reduction Project (0704-0188), Washington, DC 20503.
1. AGENCY USE ONLY (Leave blank)
2. REPORT DATE January 2001
3. REPORT TYPE AND DATES COVERED
Subcontract Final Report: December 11, 2000
4. TITLE AND SUBTITLE
The Clean Air Act Amendments of 1990: Opportunities for Promoting Renewable Energy

5. FUNDING NUMBERS

AS65.2000

6. AUTHOR(S)

D.R. Wooley and E.M. Morss

7. PERFORMING ORGANIZATION NAME(S) AND ADDRESS(ES)

Young, Sommer, Ward, Ritzenberg, Wooley, Baker \& Moore, LLC

8. PERFORMING ORGANIZATION REPORT NUMBER

9. SPONSORING/MONITORING AGENCY NAME(S) AND ADDRESS(ES)

National Renewable Energy Laboratory

1617 Cole Blvd.

Golden, CO 80401-3393

10. SPONSORING/MONITORING AGENCY REPORT NUMBER NREL/SR-620-29448

11. SUPPLEMENTARY NOTES

NREL Technical Monitor: Jeff Fang

12a. DISTRIBUTION/AVAILABILITY STATEMENT

National Technical Information Service

12b. DISTRIBUTION CODE

U.S. Department of Commerce

5285 Port Royal Road

Springfield, VA 22161

13. ABSTRACT (Maximum 200 words)

This report explores key aspects of the intersection between the nation's clean air and energy goals and proposes alternatives for encouraging renewable energy in the context of the federal Clean Air Act (CAA). As with most environmental statutes enacted in the early 1970s, the 1970 CAA embraced a somewhat rigid "command-and-control" approach to achieving its clean air goals. Although effective, this approach has been criticized for discouraging creative and cost-effective solutions to reducing air emissions. In response to this concern, Congress included the first significant market-based program to address an environmental problem - in this case, acid rain caused by sulfur dioxide $\left(\mathrm{SO}_{2}\right)$ emissions from power plants-in the $1990 \mathrm{CAA}$ Amendments. This program prompted the federal government and various state governments to pursue other market-based programs to address air pollution problems. Ten years have elapsed since the passage of the 1990 CAA Amendments, so the time is ripe to consider expanding opportunities for renewable energy development in the reform of clean air policies.

A significant potential for renewables exists in conjunction with international efforts to reduce emissions of greenhouse gases $(\mathrm{GHG})$, including $\mathrm{CO}_{2}$. Unfortunately, Congressional opposition to international GHG reduction agreements makes it difficult to develop GHG emission-reduction programs, including a cap-and-trade alternative, that would enable the renewables industry to harness this potential. The renewable industry can, however, track developments both nationally and internationally to ensure that the programs developed adequately address renewables.

\begin{tabular}{|c|c|c|c|c|}
\hline \multirow{2}{*}{\multicolumn{4}{|c|}{$\begin{array}{l}\text { 14. SUBJECT TERMS } \\
\text { Clean Air Act; air quality; renewable energy }\end{array}$}} & \multirow{2}{*}{$\begin{array}{l}\text { 15. NUMBER OF PAGES } \\
\text { 16. PRICE CODE }\end{array}$} \\
\hline & & & & \\
\hline 17. & $\begin{array}{l}\text { SECURITY CLASSIFICATION } \\
\text { OF REPORT } \\
\text { Unclassified }\end{array}$ & $\begin{array}{l}\text { 18. SECURITY CLASSIFICATION } \\
\text { OF THIS PAGE } \\
\text { Unclassified }\end{array}$ & $\begin{array}{l}\text { 19. SECURITY CLASSIFICATION } \\
\text { OF ABSTRACT } \\
\text { Unclassified }\end{array}$ & $\begin{array}{l}\text { 20. LIMITATION OF ABSTRACT } \\
\text { UL }\end{array}$ \\
\hline
\end{tabular}

